San Jose State University

SJSU ScholarWorks

Dissertations

Master's Theses and Graduate Research

Spring 2018

\title{
Relational Trust within an Urban Public Comprehensive High School District in Northern California
}

Shawn Tennenbaum

San Jose State University

Follow this and additional works at: https://scholarworks.sjsu.edu/etd_dissertations

\section{Recommended Citation}

Tennenbaum, Shawn, "Relational Trust within an Urban Public Comprehensive High School District in Northern California" (2018). Dissertations. 21.

DOI: https://doi.org/10.31979/etd.6qhg-8xa2

https://scholarworks.sjsu.edu/etd_dissertations/21

This Dissertation is brought to you for free and open access by the Master's Theses and Graduate Research at SJSU ScholarWorks. It has been accepted for inclusion in Dissertations by an authorized administrator of SJSU ScholarWorks. For more information, please contact scholarworks@sjsu.edu. 


\title{
RELATIONAL TRUST WITHIN AN URBAN PUBLIC COMPREHENSIVE HIGH SCHOOL DISTRICT IN NORTHERN CALIFORNIA
}

\author{
A Dissertation \\ Presented to \\ The Faculty of the Educational Doctoral Program in Educational Leadership \\ San José State University
}

\author{
In Partial Fulfillment \\ of the Requirements for the Degree \\ Doctor of Education
}

by

Shawn Tennenbaum

May 2018 
(C) 2018

Shawn Tennenbaum

ALL RIGHTS RESERVED 
The Designated Dissertation Committee Approves the Dissertation Titled

RELATIONAL TRUST WITHIN AN URBAN PUBLIC COMPREHENSIVE HIGH SCHOOL DISTRICT IN NORTHERN CALIFORNIA

\author{
by \\ Shawn Tennenbaum \\ APPROVED FOR THE EDUCATIONAL DOCTORAL PROGRAM IN \\ EDUCATIONAL LEADERSHIP \\ SAN JOSÉ STATE UNIVERSITY
}

May 2018

\begin{abstract}
Arnold B. Danzig, Ph.D. ～Director, Ed.D. Leadership Program
Mei-Yan Lu, Ph.D. $\quad$ Professor, Educational Leadership

Diana Abbati, Ed.D. $\quad$ Lecturer, Educational Leadership
\end{abstract}




\title{
ABSTRACT \\ RELATIONAL TRUST WITHIN AN URBAN PUBLIC COMPREHENSIVE HIGH SCHOOL DISTRICT IN NORTHERN CALIFORNIA
}

\author{
by Shawn Tennenbaum
}

The 2013 adoption of the Local Control Funding Formula and Local Control Accountability Plan provides local communities and districts with educational decisionmaking and provides a roadmap of how to improve outcomes in low-performing districts. One of the eight-priority areas California public school districts are held accountable to make progress on an annual basis is improving school climate. Building strong trust based relationships prepares schools to address a myriad of complex challenges. This dissertation examined the key facets that build relational trust between high school teachers and principals within a hierarchical role relationship in a public comprehensive high school district in Northern California. This mixed methods study stretched previous research to understand how secondary principals and teachers conceptualize relational trust. Survey and one-on-one interview data suggest gender, ethnicity, and years of experience are not significantly related to the conceptualization of relational trust and that high school teachers largely feel the same way, regardless of gender, ethnicity, or years of experience. Of note, principals and high school teachers may view the importance of the five facets of relational trust in a dissimilar manner. Principals are encouraged to understand that 10 out of 11 high school teacher groups, while also recognizing that past experiences have a profound influence on the trust building process, ranked reliability as the most important facet in the trust building process. 


\section{ACKNOWLEDGMENTS}

This journey was not about completion, rather an exploration of myself that culminated in growth, reflection, and new understandings. This dissertation is dedicated to my daughter, Brayden, who I am so proud of for developing into such an inquisitive and talented young woman. Your future is bright and each day brings new hope and joy. I wish you much happiness on your path in life; please know you are always in my heart.

Thank you to my dissertation chair and mentor, Dr. Arnold Danzig, for guiding me along this journey. Your dedication, wisdom, and support was instrumental and I cannot thank you enough. To Evelyn Muro, Steve Delay, and Carol Heiderich, I thank you for believing in me and providing me with countless opportunities. To my mom and dad, your love and unwavering support allowed me to challenge conventional wisdom. I cannot express my gratitude enough to both of you.

Thank you to all of the teachers and athletic coaches who helped me grow in and out of the classroom. There are so many who have made this opportunity possible and I thank you for believing in me. As a product of California’s public school system, I am grateful for being part of a system that believes in nurturing and developing young minds to soar to new heights. Thank you!

To Paulette, no words can describe how much your support, care, and love have meant along this journey. Change is inevitable, and not only did we experience this together, but we grew together. I would not have had the perseverance and courage to embrace all of this without you. Your energy and passion for life carried me through to the finish line and beyond. For this, I am thankful and my love grows each day. 


\section{TABLE OF CONTENTS}





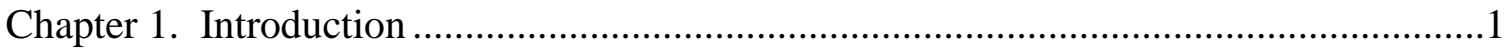

Current Reality and Statement of the Problem ............................................................

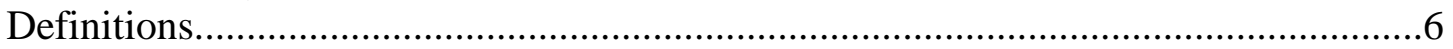

Conceptual Framework of Relational Trust...........................................................10

Significance of the Study ....................................................................................14

Equity and Trust..............................................................................................16

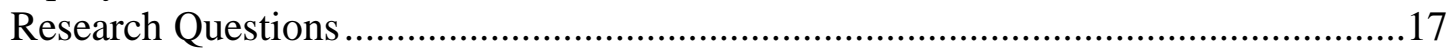

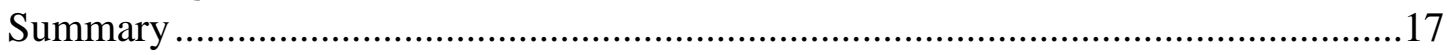

Chapter 2. Literature Review.......................................................................................19

Historical Perspective on the Scholarship of Trust and Distrust .................................19

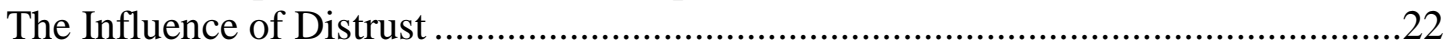

The Meaning, Key Facets, and Preconditions to Build Trust........................................27

Foundational Definition of Trust ..........................................................................

Preconditions of Trust........................................................................................31

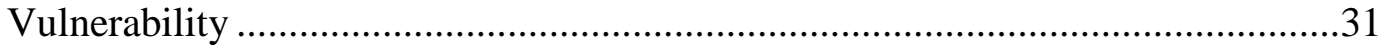

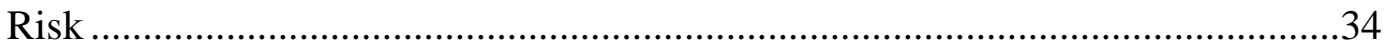

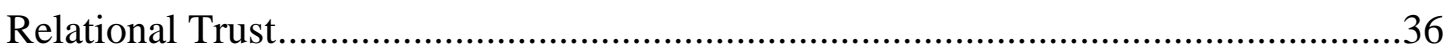

The three levels of relational trust .........................................................................38

Empirical data on the conceptualization and importance of

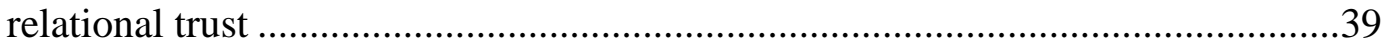

Building relational trust in schools .................................................................42

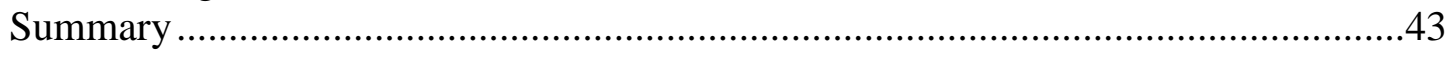

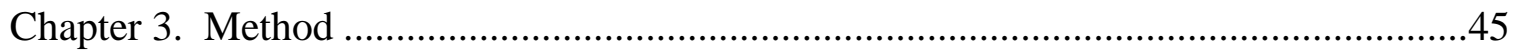

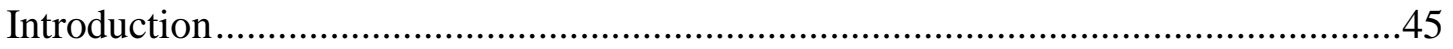



Research Design......................................................................................................4

Validity and transferability ………………..................................................49



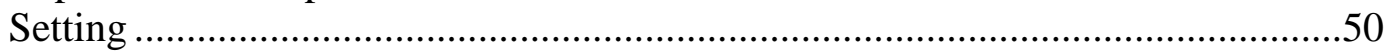

Population and sample ....................................................................................51

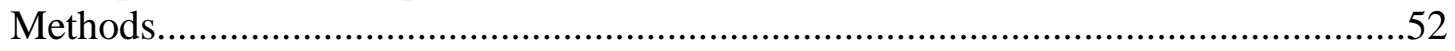

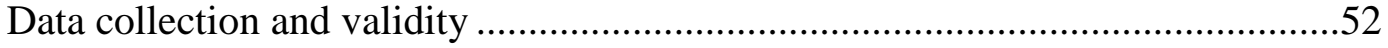

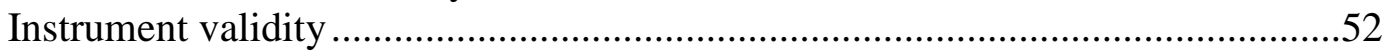

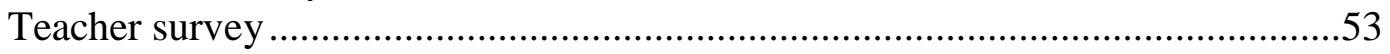

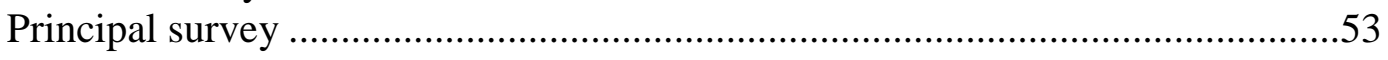

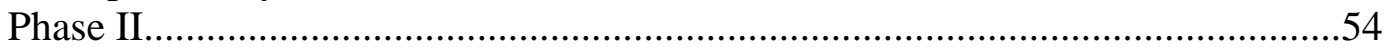




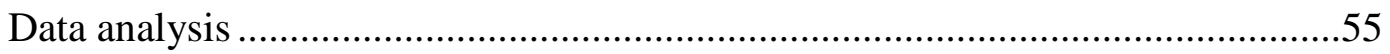

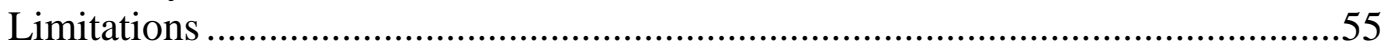





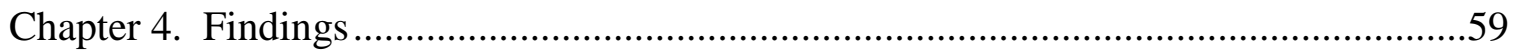

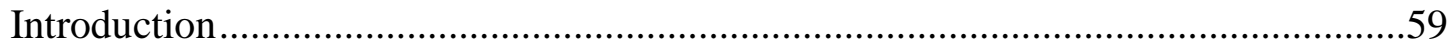

Findings: Descriptive Data from the Survey …………………………....................59

Phase I: Analysis of Survey and Open-Ended Response Data .....................................62

RQ 1. How do high school teachers and principals conceptualize

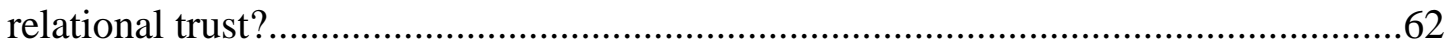

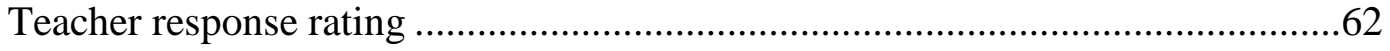

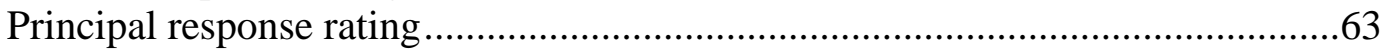

Open-ended responses .........................................................................................64

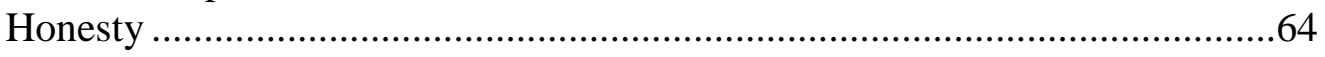

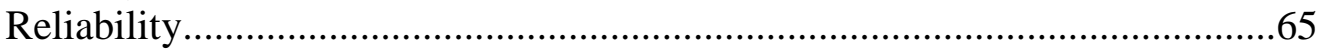



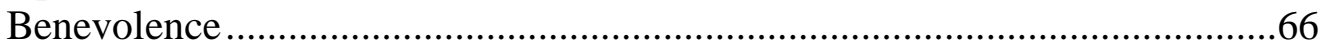

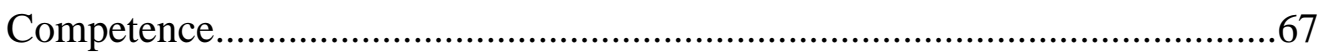

RQ 2. Which facets of relational trust do high school teachers and principals rate as most important in building relational trust?.......................................68

RQ 3. How are ethnicity and gender associated with the facets of



RQ 4. How are years of teaching experience related to the

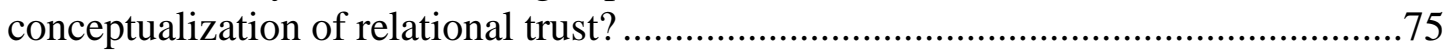

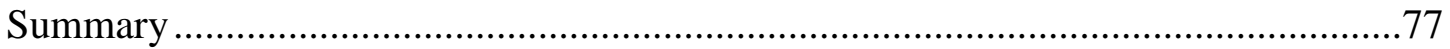

Phase II: Analysis of Interview Data with Teachers...................................................79

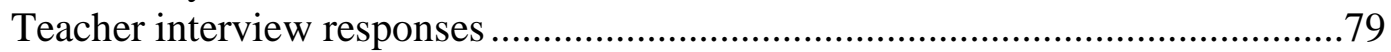

Meaning of trust in a school community ..........................................................8

How is trust conceptualized by high school teachers?.........................................81

Examples of when a principal built trust ..........................................................82

Examples of when a principal diminished trust..................................................83

Challenges and barriers in building relational trust ...........................................85

Practical rules of thumb that practitioners use to measure



Suggestions for administrators are trying to build relational trust.....................87

How past experiences influence relational trust ...............................................89

Relational trust, gender, and ethnicity ………………...................................90

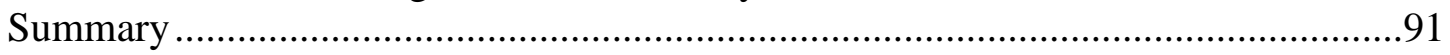



Introduction and Summary of the Study ..................................................................93

Summary of Findings and Conclusions .........................................................................94

Implications for Understanding School Leadership 
and Administrative Practice

The Importance of Past Experiences in Building

and Maintaining Trust.

Vulnerability and Risk ......................................................................................102

Recommendations for Future Research ................................................................103

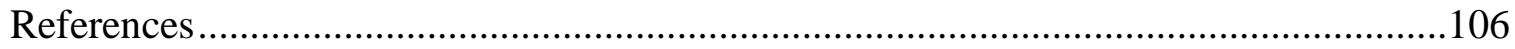



Appendix A. Teacher Survey Instrument with Consent Form ....................................112

Appendix B. Principal Survey Instrument with Consent Form ...................................118

Appendix C. One-on-One Interview Protocol ............................................................124

Appendix D. Interview Consent Form...................................................................129

Appendix E. Repeated Measures ANOVA..............................................................132 


\section{LIST OF TABLES}

Table 1. Vulnerability and Key Facets of Trust (1958 to 2015) ................................29

Table 2. Comparison of Student Demographics .....................................................50

Table 3. Demographic Characteristics of Survey Respondents.................................61

Table 4. Overall Means and Standard Deviations of the Five Facets of Relational Trust .........................................................................................63

Table 5. Ranking of the Five Facets of Relational Trust by Level of



Table 6. A Comparison of Teaching Experience and the Three Most Important Facets of Relational Trust ..........................................................76

Table 7. The Three Most Important Facets of Relational Trust ..................................78

Table 8. Demographic Characteristics of Interview Respondents..............................80 


\section{LIST OF FIGURES}

Figure 1. Conceptual framework of the systemic nature of relational trust...................13

Figure 2. Graphic organizer to explain mixed method study..................................48

Figure 3. A comparison of the ranked importance of the five facets of relational trust for high school Teachers of Color and White high school teachers

Figure 4. A comparison of the ranked importance of the five facets of relational trust for White female high school teachers and female high school Teachers of Color

Figure 5. A comparison of the ranked importance of the five facets

of relational trust between female and male high school teachers.

Figure 6. A Repeated Measures ANOVA with (forced) ranking as the dependent variable shows that respondents are significantly more likely to rank 'reliability' (M=3.5 SD=1.2) and 'honesty' $(\mathrm{M}=3.4, \mathrm{SD}=1.3)$ higher than 'competence' ( $\mathrm{M}=3.1, \mathrm{SD}=1.5)$, 'benevolence' (M=2.5, SD=1.6) and 'openness' ( $\mathrm{M}=2.6, \mathrm{SD}=1.4)$. 


\section{Chapter 1 - Introduction}

\section{Current Reality and Statement of the Problem}

California educates more than six and one quarter million students enrolled in public schools from kindergarten through grade twelve (Affeldt, 2015). This number equates to one in eight public school students in the U.S., and among those one in eight are some of the nation's most challenging students (Affeldt, 2015). According to the California Department of Education (2014), these students come from a wide range of ethnic backgrounds, live in different socio-economic circumstances, are raised in a multitude of geographic, community, and familial settings, and have diverse cultural experiences and histories. These complexities are further magnified by the fact that over half of all public school students in California qualify for free or reduced-priced meals and more than 20 percent are designated as English language learners (ELLs) with over 60 language groups represented (California Department of Education/ELL, 2014). California’s diverse student population presents both an opportunity and a challenge to educators, administrators, and school boards in their ability to nurture and develop graduates that are college and career ready. Exemplary educational leadership is necessary to meet this opportunity and challenge, which not only impacts the strength of California's economy - currently the eighth largest in the world - but the nation's economy as a whole (Leithwood \& Riehl, 2003).

Not only does California have one of the most challenging schooling environments in the nation, but also in June of 2013, California passed a new Local Control Funding Formula law, which fundamentally reformed how funding would be allocated to public 
schools (Affeldt, 2015). The adoption of the Local Control Funding Formula (LCFF) and Local Control Accountability Plan (LCAP) provided communities and districts with local educational decision-making, as well as a roadmap on how to measure and improve outcomes for all districts who received these funds. Under LCFF, districts are allowed discretion on what goals they set and how to utilize resources. In addition, California public school districts are required to focus their programs and efforts on 24 metrics within eight priority areas that require annual progress. In reality, the eight priority areas represent comprehensive components of a well-rounded educational program (Affeldt, 2015). This transformation in education policy reflected a monumental shift away from the narrow, standardized test-based focus of No Child Left Behind (NCLB), which established a singleton criterion as a measure of success for schools as opposed to a more growth based approach.

School climate is one of the eight priority areas in which districts are held accountable to make annual progress. According to the California Department of Education (2017), the school environment, similar to family and community environments, has a powerful influence on the ability of students to learn and thrive. As John Dewey noted, "a good elementary school is more akin to a family than a factory. While families are organized to provide many "goods and services" for their members, participation in family life creates the deepest forms of personal meaning and identity” (Bryk \& Schneider, 2002, p.19). Ergo, the quality of social exchanges that occur in the family and school are critically important to understand and interpret. Although the understanding of social exchanges in families and organizations is an important 
consideration, it takes on a greater role for schools due to the complex web of actors that are mutually dependent upon one another to perform the necessary operations of schooling (Bryk \& Schneider, 2002). Thus, comparable to family environments, school environments provide opportunities for social exchanges that are inherently dependent on the cooperative relations and interrelated set of mutual dependencies among all key actors. In schools, these interdependent actors include (a) principals and administrators, (b) teachers, (c) parents, and (d) students (Bryk \& Schneider, 2002). One could posit that support staff should also be included in this list since they play a significant role in supporting the successful day-to-day operations of a school.

The mutual dependencies that exist between actors within a school environment create feelings of reciprocal vulnerability and risk (Bryk \& Schneider, 2002). "Where there is no vulnerability there is no need for trust” (Tschannen-Moran \& Hoy, 1998, p. 337). However, in a school environment there is a mutual dependency that exists between a principal and his/her teaching staff, which in turn produces a sense of vulnerability and, consequentially, lends itself to the importance of building trust (Bryk \& Schneider, 2002). According to Bryk and Schneider (2002), reducing the feeling of vulnerability is critical in asymmetric power relations, such as those between principals and teachers. A recognition of vulnerability by the superordinate party and a conscious effort to relieve the uncertainty and unease of the subordinate party can create meaningful social exchanges and bonds for both parties, leading to trust. As a whole, the power base held by each individual actor (e.g., principal and teacher) directly affects the very nature of relational trust in this hierarchical relationship. Bryk and Schneider (2002) theorize 
that the social dynamic created in asymmetric power relations cannot be captured by organic nor contractual trust, and argue an "alternative conceptualization of interpersonal exchange - relational trust” (p. 20). Additionally, since trust has been identified as being a contagious construct, all actors within a school community may benefit from strong trust based relationships (Hoy \& Tschannen-Moran, 1999). Building trust between the actors within a school community not only enhances the flow of communication and the sharing of ideas, it provides the foundation to collaborate and learn together solving complex challenges to serve students (Bryk \& Schneider, 2002; Tschannen-Moran \& Gareis, 2015). Therefore, schools with high levels of trust in their principals may have the ability to create school climates that are more positive and productive (TschannenMoran \& Gareis, 2015). Furthermore, principals cannot be effective leaders without trust and those schools with high degrees of teacher trust in their principal are better positioned to carry out the educational goal of fostering student learning (Tschannen-Moran \& Gareis, 2015). Since schools across the nation and the state of California, face ongoing pressure to improve student achievement and bring all students to proficiency or above, a focus must be placed on the school conditions that promote long-term sustainability, as well as positive and productive school climates (Brewster \& Railsback, 2003). This is even more important in low-performing, high-poverty urban school districts (Brewster \& Railsback, 2003).

As noted, school climate has been identified by the state of California as a core criterion in which the performance of schools will be measured (Voight, Austin, \& Hanson, 2013). School climate as defined by Tschannen-Moran and Gareis (2015) is the 
"construct that attempts to capture the perceptions of members of a school community regarding the quality of interpersonal relationships” (p.72). In addition, TschannenMoran and Gareis (2015) state that school climate is a significant characteristic of school life, and trustworthy leadership appears to be a crucial aspect in creating conditions for a dynamic and constructive climate. Therefore, understanding the conceptualization of trust between high school teachers and principals is of great importance.

Bryk and Schneider (2002) report the following about relational trust and its' connection to academic productivity: "Even after controlling for differences among schools in various aspects of school context, student composition, and teacher background, we still find strong effects linking changes in relational trust to improvements in academic productivity” (p.114). These findings support the need to further understand relational trust and its potential impact on school climate and student achievement in California’s extremely diverse public school systems.

Another key motivation to conduct further research on the conceptualization of relational trust in California's public school system is the monumental shift in utilizing school climate as an indicator to measure the effectiveness of a school based on the Local Control Funding Formula law implemented in 2013. As a result, analyzing the research on trust and conducting further research on this concept is significant for California's educational leaders as they face one of the most complex and challenging educational environments in the nation.

Trust is an important, yet abstract concept to grasp and has many faces, definitions, dimensions, and forms depending on the context. It is essential for the purpose of this 
dissertation to analyze the broad based nature of trust, ultimately centering on relational trust and how it conceptualized by teachers and principals. Subsequently, focusing on the systemic process of how relational trust can be created between teachers and principals is imperative for educational leaders in all school communities (Bryk \& Schneider, 2002). Additionally, it is important to define the meaning of and the key facets of relational trust to provide a foundation of understanding.

\section{Definitions}

For the purpose of this dissertation, the concept of relational trust is defined as the connective tissue that connects parties together in the advancement and well-being of students (Bryk \& Schneider, 2003). In addition, this dissertation focuses on relational trust as an organizational property that is developed between parties in a school community (Bryk \& Schneider, 2002). As described by Bryk and Schneider (2002) relational trust is forged through daily interactions or social exchanges between parties, hence actors within a school community are either building or diminishing levels of relational trust each and every day. Since relational trust grows or diminishes over time, it is constantly in a state of flux (Bryk \& Schneider, 2002).

Furthermore, this dissertation builds on previous research conducted, which has identified five key of facets (e.g., benevolence, reliability, competence, honesty, and openness) that contribute to judgements of trust within a school setting (Handford \& Leithwood, 2013; Hoy \& Tschannen-Moran, 1999; Tschannen-Moran \& Gareis, 2015). The following definitions of the five key facets of trust have in general been applied to building trust among parties. However, to provide context for the conceptual framework 
on relational trust presented in this dissertation, these integral facets are operationalized specifically to address the social exchanges between teachers and principals.

Benevolence is the most common facet of relational trust. It is the confidence that the well-being of one party or something one party cares about will be protected by the other party (Hoy \& Tschannen-Moran, 1999; Tschannen-Moran, 2003). Additionally, one party can count on the other party to act in one's best interest. Relational trust is nurtured when one party does not exploit the good will of the other party creating a general sense of caring. The absence of benevolence impedes productivity because people will the use their energy thinking about alternatives (Tschannen-Moran, 2003).

Reliability is the sense that one party can count on another party to follow through on what is expected to be acted upon (Hoy \& Tschannen-Moran, 1999; Tschannen-Moran, 2003). Reliability also combines a sense of predictably in which one party will act in a predictable manner to the other party. Additionally, reliability has been defined as, “... being dependable, demonstrating commitment, having dedication, and being diligent” (Tschannen-Moran, 2004, p.34). However, reliability is also associated with actions that lead to the outcome desired by the trustors (Handford \& Leithwood, 2013). Reliability is also connected with consistency and the two terms are closely related (Handford \& Leithwood, 2013).

Honesty points to character, integrity, and authenticity (Hoy \& Tschannen-Moran, 1999; Tschannen-Moran, 2003). Furthermore, honesty is defined as the anticipation that the word or promise of one party can be relied upon (Rotter, 1967). Hoy and TschannenMoran (1999) define honesty as the following: "Statements are truthful when they 
conform to what really happened from that person's perspective and when commitments made about future actions are kept” (p.188). Additionally, the acceptance of responsibility for one's actions characterizes authenticity, which leads one party to be perceived as honest. Being dishonest breaches any trust between parties and promotes distrust (Hoy \& Tschannen-Moran, 1999; Tschannen-Moran, 2003).

Openness is the extent to which information is not withheld by one party, ultimately making one party vulnerable to the other party by sharing information (Hoy \& Tschannen-Moran, 1999; Tschannen-Moran, 2003). Handford and Leithwood (2013) define openness as the demonstration of actions or attitudes that make one individual vulnerable to another through the sharing of information, influence, and control. Openness by one party to another party signals a willingness for reciprocal trust. This process is conducted by sharing information freely without holding information or distorting information. Behaviors associated with openness include sharing important information, delegating, sharing in decision-making, and sharing power (TschannenMoran, 2004). When leaders are not open, suspicion creeps in.

Competence is critical to building relational trust when one party is dependent upon the other party to perform a task or act with a level of skill necessary for completion (Hoy \& Tschannen-Moran, 1999; Tschannen-Moran, 2003). The expectation that something will be completed with a level of skill builds a sense of relational trust between parties. Competence is crucial in relationships in which two parties are mutually dependent upon each other to perform tasks or act with skill (e.g., teachers and principals). Further, competence is defined in two forms: functional and interpersonal. Functional 
competence involves "setting an example, working hard, pressing for results, setting standards, and buffering teachers” (Tschannen-Moran, 2004, p. 34). Whereas, interpersonal competence involves "engaging in problem solving, fostering conflict resolution, handling difficult situations, and being flexible” (Tschannen-Moran, 2004, p. $34)$.

The above five facets contribute to judgements of trust between a teacher and principal, and as noted by Tschannen-Moran and Hoy (2000) the relative weight of each facet will depend on the interdependence and vulnerability in the relationship. Among teachers and principals, all five facets appear to carry significant importance (Hoy \& Tschannen-Moran, 1999). Furthermore, a factor-analysis conducted by Hoy and Tschannen-Moran (1999) demonstrates that all five facets combine together to form a single, coherent construct of trust in schools.

Previous research has concluded that education is a complex system that includes unpredictable and sometimes unknown variables (Tschannen-Moran \& Gareis, 2015). Additionally, Tschannen-Moran and Gareis (2015) state that complex systems such as schools are characterized by the phenomenon of reciprocal causation. Reciprocal causation is present when the actors within a system are both affected by and affect other processes within the system (Tschannen-Moran \& Gareis, 2015). This phenomenon can be found in schools due to the multitude of interpersonal relationships that "develop, ebb, and flow” in a school community (Tschannen-Moran \& Gareis, 2015, p.67).

The ensuing conceptual framework (see Figure 1) illustrates how a systemic process of relational trust can be created and sustained between a teacher and a principal in a 
hierarchical role relationship or asymmetric power relationship (Bryk and Schneider, 2002). In an asymmetric power relationship the principal has greater power than a teacher who in turn has greater power than a student does (principal power $>$ teacher $>$ student), yet no single role has complete dominance (Bryk \& Schneider, 2002). The primary objective of the conceptual framework is to provide clarity on the system of building relational trust, one of education's key elements that supports the overall functioning of schools and their ability and capacity to support student learning (Bryk \& Schneider, 2002).

\section{Conceptual Framework of Relational Trust}

The following conceptual framework of relational trust is based on the judgements of trust between teachers and principals in a school community (Bryk \& Schneider, 2002; Tschannen-Moran \& Gareis, 2015). This framework outlines the developmental nature of the system of relational trust between teachers and principals. Furthermore, research points to a symbiotic relationship among trust and mutual interdependence and reciprocal vulnerability. Mutual interdependence is inherent in schools as principals are dependent upon teachers to perform their role adequately, while teachers are dependent upon principals to perform their role with benevolence, reliability, honesty, openness, and competence (Tschannen-Moran \& Gareis, 2015). In the conceptual framework of relational trust a plethora of variables, such as, past experiences, ethnicity, gender, and years of experience may further contribute to how one party views another party prior to making a decision to become vulnerable. Vulnerability leads to the willingness of both parties to take a risk. These conditions are both critical preconditions to building 
relational trust. Without one party willing, to become vulnerable to another party the system of building relational trust does not occur. In the conceptual framework of relational trust, the five key facets are considered input. They are the actions one party exhibits towards another party during the many social exchanges that occur on a daily basis within a school community. These actions have critical implications in the asymmetric power relationship between a teacher and a principal. The framework below illustrates how the five facets may affect the stock (e.g., degree of relational trust) in the system. The degree of relational trust between parties then produces output from one or both parties, which can either support or diminish building trust. Diminished trust can affect productivity and, as a result, the performance of the school. Furthermore, the dynamic nature of this process produces a cyclical relationship of inputs and outputs with a codependent nexus. This conceptual framework is based on the belief that trust is a dynamic rather static concept in which trust is constantly in flux - developing, building, declining, and even resurfacing (Rousseau, Sitkin, Burt, \& Camerer, 1998). Thus, the multidimensional conceptual framework of relational trust presented is laden with many variables, conditions, and facets that can have either positive or negative implications on whether or not relational trust is achieved between two parties.

Variables such as past experiences, ethnicity, gender, and years of experience provide a lens for one or both parties when attempting to build relational trust. According to Bryk and Schneider (2003) "in the absence of prior contact with a person or institution, participants may rely on the general reputation of the other and also on commonalities of race, gender, age, religion, or upbringing” to assess the trustworthy nature of the 
individual (pp. 41-42). The more interaction the parties have over time may increase the willingness of one party to become vulnerable to another party. The conceptual framework represents the systemic nature of building relational trust between a teacher and a principal in a hierarchical role relationship (see Figure 1). 


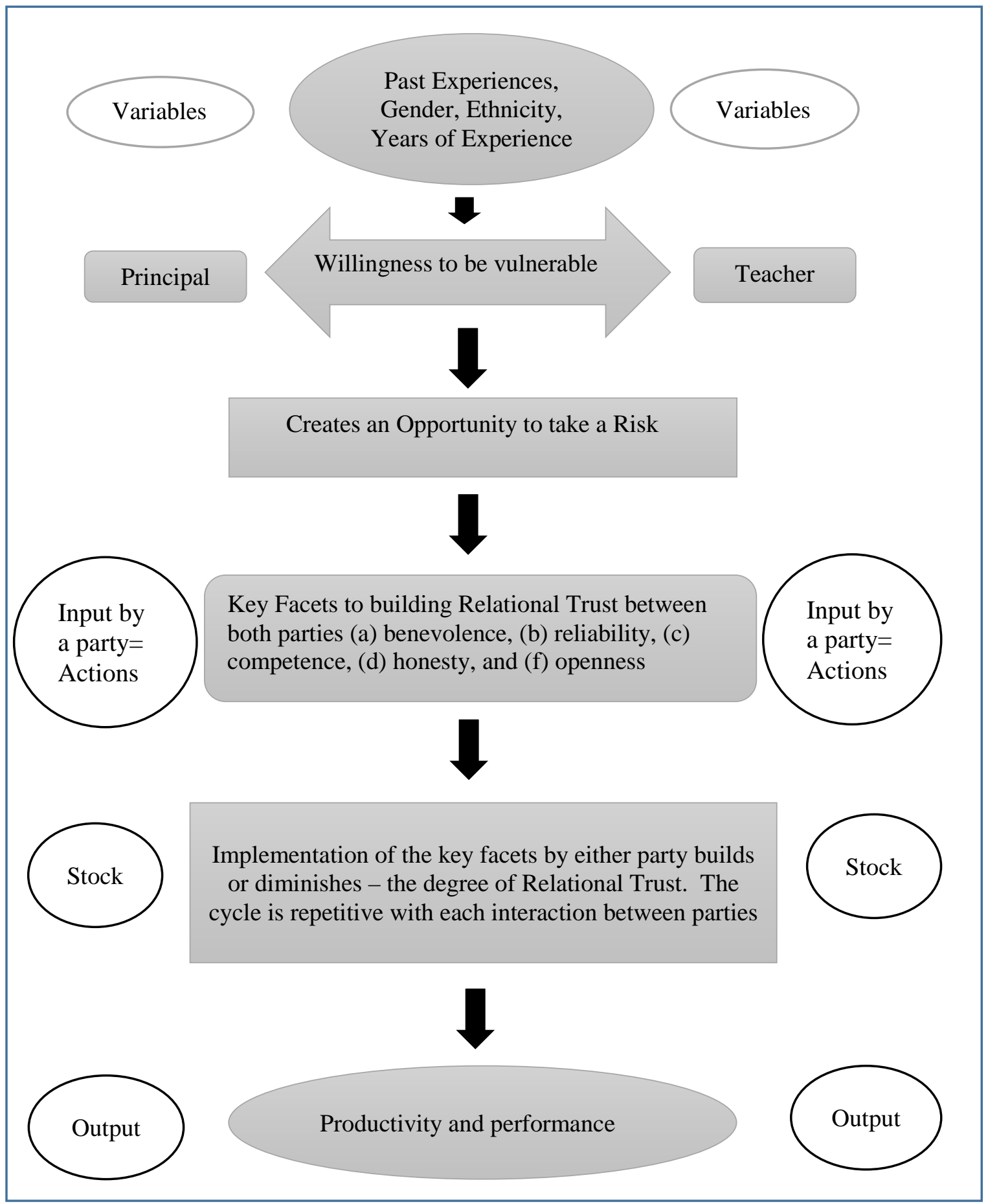

Figure 1. Conceptual framework of the systemic construct of relational trust. Adapted from the "Five Faces of Trust: An Empirical Confirmation in Urban Elementary Schools,” by W. Hoy and M. Tschannen-Moran, 1999, Journal of School Leadership, 9, 184-208. 


\section{Significance of the Study}

The significance of this study was to identify whether teachers and principals in an urban comprehensive public high school setting conceptualize the key facets of building relational trust in a similar fashion. Further, the research aims to determine if the ethnicity, gender, and years of experience of a teacher is associated with the conceptualization of relational trust and the relative importance of each of the five facets relational trust. This study draws upon theoretical concepts, empirical data, and sociological literature on trust in an effort to analyze the importance of trust and the systemic nature of building relational trust between teachers and principals in a school community. In addition, this study did not draw a comparison of the trust between high school teachers and principals at a specific school site, nor determine the level of trust at a specific school site.

In fact, a host of questions prompted this research based upon the foundational premise that as expectations within society have increased over time the expectations placed upon schools has increased as well (Tschannen-Moran \& Hoy, 2000). In short, higher expectations create the demand for higher levels of trustworthiness on the part of

all members of society. These expectations are of particular importance to those who are entrusted to educate children (Brewster \& Railsback, 2003; Tschannen-Moran \& Hoy, 2000). Ray (1997) stated there has been a growing distrust of public schools in America as evidenced by the 1.23 million students who entered home school programs between 1980 and 1997. In this regard, society values things that are tangible; such as children, money, or possessions, as well as things that are intangible; such as equity, democracy, or 
governance (Tschannen-Moran \& Hoy, 2000). With this in mind, the analysis of trust in schools is critical, since schools play an increasingly pivotal role in society (TschannenMoran \& Gareis, 2015; Tschannen-Moran \& Hoy, 2000). Furthermore, the exploration of trust is crucial, as America has shifted from traditional management practices focused on social distance and divergent interests among parties to new forms of governance with greater expectations on shared interests and goals, a higher level of effectiveness, and broader demands on educational equity and social issues (Powell, 1990). These goals fuel the need for greater levels of trust at all levels of society including, but not limited to the public's trust in schools, parents trust in teachers, students trust in teachers, teachers trust in principals, as well as principals trust in teachers (Brewster \& Railsback, 2003; Bryk \& Schneider, 2002; Tschannen-Moran \& Gareis, 2015; Tschannen-Moran \& Hoy, 2000). If schools are to realize the positive transformation necessary to meet the increased expectations placed upon them by societal pressures and reform initiatives, educational leaders will need to focus their efforts on relationships based on trust (Brewster \& Railsback, 2003; Bryk \& Schneider, 2002; Tschannen-Moran \& Gareis, 2015).

As a society we entrust our children each day to schools across the country with the primary goal of creating opportunities for all children to learn and thrive; thus, the adults who are entrusted to work together must do so in a manner to reach this lofty goal. Although, this statement may appear quite ambitious, we only need to look at the landmark decision of Brown versus Board of Education (1954) to ascertain whether or not we have realized these aspirations as a society and in schools (Lopez \& Burciaga, 
2014). Today, America's schools continue to struggle to realize equity and opportunity for all students, and according to some scholars, there is a growing lack of trust to many of the school wide reforms and improvement efforts taking place in schools (Berliner \& Glass, 2014; Brewster \& Railsback, 2003; Tschannen-Moran \& Hoy, 2000).

\section{Equity and Trust}

The phrase the achievement gap has been one of the most commonly talked about issues in U.S. Education and according to Ladson-Billings (2006) is one of the most pressing challenges we as a country still face each and every day. Nowhere is this more prevalent than in low-performing, high poverty urban school districts (Brewster \& Railsback, 2003). Consequently, our nation's students are dependent on the relationships

and ability of adults to not only work together, but to also find ways to bridge and connect differences that may inherently exist in a school community and to strengthen networks focused on student learning (Battilana \& Casciaro, 2013). The purpose of this dissertation was to unearth the scholarship surrounding the importance and meaning of trust in schools, and in particular, identify if there is an association of beliefs regarding the five key facets that build relational trust between teachers and principals. As Tschannen-Moran and Gareis (2015) concluded in their study of 64 elementary, middle, and high schools in two districts - there are a host of new directions for future research on the importance of trust in facilitating constructive interpersonal relationships in schools. Furthermore, the findings of this dissertation may guide future research into the area of trust in schools and provide a framework for school principals to utilize as they seek to build relational trust with high school teachers. This goal is particularly relevant 
to schools, which are comprised of distinct hierarchical role relationships and at the same time are looking for systems to implement and sustain change efforts for improvement (Brewster \& Railsback, 2003; Bryk \& Schneider, 2002; Tschannen-Moran \& Gareis, 2015). With this information, the researcher aims to explore how teachers and principals conceptualize the five key facets, which contribute to relational trust in a hierarchical role relationship within an urban public high school district located in a diverse metropolitan area in Northern California.

\section{Research Questions}

The objective of the study was operationalized into four specific research questions:

1. How do high school teachers and principals conceptualize relational trust?

2. Which facets of relational trust do high school teachers and principals rate as most important in building relational trust?

3. How are ethnicity and gender associated with the facets of relational trust?

4. How are years of teaching experience related to the conceptualization of relational trust?

Guided by these questions, the researcher provided a thorough examination of the literature on trust spanning multiple decades. A specific focus was placed on trust in schools and the analysis of the key facets of building relational trust in a hierarchical role relationship - areas that should be given far more attention and consideration by all educational leaders.

\section{Summary}

In sum, trustworthy leadership plays a significant role in creating the conditions that produce a positive and productive school climate (Tschannen-Moran \& Gareis, 2015). 
Therefore, it is of great importance to understand how high school teachers and principals conceptualize trust and which facets they view as necessary ingredients in building a trusting relationship. Teachers and principals alike benefit from a greater understanding of the dynamics and consequences of trust in schools (Tschannen-Moran \& Gareis, 2015). The findings of this study clearly indicate that educational leaders need to understand the dynamic nature of trust and how relational trust can be created and understood by high school teachers and principals. 


\section{Chapter 2 - Literature Review}

\section{Historical Perspective on the Scholarship of Trust and Distrust}

Trust is a very complex and contextual concept that is so ubiquitous many never even attend to it and recognize its importance until it is broken or severed. According to the philosopher Annette Baier (1985), “most of us notice...trust most easily after its sudden demise or severe injury. We inhabit a climate of trust as we inhabit an atmosphere and notice it as we notice air, only when it becomes scarce or polluted” (p. 234). This applies on both a personal level and an organizational level in that people may not realize what they have or had until it is gone, nor how it was derived to begin with. TschnnanenMoran and Hoy (2000) state the following about trust:

Trust is fundamental to functioning in our complex and interdependent society. We count on the people who grow and process our food and medicines to do so properly; we depend on those who build our houses to do so sensibly; we rely on other people with whom we share the roadways to obey traffic laws; we trust those who hold and invest our money to deal with us honestly; we depend on our government to maintain the safety of our infrastructure and to protect us from aggressors. In short, in every facet of our lives, we are dependent on other people to behave in accordance with our expectations (p. 549).

Thus, trust is a fundamental construct of an interdependent society. The role of trust has a dual purpose in schools and has been described as both a glue, and a lubricant (Tschannen-Moran, 2004). As a glue - trust binds organizational participants together, and as a lubricant - trust greases the wheels of organizational machinery (TschannenMoran, 2004). "Without trust, friction and heat bog down the work of the school...without it things fall apart” (Tschannen-Moran, 2004, p. 16). In this sense, trust mirrors the concept of social capital, in that it is not an either / or, but better seen as 
different forms along a continuum (Putnam, 2001). One may conjecture that the very nebulous nature of studying trust may be complex due to the extent of the potential variables present, as well as the multitude of contextual factors that exist between two parties or a group of individuals. Tschannen-Moran and Hoy (1998) offer the following information when studying trust: "Studying trust is like studying a moving target because it changes over the course of a relationship, and the nature of a trusting relationship can be altered instantaneously with a simple comment, a betrayed confidence, or a decision that violates the sense of care one has expected of another” (p. 335).

Furthermore, extensive research has conceptualized and theorized trust as being complex and multidimensional (Dirks \& Ferrin, 2002; Hosmer, 1995; Kramer, 1999; Tschannen-Moran \& Hoy, 2000). While there is no universally accepted single definition of trust (Rousseau, Sitkin, Burt, and Camerer, 1998) researchers have offered numerous definitions of trust that often overlap or intertwine conceptually. There is agreement, however, that trust is important in a number of ways: (a) it promotes cooperative behavior (Deutsch, 1962; Gambetta, 1988), (b) it promotes network relations (Miles \& Snow, 1992), (c) it reduces conflict and harmful transaction costs between parties (Meyerson, Weick, \& Kramer, 1996), and (d) it is a social and interpersonal experience that serves as the "grease that keeps the wheels turning” (Goodwin, 1996, p. 48). Scholars state that trust is a vital and necessary component of a healthy society, organization or school, and therefore further investigation into this area is necessary to continue to build our understanding of trust (Brewster \& Railsback, 2003; Bryk \& Schneider, 2002; Cranston, 2011; Deutsch, 1962; Gambetta, 1988; Meyerson, Weick, \& 
Kramer, 1996; Miles \& Snow, 1992; Putnam, 2001; Rousseau, Sitkin, Burt, \& Kramer, 1998; Sutherland \& Yoshida, 2015; Tschannen-Moran \& Gareis, 2015; TschannenMoran \& Hoy, 2000).

Although trust, betrayal, and suspicion have long been the subject of many scholars, the systematic study of trust and distrust began in the late 1950's. This focus was due to the increasing nature of suspicion because of the Cold War era (Deutsch, 1958) and later by the disillusionment of institutions and authority by the younger generation in the 1960’s (Rotter, 1967). Soaring divorce rates and a shift in the American ideal of the family in the 1980’s led to further research on trust and interpersonal relationships (Tshannen-Moran \& Hoy, 2000). In a sense, the systematic study of trust as a relational concept in organizations was borne out of two concepts: (a) the growing distrust created by the increasing availability of negative information, as well as society’s appetite for this type of information, and (b) the rapid changes in our society, including the shift in values, higher expectations, and increased awareness of inequity (Tschannen-Moran \& Hoy, 2000).

As our society becomes more complex and interdependent, the systematic study of trust, and specifically the role relational trust plays in school communities, is critical to understand. This aspect is even more crucial in schools that support underserved populations of students and are heavily regulated by accountability measures (Bryk \& Schneider, 2002). Sutherland and Yoshida (2015) state that educational leadership has benefited from a focus on trust development, while Whalstrom and Seashore Louis (2008) share that high levels of trust in principals is related to school effectiveness which 
in turn is related to teacher behaviors and attitudes that increase the following: (a) instructional focus, (b) participation in professional communities, and (c) engagement with parents (Bryk \& Schneider, 2002). Additionally, Adams and Forsyth (2009) share the belief that schools are 'dynamic organizations' that are part of the larger social system within our country. Therefore, principals should continue to shift educational reform away from programmatic or technical fixes to strategies that address social and contextual issues, such, as building relationships to foster a productive and positive school community. An educational leader must also be diligent in understanding that distrust can be a strong influence in a school community. For the purpose of this study, it is also vital to understand the concept and influences of distrust.

\section{The Influence of Distrust}

Although the factors that create distrust are many and multiple, understanding the concept of distrust can lead to understanding how to further our knowledge surrounding trust. This section will provide a general overview of the concept of distrust in an effort to expand our knowledge of the concept of trust. Distrust can manifest itself in many ways. For example, policymakers following the publication of a Nation at Risk in 1983 implemented a deficit framework derived out of fear that teaching could be controlled through structural reforms rather than focusing on the social structures of schools (Adams \& Forsyth, 2009). In essence, the distrust in the public school system to perform adequately for our children may have been the primary reason for initiating the structural reforms rather than allowing public schools to locally address their needs. 
Distrust impedes communication and builds suspicion (Tschannen-Moran \& Hoy, 2000). Unfortunately, the costs are high when distrust is present and the outcomes of distrust are self-protective actions, anxiety, insecurity, and feeling ill contemplating the behaviors and motives of others (Tschannen-Moran \& Hoy, 2000). Further, in schools when teachers and principals do not trust one another disengagement from the educational process occurs at the expense of student learning (Bryk \& Schneider, 2002).

In a hierarchical role relationship distrust leads to subordinates withholding information or withdrawing their trust and potentially severing ties (Bryk \& Schneider, 2002). As distrust permeates a hierarchical role relationship in schools, teachers and principals often resort to "alternative control mechanisms such as rules and contractual agreements to protect themselves” (Tschannen-Moran \& Hoy, 2000, p.550). For schools to work well synchrony must be achieved between principals and teachers, however when the desired behaviors of either the principal or teachers does not conform to expectations, schools like organizations do not function well (Bryk \& Schneider, 2002).

Furthermore, there are many barriers to building a trusting relationship in schools, much of which are manifested out of distrust on the part of teachers towards principals. One of the most serious issues that schools face is broken trust (Tschannen-Moran \& Hoy, 1998; Tschannen-Moran, 2004). Broken trust assumes that at one time trust existed between parties and this action then creates distrust. When trust is broken between a principal and a teacher the potential consequences are as noted by Tschannen-Moran and Hoy (1998) as hypervigilance, punishment, and getting even. These are primarily destructive forces that undermine the very nature of the conditions that are necessary for 
an effective school community. Broken trust leads to revenge and betrayal which can have irreversible consequences if principals and teachers are not cognizant of the dramatic costs of broken trust (Tschannen-Moran \& Hoy, 1998). Parties within a school community may be more alert to negative or destructive information and tend to prefer negative chatter to positive chatter (Tschannen-Moran \& Hoy, 2000). This can be a serious impediment to the development of trust at the organizational level and relational trust at the interpersonal level.

In Bryk and Schneider's almost a decade long longitudinal study of more than 400 Chicago elementary schools (Bryk \& Schneider, 2003) high levels of relational trust fostered a set of organizational conditions making it more conducive for individuals to operate and focus on the kinds of activities necessary for productive improvements. In addition, Bryk and Schneider shared an analysis of the trends in individual student reading and mathematics over a six-year period. Findings of the study (Bryk \& Schneider, 2003) concluded that a school with a low score on relational trust had only a one in seven chance of improving academic productivity while, schools with high levels of relational trust recorded increases in student learning, as well as created the conditions that promoted new practices in the classrooms. These findings were based upon case study data, as well as interviews and focus groups with principals, teachers, parents, and community leaders; including observations of classroom instruction, school meetings, and events. Based on these findings, one could hypothesize that schools that had a low level of trust or functioned with a high level of distrust did not have the organizational 
conditions that were conducive for improvements. Simply, applying the opposite of trust in this case would be distrust. Barber (1983) provides the following regarding distrust:

There are at least three major reasons for the decline in public trust. One has to do with the ever more powerful knowledge that the professions now have to influence individual and public welfare. Another has to do with the increasing strength of the value of equality in our society, the increasing desire of the less powerful of all kinds to have a little more control over those whose greater power vitally affects them. Ours is a revolutionary time for the value of equality. (p. 551)

As noted previously, the decline in public trust has been increasing due to the growing appetite for equality in the United States, as well as the desire by those who are affected by inequality. Technological advances, such as email and other social media platforms allow negative gossip to spread quickly amplifying the impact of broken trust or distrust (Tschannen-Moran \& Hoy, 2000). Another key variable that may create distrust in a school environment is unfavorable media coverage that can "fan the flames of mistrust, pitting teachers against principals or representing conflicts within the school community in less than productive ways” (Brewster \& Railsback, 2003, p.10).

In applying the concept of distrust to schools, Brewster and Railsback (2003) present a series of obstacles and roadblocks to building trust, which may lead to distrust in schools. Brewster and Railsback (2003) state that obstacles to trust are numerous and easy to come by in schools that have experienced the following: (a) high turnover in school leadership, (b) repeated layoffs, and (c) budget shortfalls. According to Brewster and Railsback (2003), the key obstacles and roadblocks to building and maintaining relational trust between teachers and principals are: (a) top down decision making that is perceived as arbitrary, (b) ineffective communication, (c) lack of follow through on or 
support for school improvement efforts, (d) unstable or inadequate school funding, (e) failure to remove teachers or principals who are widely viewed to be ineffective, (f) frequent turnover in school leadership, (g) high teacher turnover, and (h) teacher isolation. Each of these obstacles and roadblocks can create distrust in a school community, with the greatest impediment of all in building trust between principals and teachers being their past relationships and interactions (Brewster \& Railsback, 2003).

Strong trust based relationships between principals and teachers have been identified as an important foundation of a school's readiness for change, school effectiveness, and sustainability leading researchers to agree that high levels of trust are essential to create conditions that produce open and healthy school climates (Brewster \& Railsback, 2003; Bryk \& Schneider, 2002; Bryk \& Schneider, 2003; Cranston, 2011; Handford \& Leithwood, 2013; Hoy \& Tschannen-Moran, 1999; Tschannen-Moran \& Gareis, 2015; Tschannen-Moran \& Hoy, 1998, 2000). According to Bryk and Schneider (2002), social relationships based on trust comprise a fundamental component of a school's capacity to improve and reform should be on "enhancing the human resources of schooling" (p.5). Of note, the history of power relations between principals and their faculties have been strong determinants on the willingness of a staff to adapt to reform efforts and the change process (Bryk \& Schneider, 2002). Thus, strong trust based relationships are at the core improving urban schools (Bryk \& Schneider, 2002). 


\section{The Meaning, Key Facets, and Preconditions to Build Trust}

This section of the literature review explores the definitions of trust, the key facets of trust, and preconditions to build trust because it is necessary to further explore the meaning of trust and synthesize the prior research on this concept.

Life in the $21^{\text {st }}$ century has gotten more complex over time with shifting economic realities, changing expectations and the desire for and availability of information. Therefore, as a society we are more apt to notice issues of trust (Tschannen-Moran \& Hoy, 2000). This reality has led many to study and attempt to define trust. However, the research on trust has led to varying definitions of trust and its meaning due to the dynamic nature and consistently moving target of trust (Tschannen-Moran \& Hoy, 2000).

From a philosophical perspective, trust incorporates ethical and moral behavior (Baier, 1986; Hosmer, 1995). For example, trust is necessary for the "effective cooperation and communication which are the bases for productive relationships” (Baier, 1986, p. 334). Thus, trust in an ethical and moral sense binds two parties together in a relationship.

In economic terms, trust is essentially a rationale of costs and benefits (Coleman, 1990; Williamson, 1993). According to Williamson (1993) trust is the probability that an actor will "perform an action that is beneficial or at least not detrimental” based on a spoken or written agreement (p. 463). For example, a loan or an offer for assistance that is returned to the original party without an explicit guarantee.

When examining trust from an individualistic perspective, trust is derived from an individual's willingness to rely on and make themselves vulnerable to others (Frost, 
Stimpson, \& Maughan, 1978; Rotter, 1967). Rotter (1967) was interested in the capacity of trust, which was based on one’s past experiences, whereas Frost et al. (1978) defined trust as a specific judgment about the character of a person. Hence, trust in their view, was "an expectancy held by an individual that the behavior of another person or a group would be altruistic and personally beneficial” (Tschannen-Moran \& Hoy, 1998, p. 336).

Trust from an organizational perspective is often a collective judgment of one party that another party will not act opportunistically, will be honest in negotiations, and make a good faith effort to their commitments (Bradach \& Eccles, 1989; Cummings \& Bromily, 1996). Further, Robinson (1996) shared the following integrated understanding of the concept of trust:

[...] one's expectations or beliefs about the likelihood that another's future actions will be beneficial, or at least not detrimental, to one's interests [...] As a social construct trust lies at the heart of relationships and contracts, influencing each party's behavior toward the other [...] as a general positive attitude toward another social entity, trust acts as a guideline, influencing one's interpretation of social behaviors with a relationship. (p. 576)

Additionally, trust is multifaceted and may have different degrees and stages based on the degree of the trusting relationship (Tschannen-Moran \& Hoy, 2000). Overall, the research (see Table 1) has offered many variations on the definition of trust, however each of the studies below have identified one or more of the key facets that build trust between two parties as depicted in Table 1. The table below illustrates seven decades of research on trust highlighting one common precondition (e.g., vulnerability) and identifying five key facets (e.g., benevolence, reliability, competence, honesty, and openness) that build trust. Although, other facets such as integrity, consistency, respect, and professionalism are mentioned in the studies, my research study focused on the five 
facets of trust below that inspired the conceptual framework on relational trust within this study.

Table 1

Vulnerability and Key Facets of Trust (1958 to 2015)

\begin{tabular}{|c|c|c|c|c|c|c|}
\hline Trust Studies & Vulnerability & Benevolence & Reliability & Competence & Honesty & Openness \\
\hline Deutsch, 1958 & $\mathrm{X}$ & $\mathrm{X}$ & & & & \\
\hline Rotter, 1967 & & & $\mathrm{X}$ & & $\mathrm{X}$ & \\
\hline Zand, 1972 & $\mathrm{X}$ & $\mathrm{X}$ & & & & \\
\hline $\begin{array}{l}\text { Ellison \& } \\
\text { Firestone, } 1974\end{array}$ & $\mathrm{X}$ & $\mathrm{X}$ & & & & $\mathrm{X}$ \\
\hline $\begin{array}{l}\text { Frost, Stimpson, } \\
\text { \& Maughan, } \\
1978\end{array}$ & & $\mathrm{X}$ & & & & \\
\hline $\begin{array}{l}\text { Butler \& } \\
\text { Cantrell, } 1984\end{array}$ & & $\mathrm{X}$ & $\mathrm{X}$ & $\mathrm{X}$ & $\mathrm{X}$ & $\mathrm{X}$ \\
\hline $\begin{array}{l}\text { Hoy \& } \\
\text { Kupersmith, } \\
1985\end{array}$ & & $\mathrm{X}$ & $\mathrm{X}$ & & $\mathrm{X}$ & \\
\hline Baier, 1986 & $\mathrm{X}$ & $\mathrm{X}$ & & $\mathrm{X}$ & & \\
\hline Gambetta, 1988 & $\mathrm{X}$ & $\mathrm{X}$ & & & & \\
\hline $\begin{array}{l}\text { Bradach \& } \\
\text { Eccles, } 1989\end{array}$ & $\mathrm{X}$ & $\mathrm{X}$ & & & & \\
\hline Coleman, 1990 & $\mathrm{X}$ & & & & & \\
\hline Fukuyama, 1995 & & $\mathrm{X}$ & $\mathrm{X}$ & & $\mathrm{X}$ & \\
\hline Hosmer, 1995 & & $\mathrm{X}$ & & & $\mathrm{X}$ & \\
\hline $\begin{array}{l}\text { Mayer, Davis, \& } \\
\text { Schoorman, } 1995\end{array}$ & $\mathrm{X}$ & & $\mathrm{X}$ & $\mathrm{X}$ & & \\
\hline $\begin{array}{l}\text { Cummings \& } \\
\text { Bromily, } 1996\end{array}$ & & $\mathrm{X}$ & $\mathrm{X}$ & & $\mathrm{X}$ & \\
\hline
\end{tabular}


Table 1 Continued

\begin{tabular}{|c|c|c|c|c|c|c|}
\hline Trust Studies & Vulnerability & Benevolence & Reliability & Competence & Honesty & Openness \\
\hline Mishra, 1996 & $\mathrm{X}$ & $\mathrm{X}$ & $\mathrm{X}$ & $\mathrm{X}$ & $\mathrm{X}$ & $\mathrm{X}$ \\
\hline $\begin{array}{l}\text { Rousseau, Sitkin, } \\
\text { Burt, \& Camerer, } \\
1998\end{array}$ & $X$ & $\mathrm{X}$ & $\mathrm{X}$ & & $\mathrm{X}$ & \\
\hline $\begin{array}{l}\text { Tschannen-Moran } \\
\text { \& Hoy, } 1998\end{array}$ & $\mathrm{X}$ & $\mathrm{X}$ & $\mathrm{X}$ & $\mathrm{X}$ & $\mathrm{X}$ & $\mathrm{X}$ \\
\hline $\begin{array}{l}\text { Hoy \& } \\
\text { Tschannen- } \\
\text { Moran, } 1999\end{array}$ & $X$ & $\mathrm{X}$ & $\mathrm{X}$ & $\mathrm{X}$ & $\mathrm{X}$ & $\mathrm{X}$ \\
\hline $\begin{array}{l}\text { Tschannen- } \\
\text { Moran \& Hoy, } \\
2000\end{array}$ & $X$ & $X$ & $X$ & $\mathrm{X}$ & $\mathrm{X}$ & $X$ \\
\hline $\begin{array}{l}\text { Bryk \& } \\
\text { Schneider, } 2002\end{array}$ & $\mathrm{X}$ & $\mathrm{X}$ & & $\mathrm{X}$ & & \\
\hline $\begin{array}{l}\text { Tschannen- } \\
\text { Moran, } 2003\end{array}$ & $\mathrm{X}$ & $\mathrm{X}$ & $\mathrm{X}$ & $\mathrm{X}$ & $\mathrm{X}$ & $\mathrm{X}$ \\
\hline $\begin{array}{l}\text { Bryk \& } \\
\text { Schneider, } 2003\end{array}$ & $\mathrm{X}$ & $\mathrm{X}$ & & $\mathrm{X}$ & & \\
\hline $\begin{array}{l}\text { Tschannen- } \\
\text { Moran, } 2004\end{array}$ & $\mathrm{X}$ & $\mathrm{X}$ & $\mathrm{X}$ & $\mathrm{X}$ & $\mathrm{X}$ & $\mathrm{X}$ \\
\hline $\begin{array}{l}\text { Lapidot, Kark, \& } \\
\text { Shamir, } 2007\end{array}$ & $\mathrm{X}$ & & & & & \\
\hline $\begin{array}{l}\text { Handford \& } \\
\text { Leithwood, } 2013\end{array}$ & & & $\mathrm{X}$ & $\mathrm{X}$ & & $\mathrm{X}$ \\
\hline $\begin{array}{l}\text { Tschannen- } \\
\text { Moran \& Gareis, } \\
2015\end{array}$ & $X$ & $\mathrm{X}$ & $\mathrm{X}$ & $\mathrm{X}$ & $\mathrm{X}$ & $\mathrm{X}$ \\
\hline \multicolumn{7}{|c|}{$\begin{array}{l}\text { Note. An X in the cells represents which of the five facets were identified in the study. } \\
\text { Adapted from the research conducted by Tschannen-Moran and Hoy (2000) and } \\
\text { Handford and Leithwood (2013) which represents seven decades of trust research have } \\
\text { shown vulnerability as a precondition of trust, as well as identified the five facets to } \\
\text { building trust. }\end{array}$} \\
\hline
\end{tabular}




\section{Foundational Definition of Trust}

For the purpose of this study, Mishra's (1996) multidimensional definition of trust will be utilized as foundational: “Trust is one party’s willingness to be vulnerable to another party based on the belief that the latter party is (a) benevolent, (b) reliable, (c) competent, (d) honest, and (e) open” (Tschannen-Moran \& Hoy, 1998, p. 337).

Hoy and Tschannen-Moran (1999) conducted a study of 898 elementary teachers across 50 schools in one large urban public elementary school system in the Midwestern United States, which substantiated their definition of trust, while also supporting the belief that vulnerability and risk are inherent in all trust relations. The results suggested that trust has multiple faces and the five facets of trust were found in all trust relationships. Further, the study concluded the following findings (a) faculty trust in schools is pervasive, (b) when teachers trust their principal they are more likely to trust each other, (c) distrust breeds further distrust, and (d) broken trust can spread through a school community. The next section of the literature review will address the preconditions of trust. Specifically, as noted by many scholars, trust has one common precondition among most definitions - 'vulnerability.'

\section{Preconditions of Trust}

Vulnerability. The precondition of vulnerability permeates the literature on trust and regardless of the underlying conceptual or theoretical framework of the study (e.g.,

philosophical, economic, organizational, sociological or individual) and has been identified as a necessary precondition to building relational trust between two parties (Baier, 1986; Bigley \& Pierce, 1998; Bryk \& Schneider, 2002; Coleman, 1990; Handford 
\& Leithwood, 2013; Hoy \& Tschannen-Moran, 1999; Lapidot, Kark, \& Shamir, 2007;

Rousseau, Sitkin, Burt, \& Camerer, 1998; Tschannen-Moran \& Hoy, 1997, 1998, 2000;

Tschannen-Moran \& Gareis, 2015. Vulnerability is an important precondition of trust relationships and is defined as making oneself vulnerable to another party by taking a risk (Sutherland \& Yoshida, 2015). Zand (1972) stated that trust consisted of actions that led to increased vulnerability to another party. Essentially, being vulnerable implies that there is something to be lost. Further, there is no place or need for trust if the trusting party is not vulnerable to the acts of the party he or she trusts (Lapidot, Kark, \& Shamir, 2007; Zand, 1972). Since vulnerability is a major component of trust relationships, and has been identified as a precondition to building relational trust, the extent and nature of subordinate vulnerability in a hierarchical role relationship is an important concept to understand (Lapidot, Kark, \& Shamir, 2007).

Baier (1986) stated that much of the early philosophical work on trust focused on people of roughly equal power. Yet, the reality in organizations is that people have varying degrees of power and authority. This, in turn, creates differing viewpoints of the criteria in which trust is built based on the judgments of the role of the person (Gabarro, 1978). Not only are there differing viewpoints of trust within organizations based on power, subordinates were able to recall more trust-related incidents than superiors and trust violations were likely to be more pronounced (Tschannen-Moran \& Hoy, 2000). Hence, the relationship of role and power are important aspects to decipher in schools since teachers and principals interact frequently in a mutual effort to implement and sustain positive and productive school environments. 
Research has described the relationship between the teacher and principal in many ways (Bryk \& Schneider, 2002). For example, Wang and Bird (2011) describe this relationship as the leader - follower relationship. However, the mere fact that Wang and Bird (2011) refer to principals as leaders, while teachers are referred to as followers implies a sense of inferiority of the teacher as an expert or leader, while also devaluing the reciprocal nature and mutual interdependency of the relationship. In addition, leadership within a school community resides in various role sets (e.g., teacher, student) and locations beyond simply the principal's office.

In comparison, Darling-Hammond (1988) and Rowan (1990) suggest that the relationship between a principal and teacher is one where some principals involve teachers in sustained dialogue and decision making about educational matters. In addition, these principals recognize teachers as equal collaborates acknowledging their professionalism and utilizing their knowledge and skills. Focusing on relations between principals and teachers, principals can serve to transform school cultures or to maintain them (Firestone \& Louis, 1999; Leithwood \& Jantzi, 1999). It is important to further analyze the mutual vulnerability of both the teacher and principal within a distinct role set in a school community to gain a better understanding of this concept.

The relationship between principals and teachers are based on their formal roles, which affect the nature of relational trust due to each individual's power base (Bryk \& Schneider, 2002). In general, no one person in a school community holds absolute power. All parties, however, that hold formal roles within a school community remain vulnerable to each other (Bryk \& Schneider, 2002). This vulnerability manifests itself in 
a reciprocal nature. For instance, the teacher is concerned with exploitation and unfair treatment, while the principal is worried that teachers will not follow through on their responsibilities and possibly undermine his or her authority (Bryk \& Schneider, 2002). These mutual vulnerabilities are heightened by the principal's isolation from the classroom and lack of time to closely supervise the actions of teachers (Bryk \& Schneider, 2002). As a result, principals have to trust that teachers will advance the learning of students and will essentially go the extra mile to improve the school. In contrast, teachers have to trust that principals will act fairly in carrying out the procedural requirements of the school, while also supporting them in their daily responsibilities. This mutual vulnerability can be reduced by the actions of both parties.

On the part of the principal, actions that are taken to include teachers in shared decision-making affords them the opportunity to exercise their power and thus reduces their vulnerability (Bryk \& Schneider, 2002). When these activities are consistently carried out vulnerability reduces. Thus, any actions that are taken by the principal to reduce the vulnerability of teachers is not only highly salient, it promotes relational trust between both parties. As noted, vulnerability is one of the preconditions to develop relational trust; the second precondition is risk. Both preconditions form the basic development of human relationships (Tschannen-Moran \& Hoy, 2000).

Risk. Risk has been defined as the perceived probability of loss by either party (Coleman, 1990; Williamson, 1993, Tschannen-Moran \& Hoy, 2000). In essence, risk creates the opportunity for relational trust. In a study of urban elementary schools conducted by Tschannen-Moran (2004), high levels of trust supported the risk taking of 
teachers in a myriad of ways. For example, trust promoted risk taking behaviors in the classroom in which teachers experimented with new teaching practices, which led to increased student achievement and an increase in the belief that teachers could make a difference for even the most disadvantaged students. Moreover, Tschannen-Moran (2004) found when a teacher becomes willing to be vulnerable to a principal there is an inherent sense of risk taken by the teacher. When a teacher is willing to take a risk the principal can support this risk taking by acting in a manner that is predictable and the expected behavior materializes (e.g., reliability) Tschannen-Moran (2004). Hence, one’s actions can either promote or diminish the risk taking of the other party by acting in a trustworthy or non-trustworthy manner. In contrast, when teachers and principals do not trust one another they both will seek to minimize their vulnerability and risk by adopting self-protecting positions (Tschannen-Moran \& Gareis, 2015).

There is salient research on the direct connection between relational trust and the willingness of teachers to take risks in school settings (Bryk \& Schneider, 2002). The researchers (Bryk \& Schneider, 2002) found that schools with stronger levels of relational trust have shared decision-making models and schools with lower levels of relational trust have trouble resolving simple organizational concerns. Furthermore, as described by Bryk and Schneider (2002) in their study of urban elementary schools in Chicago, when relational trust was strong, reform initiatives and change were more likely to be engaged in by the staff. Thus, the ability to take a risk may be predicated on having strong relational trust between principals and teachers. For example in the study (Bryk \& 
Schneider, 2002), one elementary school had strong relational trust between school officials and this was found to reduce the risk associated with change.

In summary, it would stand to reason, based on these findings, that risk and trust are concepts that are connected and have a reciprocal relationship (i.e., increased levels of trust are associated with a greater willingness to take risks). Furthermore, to gain trust one must be willing to first become vulnerable and take a risk. Within a school, teachers who engage in positive risk taking behaviors maybe more likely to try new and innovative instructional and pedagogical practices in the classroom as noted by Tschannen-Moran (2004). For a principal, positive risk taking may include engaging in shared leadership with teachers or creating open dialogues with teachers to gain feedback and input. However, to take a positive risk one must have some trust in the other party. The awareness and understanding of vulnerability and risk is paramount for building relational trust.

\section{Relational Trust}

This section examines the research on relational trust and analyzes the significant role it plays in the school community because relational trust is a critical concept that is deeply embedded in an explicit focus on the interpersonal social exchanges within a school community (Bryk \& Schneider, 2002). As noted, schools are characterized by distinct relationships based upon roles, authority, power, and social exchanges, teachers with students, teachers with teachers, teachers with parents, and all groups with the principal. According to Bryk and Schneider (2002), each party in a relationship maintains some level of understanding of their role and obligations, while also having 
some expectation of the role and obligations of others. Thus, for a school community to work well each party must clearly understand the obligations and expectations in each distinct role relationship.

All parties within a school are dependent upon one another to achieve desired outcomes regardless of how much power any given role has within the school community. Principals depend on teachers to deliver the curriculum, engage in professional activities that support students and parents, and maintain a cohesively professional community. Teachers' largely depend on the decisions and particularly the decision making of principals. For example, the allocation of resources, assignments of classes, as well as training and professional development are all influenced by a principal's decision-making.

Furthermore, according to Bryk and Schneider (2002) as individuals interact with one another they are constantly discerning the intentions and actions of others. This discernment is even more pronounced in relationships based on power and authority (e.g., hierarchical relationships). Relational trust relies on the maintenance and growth of the synchrony between parties based on mutual expectations and obligations (Bryk \& Schneider, 2002). For schools to work well, synchrony between the major actors (e.g., principal and teacher) must be achieved. If relational trust is weak, typically one party withdraws or in some cases severs their ties, thus regular validation must occur through actions to avoid this withdrawal (Bryk \& Schneider, 2002). Further, relational trust diminishes when teachers or principals perceive that one party is not acting in the manner that is consistent with their role. Bryk and Schneider (2002) conjecture that these 
judgements of trust are grounded in each party’s historical perspective (e.g., past experiences), cultural beliefs rooted around the origin of his or her family and community, and prior workplace interactions.

The three levels of relational trust. Relational trust is conceptualized around a three-level theory described by Bryk and Schneider (2002). The first level is based on the intrapersonal actions of discerning the intentions of others. Second, the interpersonal level is deeply rooted in role relations created by the culture of a school community, as well as the history, and understandings that have been shaped over time. The last level culminates at the organizational level, including but not limited to effective decisionmaking, increased social support for innovation, efficient control of work, and the belief to support students.

As noted previously by Bryk and Schneider (2003) "relational trust is the connective tissue that binds individuals together to advance the education and welfare of students” (p. 44). If this is true, then the foundation of a positive and productive school community may be dependent upon the ability of adults to create a culture of trust amongst themselves, while also improving their interpersonal relationships, bridging and bonding differences, and strengthening networks to affect change.

Further, relational trust is a catalyst for change (Bryk \& Schneider, 2002). Based on their research, Bryk and Schneider (2002) posit that four considerations are dynamically intertwined to create relational trust. The four considerations or facets of relational trust are (a) respect, (b) competence, (c) personal regard for others (e.g., benevolence), and (d) integrity. 
In sum, for relational trust to be built, actors within a school community must understand that all four facets of relational trust are consistently discerned and analyzed; a serious deficiency in one facet can be sufficient to undermine the relational trust between the actors.

\section{Empirical data on the conceptualization and importance of relational trust.}

Teachers and principals are essential actors within the school setting and their relational trust is essential to the success of the school (Bryk \& Schneider, 2002). Thus, it is important to examine how these two distinct roles conceptualize relational trust. "Trust has been called the foundation of school effectiveness" and yet the research in this area is lacking (Tschannen-Moran \& Hoy, 1998, p. 341) For example, at the core of all school reform words like "trust,” "respect,” "collegiality,” and "buy-in” are found again and again. However, Brewster and Railsback (2003) found "few publications address the issue explicitly or examine it in much depth” (p. 2). Notable empirical research provides insight on this topic from Tschannen-Moran and Hoy's (1998) climate study of 86 middle schools, which included responses from 2,741 teachers. The study selected schools from urban, suburban, and rural areas, as well as schools with different socioeconomic levels. The study was conducted using two different scales comprised of seven Likert-type items and found that trust in the principal was determined by the behavior of the principal. "In other words, the principal controls his or her own destiny by acting in ways that engender trust or distrust” (Tschannen-Moran \& Hoy, 1998, p. 348). Although, there is a large sample size of teachers and schools represented in the study, there are quite a few limitations, as well. First and foremost, there was no differentiation of the gender of each 
teacher who responded to the anonymous surveys. This critical aspect could lead to understanding whether or not ethnicity and gender play a role in developing relational trust. A question to ponder: Is this finding consistent between male and female teachers respectively?

The second limitation in the study (Tschannen-Moran \& Hoy, 1998) was that the surveys were conducted at the middle school level specifically and did not account for high school teachers' perspectives. One may question whether these same results would be found at the high school level.

As cited by Brewster \& Railsback (2003), Blake and MacNeil (1998) examined ways of building trust in schools. The research was conducted by surveying 129 teachers who were enrolled in an education administration program about their perceptions of principals’ competencies and behavior. Blake and MacNeil's (1998) study again did not differentiate whether or not the participants were male or female. However, the findings of Blake and MacNeil's (1998) study concluded that the factors that were most important in developing trust were principals "being kind toward people, presenting themselves in a cheerful manner, patience, thoughtful of other's feelings, respectful, friendly, and approachable” (Brewster \& Railsback, 2003, p. 43).

Handford and Leithwood (2013) conducted a mixed method study of three "high trust” and three "low trust" schools in which teachers were surveyed from 39 districts and 138 schools located in nine states. Responses were provided by 3,900 teachers in 134 schools within 40 school districts with a 55 percent response rate. The nine states were located in the mid-east, mid-west, and south-west regions of the USA. Post survey three 
to five teachers at each of the six schools identified as either "high trust" or "low trust" volunteered to be observed and interviewed. The findings from this study concluded that there is considerable similarity in the influence of the five most salient facets (e.g., competence, consistency, openness, integrity, respect) of principal trustworthiness. Both groups of teachers identified the three most frequently selected facets, competence, consistency, and openness, during the follow up interviews and observations.

Interestingly, benevolence appears instead of respect in "low-trust" schools, while integrity appears in each of the "high trust" schools, but not in the "low-trust" schools. Once again, the results of this study are in alignment with previous studies. There were significant limitations of this study that included small sample size of interviews conducted, lack of high school perspectives, and the lack of differentiation between male and female teacher perspectives.

In Bryk and Schneider's (2002) four yearlong exploration into twelve different elementary school communities in Chicago, they concluded that relational trust operates as a resource for change in that uncertainty and vulnerability are decreased for both teachers and principals. In schools with high levels of relational trust teachers reported that there was a general atmosphere of respect among colleagues. In addition, teachers in high trust schools valued others who are considered experts in their content (e.g., competence). Notably, this study found teachers in high trust environments cared for and confided in others (e.g., benevolence). The low trust schools had the opposite findings. These findings included that teachers felt they had little or no respect from colleagues and felt uncomfortable confiding in or trusting one another. Further, in high trust 
environments, teachers reported they trusted their principal because they felt supported and that the principal looked after their well-being, while also placing students first. In contrast, in low trust schools teachers reported that the principal did not respect them, nor were they comfortable confiding in them. These survey results were consistent with the researchers' field observations and substantiated the differences between high trust and low trust school environments.

In Tschannen-Moran and Gareis’ (2015) study of 64 elementary, middle, and high schools in two school districts, one urban and the other suburban, they surveyed teachers to investigate trust and leadership behaviors, as well as trust and climate. Their results from over 3,000 teachers concluded that principal behavior was a salient ingredient to a healthy school climate. They found that trust in the principal was directly related to the behavior of the principal and that these behaviors were strongly linked to the faculty trust in them. These results were consistent across all levels of schooling. Further, the results suggested that principals who were friendly, approachable, and open to input were important to teachers. Thus, teachers trusted principals that were open and approachable. These results were also consistent with previous studies conducted by Bryk and Schneider (2002), and Handford and Leithwood (2013), who conducted quantitative and qualitative methodologies respectfully.

Building relational trust in schools. The research on trust in schools indicates a consensus for the view that relational trust is an important and necessary ingredient that can pave the way for school performance outcomes, change efforts, and initiatives to create a healthy and productive school (Adams \& Forsyth, 2009; Brewster \& Railsback, 
2003; Bryk \& Schneider, 2002; Cosner, 2010; Hanford \& Leithwood, 2013; Kensler, Caskie, Barber, \& White, 2010; Sutherland \& Yoshida, 2015; Tschannen-Moran \& Gareis, 2015; Tschannen-Moran \& Hoy, 1998; Tschannen-Moran \& Hoy, 2000; Wang \& Bird, 2011). Researchers found that the key facets (e.g., benevolence, reliability, competence, honesty, openness) of developing trust in hierarchical role relationships warrant further investigation (Tschannen-Moran \& Hoy, 1998; Tschannen-Moran \& Hoy, 2000).

In sum, each of the studies presented in this section provides an amalgam of the results that have brought insight and experiences regarding the conceptual nature of how to build relational trust between teachers and principals. The need for further research extenuates and correlates back to the proposed research questions of this dissertation:

1. How do high school teachers and principals conceptualize relational trust?

2. Which facets of relational trust do high school teachers and principals rate as most important in building relational trust?

3. How are ethnicity and gender associated with the facets of relational trust?

4. How are years of teaching experience related to the conceptualization of relational trust?

\section{Summary}

A review of the literature and research conducted over the years highlighted the difference between struggling schools who made significant gains, and those who did not. The difference was based on the quality of the relationships within a school and supported by the U.S. Department of Education's Comprehensive School Reform (CSR) Program (Hale, 2000). In the CSR report, Hale (2000) stated if school improvement 
efforts are to be successful, school leaders must build strong relationships based on trust. Furthermore, Adams and Forsyth (2009) asserted the processes that are lubricated by trust have the potential to improve school performance.

The research in this study provides a solid conceptual foundation and understanding on the historical perspective on trust and distrust, as well as preconditions that provide an opportunity to build trust. The importance of relational trust and how the five key facets are integral to building relational trust was explicated. By analyzing empirical research, it became apparent on the importance on how relational trust is conceptualized by teachers and principals. As previously noted, there is intriguing evidence that relational trust matters in a school setting, yet research has offered little insight about which facets of relational trust are more important to male and female teachers. Further, is there an association of belief between teachers and principals regarding which key facets are of importance in urban public comprehensive high schools? Moreover, this study also stretches the previous research conducted on trust in schools by examining if ethnicity, gender, or the experience level of a teacher influences their perception on the importance of each of the five key facets of relational trust. It appears that an educational system working toward a more positive and productive school climate should understand how relational trust is built and what educators can do to engender this process. Therefore, recommendations on how to comprehensively move a school community from a deficit in relational trust, to a high degree of relational trust, specifically at the secondary level, is an area that would benefit from more extensive research and recommendations. 


\section{Chapter 3 - Method}

\section{Introduction}

Schools are comprised of a plethora of networks of sustained relationships (Bryk \& Schneider, 2002). Consequently, the social exchanges that occur between parties and the meaning that is derived from these exchanges profoundly affect a school's functioning (Bryk \& Schneider, 2002). Research has identified that social relationships in school communities based on trust are essential ingredients for the day to day functioning of the school (Bryk \& Schneider, 2002; Tschannen-Moran \& Hoy, 2000). Moreover, researchers have determined that a school community with a broad base of social trust enhances the ability of educational leaders who embark on ambitious improvement initiatives (Bryk \& Schneider, 2002). Trust is even more important as we focus our efforts on high risk, disadvantaged urban schools and their task of educating all students (Bryk \& Schneider, 2002). Thus, it is incumbent on educators to improve their understanding of trust and the critical role of relational trust in a school community.

Chapters 1 and 2 provided the history and necessity for public school educational leaders to understand the importance of trust and the critical role of relational trust between parties in a public school setting. Specifically, the concept of relational trust and the preconditions and facets of building relational trust between teachers and principals was examined. Therefore, the purpose of this mixed methods study was to analyze how high school teachers and principals’ conceptualize the five key facets of building relational trust (e.g., benevolence, reliability, competence, honesty, and openness) in a hierarchical role relationship (Baier, 1986; Bradach \& Eccles, 1989; Bryk \& Schneider, 
2002, 2003; Butler \& Cantrell, 1984; Cole, 1990; Cummings \& Bromily, 1996; Deutsch, 1958; Ellison \& Firestone, 1974; Frost, Stimpson, \& Maughan, 1978; Fukuyama, 1995; Gambetta, 1988; Handford \& Leithwood, 2013; Hosmer, 1995; Hoy \& Kupersmith, 1985; Hoy \& Tschannen-Moran, 1999; Lapidot, Kark, \& Shamir, 2007; Mayer, Davis, \& Schoorman, 1995; Mishra, 1996; Rousseau, Sitkin, Burt, \& Camerer, 1998; Rotter, 1967; Tschannen-Moran, 2003, 2004; Tschannen-Moran \& Gareis, 2015; Tschannen-Moran \& Hoy, 1998; Zand, 1972).

Specifically, this study examined which key facets teachers and principals rate as more important. Further, this study builds on the previous research conducted on trust in schools and utilized previous findings to triangulate with the quantitative and qualitative data that was gathered to ensure validity and reliability. Previous research in the area of relational trust has identified five key facets that support the process of building relational trust between teachers and principals in public schools. However, the majority of these studies have primarily focused their research in elementary schools. Further, this mixed methodological study examines whether or not ethnicity, gender, and years of experience influence how a teacher conceptualizes relational trust and the five facets.

This analysis will be guided by the systematic construct of building relational trust presented in Chapter 1. With this information, the researcher aims to explore how high school teachers and principals' conceptualize the key facets of building relational trust in a hierarchical role relationship within an urban public comprehensive high school district located in a diverse metropolitan area in Northern California. 


\section{Research Questions}

The objective of the study was operationalized into four specific research questions:

1. How do high school teachers and principals conceptualize relational trust?

2. Which facets of relational trust do high school teachers and principals rate as most important in building relational trust?

3. How are ethnicity and gender associated with the facets of relational trust?

4. How are years of teaching experience related to the conceptualization of relational trust?

Examining the development of relational trust through this lens may point to potential opportunities for educational leaders to understand the conditions and processes that enable teachers and administrators to learn to trust one another to meet the growing expectations placed upon schools today (Tschannen-Moran \& Gareis, 2015). Further, the task of cultivating trust strong-based relationships and school climates built on high levels of trust may be one of the greatest challenges educational leaders undertake for the millions of students enrolled in California’s public schools (Tschannen-Moran \& Gareis, 2015).

\section{Research Design}

According to Merriam \& Tisdell (2016) formulating and conducting a study is "to raise a question that perplexes and challenges the mind” (p.76). Thus, this researcher constructed questions for investigation based upon his own curiosity and conceptual framework. In attempting to answer my research questions, this researcher examined a topic of interest to study centered on building a clear understanding of the key facets that build relational trust in a secondary school community between teachers and principals. 
This mixed methodological study was operationalized using three different research approaches: quantitative data and inductive content analysis, qualitative data and inductive content analysis, and past findings on the research of trust in public schools. The use of a mixed methods design aligns well with the descriptive nature of this dissertation. The explanatory sequential design of this study includes the collection of both quantitative and qualitative data (Creswell, 2015). In this design, the quantitative sample proceeds from a random sample procedure (e.g., survey), while the qualitative sample proceeds from purposeful sampling (e.g., semi-structured interviews) of the same database (Creswell, 2015).

The graphic organizer and framework below was created to simplify the complexity and multiple steps of this mixed methods study (see Figure 2).

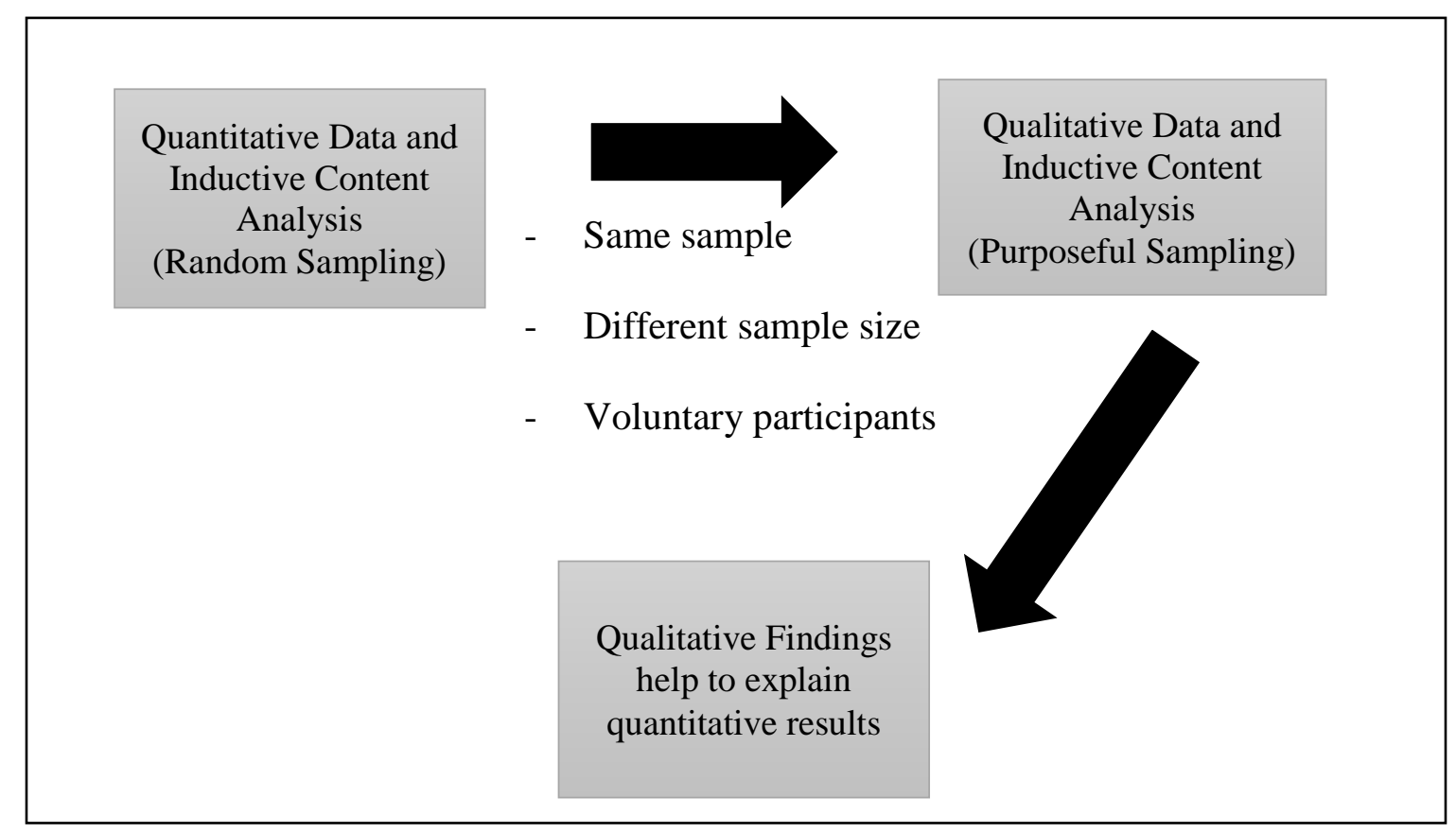

Figure 2. Graphic organizer to explain the mixed methods study. Adapted from Creswell, J.W. (2015). A Concise Introduction to Mixed Methods Research. Thousand Oaks, CA: Sage. 
As noted by Creswell (2015), two issues arise from using this type of methodology: (a) Should the participants of the qualitative sample come from the same population as the quantitative sample? (b) Should both samples be of equal size? In this study, the voluntary participants are from two distinctly different roles within a school community: high school teachers and principals. In the first phase of this study (e.g., survey), the number of the random sample of participants was significantly larger in the high school teacher database. This was simply due to the larger sample size that was inherent in the high school teacher population included in this study. Conversely, the random sample of the principal population was much smaller since only one principal was employed at each of the eleven comprehensive high schools in this study. Furthermore, the qualitative data gathered during the second phase was drawn from the same sample of high school teachers and principals and thus, supported and helped to explain the quantitative results. The qualitative data gathered was conducted using purposeful sampling by the researcher on a voluntary basis. Thus, the qualitative sample was a subset of the quantitative sample, and because qualitative data collection consists of gathering data from fewer participants the sizes of the samples were unequal. Additionally, the quantitative data gathered assisted the researcher in developing the semi-structured interview questions asked in the qualitative sample. Having different units of analysis served this study well since the intent of the explanatory sequential design is to use different perspectives to explain the findings (Creswell, 2015).

Validity and transferability. Due to the very nebulous nature of "trust," the researcher proceeded with a thoughtful and careful approach to engaging in research. 
Along with this approach, the researcher intentionally identified that my own potential bias, knowledge, and perceptions must be tempered in an effort not to taint or distort any and all findings (Harry, Sturgess, \& Klingner, 2005), and ensured that a critical friend would be consulted to review the findings.

\section{Description of Participants}

Setting. This study chose a sampling of eleven urban public comprehensive high schools within the same district located in Northern California. The Superintendent provided consent for the researcher to conduct research within the high school district. The eleven urban public comprehensive high schools selected have similar student demographics and geographic locations. Furthermore, the student demographics of the selected high schools are reflective of the state of California's public school student demographics (see Table 2). This unit of analysis served as the setting for the study.

Table 2

Comparison of Student Demographics

2016-17 Student California $\quad$ District
Demographics

African American

$5.6 \%$

$2.4 \%$

American Indian

$.5 \%$

$.3 \%$

Alaskan Native

Filipino

$2.5 \%$

$7.0 \%$

Hispanic or Latino

$54.2 \%$

$51.6 \%$

Asian

$9 \%$

$31.2 \%$

Pacific Islander

$.5 \%$

$.5 \%$ 
Table 2 Continued

White

Two or more races

Not reported
$23.6 \%$

$3.3 \%$

$.7 \%$
$5.3 \%$

$1.7 \%$

$.2 \%$

Note. A comparison of the student demographics of the unit of analysis and the student demographics in California's public schools (California Department of Education, 2017).

By analyzing the potentially different viewpoints based on power and authority across all eleven schools, a broader spectrum of results could be attained.

Population and sample. To explore the conceptualization of relational trust between teachers and principals at the secondary level within the school district participants were invited to participate in the voluntary on-line survey. This equated to the distribution of 905 teacher surveys and 11 principal surveys in Phase I of the study. The sample comprised a diverse group of professionals between the ages of 22 and 70, who are employed by the high school district. The voluntary on-line survey had optional questions regarding ethnicity, gender, and years of experience that each participant could complete. Participation was voluntary and participants had the option to opt-out of any phase of the research at any time. No exclusionary criteria was employed. Those who consented to participate in the voluntary on-line survey $(\mathrm{N}=100)$ were asked if they would like to be considered for Phase II of the study. Of those who opted to participate in follow-up one-on-one interviews, six participants $(\mathrm{N}=6)$ across the eleven school sites were selected for follow up one-on-one interviews. The six participants included three male teachers varying in years of experience and ethnicity and three female teachers 
varying in years of experience and ethnicity. Interviews were held at a neutral location depending upon the preference of the participants.

\section{Methods}

Data collection and validity. All data collected was utilized in the most valid and ethical manner possible to answer the research questions presented in this study (Creswell, 2015). The first phase of this study gathered quantitative data and was designed after utilizing a small sampling of educators $(\mathrm{N}=6)$ to assist in calibrating the survey questions and to provide face validity. This data was obtained using two different surveys: Teacher Survey and Principal Survey. Each of the two surveys included identical questions except for the title (e.g., Teacher Survey and Principal Survey). The surveys were color coded and numerically coded for data collection purposes with no identifying school or participant information. All participants received an on-line survey that included an introduction of the study, an informed consent letter assuring confidentiality, and the on-line survey. This information was provided in section one of the survey.

Instrument validity. The instruments used in the study were reviewed by a small group of teachers and administrators ( $\mathrm{N}=6)$, as well as two doctoral candidates within the same program for feedback and input. The pilot test was conducted to provide clarity on question format, terminology, typos, grammar, and punctuation. Further, the group pre-tested the instruments for ease of use, flow, and to test the on-line aspect of the instruments. The purpose of the pilot test was to provide face validity for each of the instruments utilized in the study. 
Teacher survey. The Teacher Survey (see Appendix A) utilized by the researcher in Phase I included a five point Likert-type scale format regarding each of the five facets of relational trust (e.g., benevolence, reliability, competence, honesty, and openness) and asked participants to rate the importance of each facet using a 1 to 5 scale.

In Section One, the study was explained, which included the procedures, process, and voluntary consent for participation in the study.

In Section Two, a response of one on the scale represented that the facet of relational trust was not important. A five on the scale represented that the facet of relational trust was very important. Each Likert-type scaled question was followed by an open-ended question. These five questions comprised section two of the survey.

Section Three of the voluntary on-line survey asked the participants to rank the five facets of relational trust. This section of the survey asked participants to force rank which facet of relational trust was most important by indicating a five to least important by indicating a one. The forced ranking section used a five-point Likert-type scale (1-5). The participants were asked to rate each facet only once in order to obtain a true forced ranking. One open-ended question followed the forced ranking section.

Section Four of the survey was utilized by the researcher as a screener for participants who were willing to conduct a follow up one-on-one interview. Section Five asked the participants to indicate their gender, ethnicity, and years in education.

Principal survey. The second survey employed by the researcher was the Principal Survey (see Appendix B). This survey was utilized by the researcher to gather information from each of the principals that voluntarily chose to participate in the study. 
The format of this survey was identical in nature to the Teacher Survey. The only difference was the title. All Principal Surveys were color coded and numerically coded for data collection purposes with no identifying school or participant information. Clear guidelines for administering trust surveys from Tschannen-Moran and Hoy (2003) provided a foundation for the researcher in protecting the participants in the study. These guidelines included the following information: (a) it is critical that ethical standards are adhered to in administering trust surveys, (b) the surveys must be administered anonymously so there is no way for the results to be traced to the participant, (c) participants should be told the purpose of the research, and (d) that their participation is voluntary. Further, these guidelines provided the researcher with reliable and valid procedures to follow when administering the Trust Surveys.

Phase II. The second phase of the study utilized voluntary semi-structured interviews to increase clarity and the validity of Phase I responses. Further, the researcher developed the interview questions in relation to the original surveys to ensure alignment of the data collected. The interviews were semi-structured using an initial protocol (see Appendix C), but also relied on the researcher to prompt and inquire as necessary (Creswell, 2015). Each interview began with a clear explanation of the study, while also informing the participants that their participation was voluntary and anonymous. All participants were provided with the procedures and a consent form prior to the interview being conducted (see Appendix D). During the interviews, there was an opportunity for each participant to ask questions of the researcher. Rapport and trust was established through this process. The interviews each took no more than one 
hour. All interviews were recorded in an on-line data storage system then transcribed and stored using a coding and analysis system. Each interviewee was assigned a code to protect their anonymity (e.g., I1-9) in the findings sections. Further, voluntary participants were able to conduct the interview via phone or in person at a location of their choice. In sum, the interpreted results from both the quantitative and qualitative instruments were compared and contrasted to the findings of prior research conducted on the key facets that build relational trust in a school community. This comparison supported the critical role relational trust plays in a school community as well as provided future implications to research.

Data analysis. The quantitative data analysis began with simple descriptive statistics of the survey data including, percentages, mean, median, standard deviation, frequencies, and range. Further analysis considered cross tabulation of the data.

The qualitative data analysis included organizing the data and systemically coding the data identifying emergent themes through a method of pattern matching. A "two-level scheme” to organize all interview data was utilized on a data accounting sheet. The researcher then identified themes of the participants, which were sorted through a partially ordered meta-matrix. All responses from the participants were color coded to determine similarities and differences. This process allowed the researcher to analyze all of the data in an organized format. The researcher was able to collect data, map, and code the themes using the Inductive Content Analysis process (Elo \& Kyngäs, 2008).

Limitations. The limitations of this mixed method research study include its bounded nature (Ellinger, Watkins, \& Marsick, 2005). There are four distinct areas in 
which this study was bound: unit of analysis, period of time, the context, and the data collected was not on going. First, the study included two sample populations: high school teachers and principals. The unit of analysis included voluntary participants from the eleven comprehensive public high schools within one high school district. All sites are located in the same geographic area and are similar demographically which mitigated some of the variance of pulling data from multiple settings that have inherent differences. Second, the period of time for the collection of the data was during the fall semester of 2017. This short time frame does not account for a longitudinal aspect of analyzing data over a long period of time. Thus, the period of time for data collection was a relatively small window of opportunity. The context of the study was an on-line survey and inperson interviews at neutral sites. Thus, the self-reported data was subjective and based on personal experiences. As many systems begin with just intentions, we are reminded of Brent Duckor’s (2017) article, Got Grit? Maybe..., in which he shares that schools and districts should be cautious in using self-reported data for school improvement purposes. Further, Duckor (2017) reminds readers that there are many inherent problems when using Likert-type surveys to measure complex psychological constructs, just as there are issues using multiple-choice tests to determine student achievement with underserved populations. Therefore, in order to achieve equitable outcomes that represent true valid and reliable measures, researchers should proceed cautiously when interpreting data that may be used for school improvement purposes. Although there are limitations, to provide balance, a mixed methods approach was implemented to offset the potential limits of having only one type of data collection. 
Researcher bias. Merriam \& Tisdell (2016) stated, "getting started on a research project begins with examining your own orientation to basic tenets about the nature of reality, the purpose of doing research, and the type of knowledge to be produced through your effort” (p.14). A priority in ensuring validity in research is understanding one's own identity prior to conducting educational research. It is essential to unearth the underlying beliefs and positionality that can potentially influence and guide a researcher in a particular direction. As an educational researcher, identifying my own personal beliefs and the potential tensions that may exist, along with understanding my own perspectives was step one. In a sense, the self-examination of my understandings, awareness, and identity as a white male was paramount before engaging in research in an educationally diverse school community. My willingness to self-examine and identify potential dangers (e.g., positional authority as a school superintendent, white privilege, my own personal beliefs, and past educational experiences) also helped to focus my lens for conducting valid research. According to Milner (2007) "when researchers are not mindful of the enormous role of their own and others' racialized positionality and cultural ways of knowing, the results can be dangerous to communities and individuals of color" (p. 388).

\section{Summary}

In sum, the mixed methods study began with a random sampling of high school teachers and principals in eleven high schools within one large, urban public comprehensive high school district. Phase I of the research design gathered quantitative data using a pre-piloted instrument. High school teachers and principals completed a 
voluntary on-line survey that included five point Likert-type scale questions regarding each of the five facets of relational trust and one open-ended question after each question. Participants were also asked to force rank the five facets using a five point Likert-type scale format. Participants were asked optional questions to identify their gender, ethnicity, years of experience, and if they would like to participate in a follow up one-onone interview. The researcher utilized the same sample of participants for Phase II of the study. Phase II included six one-on-one interviews with three female high school teachers and three male high school teachers. The high school teachers selected represented varying years of experience. All six voluntarily participated in the interviews, which were held a neutral location of their choosing. The purpose of gathering the qualitative data was to support and explain the quantitative results in an effort to highlight how high school teachers and principals conceptualize relational trust. 


\section{Chapter 4 - Findings}

\section{Introduction}

This mixed methods study examined how high school teachers and principals conceptualized relational trust and determined which of the five facets were more important to them in the trust building process. What follows are findings describing five facets of relational trust and how these factors are associated with three different variables (e.g., gender, ethnicity, years of experience). Further, group comparisons are drawn among the following groups: (a) high school teachers and principals, (b) male and female high school teachers, (c) White and high school Teachers of Color, (d) White female and female high school Teachers of Color, and (d) the years of experience of the high school teachers. The findings also revealed how high school teachers past experiences play a significant role in building relational trust. The data are presented as follows: Descriptive Statistics, Phase I (survey data and open-ended responses), then Phase II (interview data) to answer the four research questions of the study.

\section{Findings: Descriptive Data from the Survey}

In total, 905 voluntary on-line surveys were distributed electronically to teachers in each of the 11 high schools within the high school district. The number of surveys distributed to each of the teacher groups varied in number based on staffing and student enrollment. The researcher sent the on-line surveys to each teacher group on three separate occasions. Ninety-six surveys were returned from the overall teacher population equating to a response rate of $10.6 \%$ (see Table 3 ). Teachers who responded to the survey represented all 11 high schools. Of the 96 high school teachers who responded, 
63 (66\%) were female and 33 (34\%) were male. One hundred percent of the participants voluntarily chose to identify their gender. This was an important aspect of the study, which provided data to answer research question three.

In contrast, 72 high school teachers (75\%) voluntarily responded to the optional question identifying their ethnicity. Of those who chose to complete this question, 45 (63\%) indicated they were White or Caucasian, while 27 (37\%) indicated they were Teachers of Color. The Teachers of Color group represented a broad range of ethnicities, including the following: Latino/a, Hispanic, Mexican-American, Vietnamese, Filipino, Asian, African-American, Native American, East Indian, and Bi-Racial. Further, within the female group 50 high school teachers chose to identify their ethnicity. This equated to $79 \%$ percent of the 63 female high school teachers who participated in the study. The male group of high school teachers did not have a representative group other than White. This was an interesting aspect to take into consideration when analyzing the descriptive nature of the participant demographics. Overall, female high school teachers were more apt to participate in the study and were more willing to indicate their ethnicity than their male counterparts were.

The last optional question asked teachers to identify how many years of experience they had in the classroom. Four categories were provided: (a) 1-5 years, (b) 6-10 years, (c) 11-15 years, and (d) 16 plus years of experience. One hundred percent of the high school teacher group chose to answer this question. Sixteen high school teachers (17\%) were in their first five years in the classroom, 14 high school teachers (15\%) had been teaching for 6-10 years, 18 high school teachers (19\%) had been teaching for 11-15 years, 
and 48 of the high school teachers (50\%) who chose to participate in the survey had been teaching for 16 plus years. This result was another significant aspect of the study, which provided data to answer research question four.

In sum, female high school teachers participated at a greater rate in the study and chose to identify their ethnicity more than the male participants did. All participants identified their gender and how many years of teaching experience they had in the classroom. In addition, veteran high school teachers participated in the study at a greater rate than novice or new teachers.

The voluntary on-line survey was sent to 11 principals. Four principals (36\%) completed the on-line survey (see Table 3). Of those, two principals (50\%) were female and two principals (50\%) were male. One hundred percent of the principals indicated they had 16 plus years of experience in education. Since only two principals indicated their ethnicity this aspect was not included in the study.

Table 3

Demographic Characteristics of Survey Respondents

High School Teachers $(n=96)$

\begin{tabular}{|c|c|c|c|c|c|c|c|c|c|}
\hline Female & Male & $\begin{array}{l}\text { Teachers } \\
\text { of Color }\end{array}$ & $\begin{array}{l}\text { White } \\
\text { Teachers }\end{array}$ & $\begin{array}{l}\text { Female } \\
\text { Teachers } \\
\text { of Color }\end{array}$ & $\begin{array}{l}\text { Female } \\
\text { White } \\
\text { Teachers }\end{array}$ & $\begin{array}{l}1-5 \\
\text { years }\end{array}$ & $\begin{array}{l}6-10 \\
\text { years }\end{array}$ & $\begin{array}{l}11-15 \\
\text { years }\end{array}$ & $\begin{array}{l}16+ \\
\text { years }\end{array}$ \\
\hline 63 & 33 & 27 & 45 & 22 & 28 & 16 & 14 & 18 & 48 \\
\hline \multicolumn{10}{|c|}{ Principals $(n=4)$} \\
\hline \multicolumn{2}{|c|}{ Female } & Male & \multicolumn{2}{|c|}{$1-5$ years } & 0 years & \multicolumn{2}{|c|}{ 11-15 years } & \multicolumn{2}{|c|}{$16+$ years } \\
\hline \multicolumn{2}{|l|}{2} & 2 & \multicolumn{2}{|c|}{0} & 0 & \multicolumn{2}{|c|}{0} & \multicolumn{2}{|c|}{4} \\
\hline
\end{tabular}

Note. $\mathrm{N}=$ total number of participants. $\mathrm{n}=$ number of participants in each subgroup. 


\section{Phase I: Analysis of Survey and Open-Ended Response Data}

Survey and open-ended response data were compiled, analyzed, and categorized to identify the following: (a) salient points to answer the research questions, (b) emerging themes and patterns, and (c) similarities and comparisons between the different groups as noted above. In addition, participant descriptive data were examined and probed in the second phase of data collection, one-on-one interviews, to further explore the conceptualization of relational trust and to support the data collected in phase one. The findings presented below highlight the multiple perspectives of high school teachers and principals. A code by participant number and school was utilized for anonymity.

\section{RQ 1. How do high school teachers and principals conceptualize relational trust?}

The first five questions on the on-line survey asked participants to rate the relative importance of each of the five facets of relational trust using a five point Likert-type scale. A rating of five indicated the facet was very important, while a rating of one indicated the facet was not important. This information is depicted in Table 4.

Teacher response rating. High school teachers indicated that all five facets were important in the trust-building process $(M=4.35$ to 4.69$)$. The standard deviations $(S D=.59$ to .81$)$ indicated the data points are clustered close to the mean. Of the five facets of relational trust presented in the study, honesty had the highest mean $(M=4.69)$. Teachers in descending order rated honesty, reliability, openness, benevolence, and competence. However, the conceptualization of relational trust as indicated by teacher responses identified that all five facets are integral to the trustbuilding process. 
Principal response rating. Principals were provided an identical on-line survey and were asked to complete the same questions. Based on their responses, honesty and reliability had the greatest mean $(M=5)$. Based on the mean scores, principals rated all five facets in the exact same order as teachers. Even with a small sample size of principals $(n=4)$ the similarity between how teachers rated the five facets and how the principals rated the five facets was noteworthy. Moreover, this finding recognizes that when teachers and principals are presented with a single question regarding the relative importance of each of the five facets of relational trust there was a similar ranking of belief. In addition, both groups indicated that all five facets are integral in building relational trust (see Table 4). This finding supported the multidimensional definition of trust presented in this study (Mishra, 1996; Tschannen-Moran \& Hoy; 1998, 2000).

Table 4

Overall Means and Standard Deviations of the Five Facets of Relational Trust High School Teachers $(n=96)$

\begin{tabular}{lcc}
\hline Facets of Trust & Mean & Standard Deviation \\
\hline Honesty & 4.69 & 0.59 \\
Reliability & 4.66 & 0.61 \\
Openness & 4.59 & 0.67 \\
Benevolence & 4.56 & 0.75 \\
Competence & 4.35 & 0.81
\end{tabular}


Table 4 Continued

Principals $(n=4)$

\begin{tabular}{lcc}
\hline Facets of Trust & Mean & Standard Deviation \\
\hline Honesty & 5.0 & 0 \\
Reliability & 5.0 & 0 \\
Openness & 4.5 & 1 \\
Benevolence & 4.5 & .5 \\
Competence & 4.25 & \\
\hline
\end{tabular}

Note. $\mathrm{n}=$ number of participants in each subgroup.

Open-ended responses. High school teachers and principals were asked via an open-ended response question to describe how they conceptualized each of the five facets of relational trust by sharing an experience of honesty, reliability, openness, benevolence, and competence.

Honesty. Honesty was conceptualized as 'being transparent' by high school teachers. Nineteen or $56 \%$ of the 34 high school teachers who chose to answer the open-ended question stated that being transparent was a characteristic of being honest. For example, one teacher stated the following about being honest: "secrecy or hidden agendas are the exact opposite of trust” (Teacher 61-7). Another teacher described how honesty builds trust:

They were honest to tell me when I did something incorrectly so that I could change it and do it correctly. I know I can trust them to tell me how to do something correctly. I will go back to them. (Teacher 53-6) 
In addition, six high school teachers or $18 \%$ shared experiences that highlighted examples of a principal not being honest which led to distrust. Each of the negative experiences indicated when a principal was dishonest it led to lack of trust. In sum, one teacher stated the following about the importance of honesty to the trust building process: "Honesty is imperative to gaining trust. Any level of lie can break the strongest of trust bonds” (Teacher 41-4). None of the four principals answered the open-ended question regarding honesty.

Reliability. Forty-six high school teachers responded to the open-ended question about reliability. Being reliable was conceptualized in the following ways: (a) being valued as a person and as a professional, and (b) following through with action. Further, 22 (48\%) of the 46 high school teachers described reliability as being valued as a person and as a professional. Twenty (43\%) of the 46 high school teachers described reliability as following through with action; such as completing a task, answering emails, or providing resources. One high school teacher stated the following about how reliability builds trust: “...when a principal, or any admin, makes a commitment, it builds a significant amount of trust when they follow through” (Teacher 72-9). One high school principal chose to answer the open-ended question about reliability and stated "follow through has to happen” (Principal 1-2).

Openness. Openness was conceptualized by high school teachers to be when a principal listened to their concerns, thus they felt valued as a person and as a professional. Thirty-six high school teachers chose to respond to the open-ended question. Further, teachers described the facet of openness as being supported by their 
principal through a give and take relationship, being available, and having an open door. Twenty-nine or $81 \%$ of high school teachers who responded described a time when they were listened to as an experience of openness. While, 22 or $61 \%$ of high school teachers who responded shared an experience of feeling valued by a principal who was open. One teacher described openness the following way: “...current principal is able to hear when something is not a good idea or there is a better way to say or present something to staff. He seeks feedback and truly has an open door" (Teacher 22-3). While another teacher described openness by stating: "relationships are built on give and take and listening. I am far more likely to build a relationship with someone who is willing to listen and give an honest reaction" (Teacher 41-4). None of the principals chose to answer the openended question regarding openness.

Benevolence. Fifty-five high school teachers answered the open-ended question about benevolence. Benevolence was described by 19 or $35 \%$ of the high school teachers who responded as being valued as a person and as a professional, while 16 or $29 \%$ of the high school teachers who responded described the manner in which they were supported as being benevolent. The above experiences were furthered characterized by 18 responses (33\%) of feeling valued and supported in a time of need - illness, injury, or death. One high school teacher described a benevolent experience in the following manner:

When I had an extended illness, the principal made it clear to me that he wanted me back but wanted me to stay home as long as needed to take care of myself; did it make me "trust" him more...? I suppose not really, but it validated the trust I already had. (Teacher 96-11)

Another teacher described how benevolence builds relational trust: 
When I experienced a personal crisis and had to communicate it to the principal, her expressed concern and follow-up concern led to my trusting her and lowered my stress levels around work. Also, I felt obligated and wanted to return the trust. (Teacher 61-7)

Two principals chose to respond to the open-ended question. One principal stated they experienced benevolence when they had lost a family member (Principal 1-2).

Competence. Forty-two high school teachers chose to respond to the open-ended question about competence. Twenty-two or 52\% of the high school teachers who responded described a competent principal as having the knowledge and skills to lead the school. A principal who follows through with action was described by six high school teachers (14\%) as being competent. In addition, five high school teachers (12\%) commented that a principal was more competent if they have had teaching experience. Of note, one high school teacher described how new administrators can build relational trust: "new administrators have a steep learning curve; unless and until I realize they are not worthy of my trust, I am willing to cope with the issues that arise from developing competence” (Teacher 80-9). One principal chose to respond to the open-ended question and stated the following: "being able to find an answer and doing so is important" (Principal 2-3).

In general, high school teachers shared three consistent themes that emerged through their experiences with principals when describing the five facets of trust: (a) follow through with action, (b) being supported, and (c) being valued as a person and as a professional. Other characteristics that emerged included respect, integrity, humility, loyalty, and consistency. High school teachers also responded that lacking in one of five 
facets of relational trust could hinder trust. The principal responses supported the above themes.

\section{RQ 2. Which facets of relational trust do high school teachers and principals rate as most important in building relational trust?}

High school teachers and principals in the study were asked to complete a forced ranking identifying which of the five facets of relational trust was the most important and least important. A five point Likert-type scale was utilized with a ranking of five as the most important and a ranking of one as not important. The forced ranking was designed to allow a participant to only record one rank $(5,4,3,2$, and 1$)$ for each of the five facets. The purpose of the forced ranking was to identify which of the five facets high school teachers and principals would indicate as the most important and which facet would be ranked as the least important, in descending order. Further, this question was designed to identify similarities or differences in beliefs between the two roles.

As noted above and depicted in Table 4, both high school teachers and principals responded that all five facets were important in the trust building process. When asked to force rank the five facets, reliability was selected as the most important facet by high school teachers in creating relational trust (see Table 5). Whereas, all four principals responded that reliability was not as important as the other four facets (e.g., benevolence, competence, honesty, openness). In addition, 55.9\% of the 96 high school teachers who responded to the voluntary on-line survey rated reliability as the most important facet in building relational trust with a Likert-type scale score of five or four. In fact, when disaggregating all of the forced rankings, $83.9 \%$ of the 96 high school teachers rated reliability with a Likert-type scale of five, four, or three. Competence and honesty were 
ranked as the second and third most important facets in building relational trust respectively. Almost forty-eight percent (47.8\%) of the high school teacher's ranked competence with a Likert-type scale score of five or four and $45.0 \%$ of high school teacher's ranked honesty with a Likert-type scale score of five or four.

A Repeated Measures ANOVA was conducted to determine the reliability of the forced rankings of the five facets (see Appendix E). Based on statistical testing, there was a significant difference between the percentage of respondents who ranked the three most important facets (e.g., reliability, competence, honesty) and the fourth and fifth ranked facets (e.g., openness, benevolence). For example, 29.4\% of the high school teacher's ranked openness with a Likert-type scale of five or four and $28.4 \%$ ranked benevolence with a Likert-type scale score of five or four. To conclude, just over one out of four high school teachers indicated benevolence was the most important facet in building relational trust.

In comparison, all four principals rated reliability with scores of three, two, or one (see Table 5). Further, three out of four principals (75\%) rated benevolence as the most important facet in building relational trust with a Likert-type scale score of five or four. Conversely, the 96 high school teachers who participated in the voluntary on-line survey rated benevolence as the least important facet in building relational trust with $54.2 \%$ of the teachers rating benevolence with a Likert-type scale score of two or one. Fifty percent of the principals ranked honesty and competence with a Likert-type scale score of five or four. Openness was ranked by one principal (25\%) as the most important facet with a Likert-type scale score of five or four. 
Overall, teachers and principals ranked competence, honesty, and openness in a similar manner. And although the size of the high school teacher and principal groups are very different, the similarities of responses among all participants is apparent in how both parties view these three facets in the trust building process. However, there was a dissimilarity between how high school teachers and principals conceptualize the importance of reliability and benevolence in the trust building process. These comparisons shed light on how the two roles conceptualize the importance of each of the five facets of relational trust, while also providing insight into how each group can utilize the five facets to build relational trust. For example, high school teachers indicated that reliability was the most important facet in the trust building, whereas principals ranked benevolence as the most important facet. Further, none of the principals ranked reliability with a score of five or four. Thus, based on the scores high school teachers indicated that a reliable principal was integral to the trust building process and a benevolent principal was not as important to the trust building process. Therefore, principals should be cognizant of the importance reliability plays in the trust building process for high school teachers and that acting in a reliable manner may help to build relational trust with high school teachers. 
Table 5

Ranking of the Five Facets of Relational Trust by Level of Importance

Teachers $(n=96)$

Facets of Trust

Ranking of 5 or 4

Reliability

Competence

Honesty

Openness

Benevolence

Principals $(n=4)$
$55.9 \%$

$47.8 \%$

$45.0 \%$

$29.4 \%$

$28.4 \%$

Facets of Trust

Ranking of 5 or 4

Benevolence $75 \%$

Honesty $50 \%$

Competence $50 \%$

Openness $25 \%$

Reliability

$0 \%$

Note. $\mathrm{n}=$ number of participants in each subgroup.

RQ 3. How are ethnicity and gender associated with the facets of relational trust?

Survey responses from high school teachers, White $(n=45)$ and Person $(s)$ of Color $(n=27)$, indicated they conceptualized the five facets of relational in a similar manner. As shown in Figure 3, 61.5\% of the Teachers of Color and 52.2\% of White Teachers ranked reliability as the most important facet in the trust building process. Competence 
was ranked by $46.6 \%$ of White Teachers as the second most important facet. Whereas, $44 \%$ of the Teachers of Color ranked competence as the third most important facet.

There was a slight variation in belief regarding the importance of honesty with $41.9 \%$ of White Teachers ranking honesty as the third most important facet, while $48.0 \%$ Teachers of Color ranked honesty as the second most important facet. Overall, both groups of high school teachers ranked reliability, competence, and honesty as the three most important facets in the trust building process. Benevolence and openness were slightly more important to White Teachers than Teachers of Color. However, both groups ranked benevolence and openness as the two least important facets in the trust building process respectively.

In sum, White Teachers and high school Teachers of Color ranked the importance of the five facets in a similar manner. This finding suggests that ethnicity was not associated with rankings of the five facets of trust (see Figure 3).

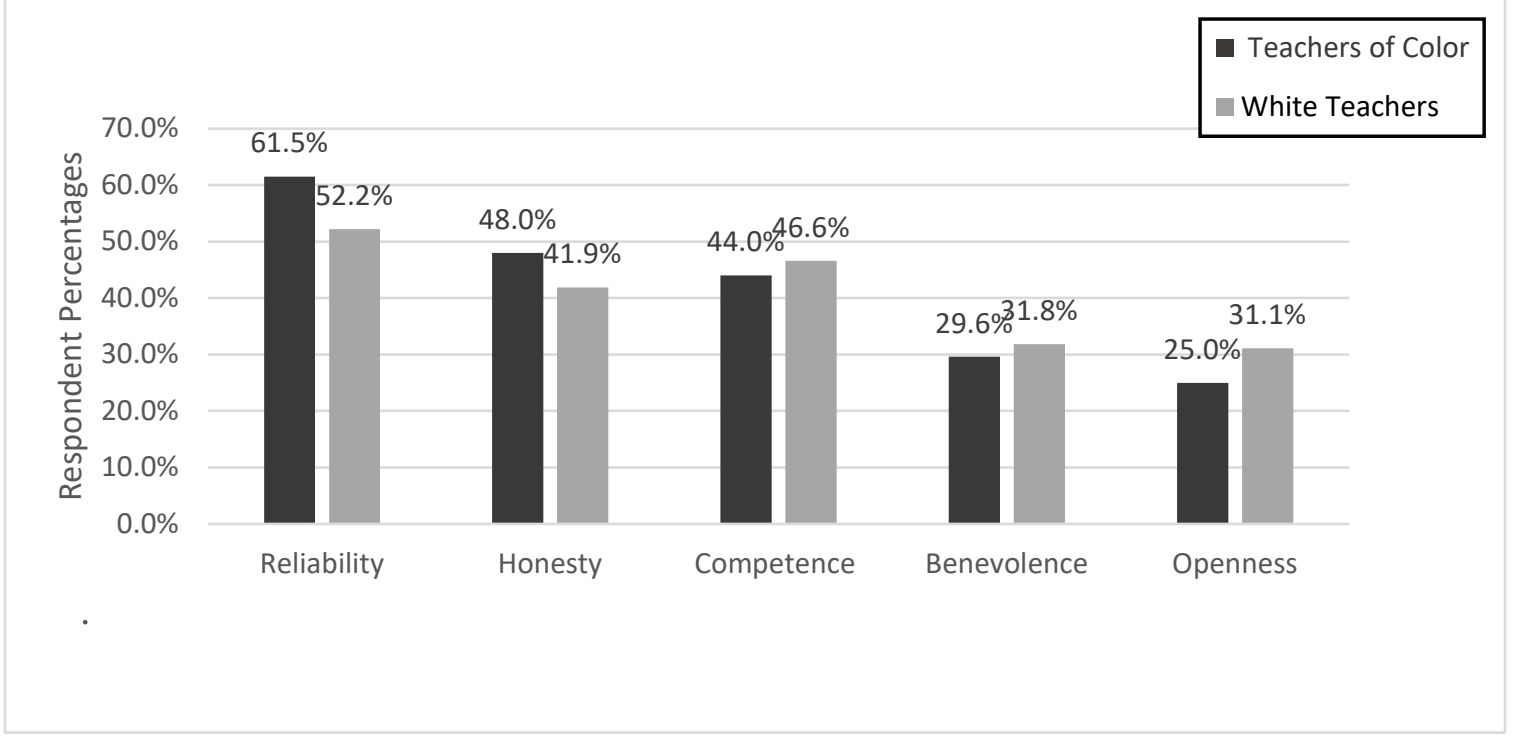

Figure 3. A comparison of the ranked importance of the five facets of relational trust for high school Teachers of Color and White high school teachers 
The survey data was further disaggregated to examine how two variables (e.g., gender, ethnicity) may be related to how the five facets are conceptualized (see Figure 4). Survey responses from White female high school teachers $(n=28)$ and female high school Teachers of Color $(n=22)$ indicated reliability was the most important facet to both groups respectively. Both groups ranked reliability as the most important facet in the trust building process. Almost sixty percent (59.2\%) of White female high school teacher's ranked reliability as the most important facet and $61.9 \%$ of the female high school Teachers of Color ranked reliability as the most important facet. Fifty-five percent of the female high school Teachers of Color and 53.6\% of the White female high school teachers ranked competence as the second most important facet. Just over fortytwo percent (42.3\%) of the White female high school teachers ranked honesty as the third most important facet, while $36.9 \%$ of the female high school Teachers of Color also ranked honesty as the third most important facet. The two groups ranked the three most important facets in a similar manner. Both groups ranked benevolence and openness as the least important facets in the trust building process. White female high school teachers ranked benevolence, $25.9 \%$, slightly above openness, 25.0\%. Whereas, female high school Teachers of Color ranked openness, 31.6\%, slightly above benevolence, 27.3\%. Based on an analysis of the data, White female high school teachers and female high school Teachers of Color conceptualized the five facets in a similar manner. Thus, there was little to no difference between the rankings of the facets of relational trust for White female high school teachers and female high school Teachers of Color. 


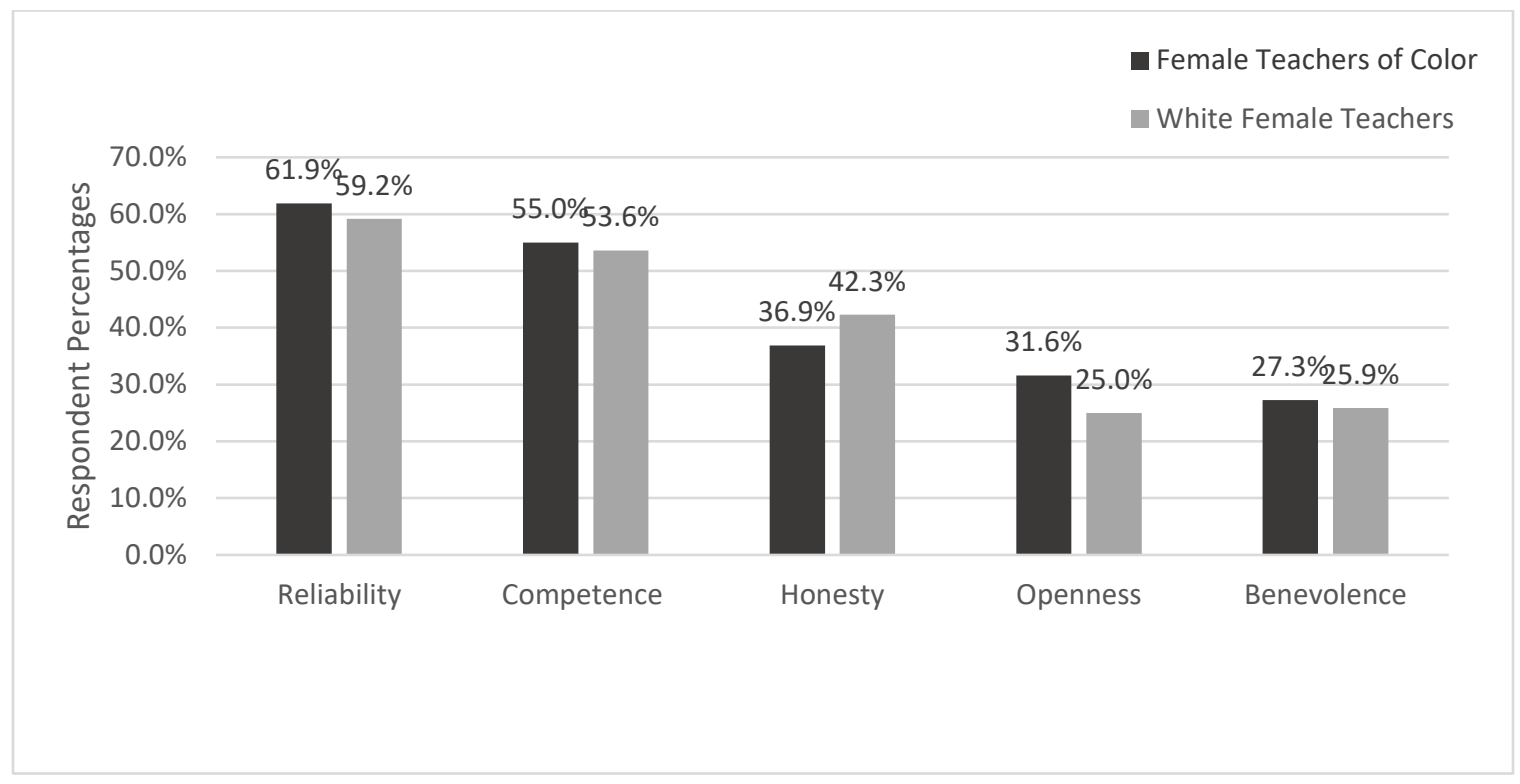

Figure 4. A comparison of the ranked importance of the five facets of relational trust for White female high school teachers and female high school Teachers of Color.

Figure 5 depicts how Female $(n=63)$ and Male $(n=33)$ high school teachers conceptualized the five facets of relational trust. Survey responses from female high school teachers (58.3\%) indicated that reliability was the most important facet in the trust building process. Furthermore, female high school teachers (55\%) ranked competence just below reliability. In comparison, male high school teachers ranked reliability (50\%) and honesty (50\%) as the two most important facets in the trust building process. Female high school teachers (42.9\%) ranked honesty as the third most important facet, while $36.4 \%$ of the male high school teachers ranked benevolence as the third most important facet. Both groups ranked reliability as the most important facet in the trust building process. An analysis of the data points to a similar viewpoint on the most important facet, reliability, and the importance of honesty in the trust building process. However, there was a difference in how the two groups viewed competence and benevolence. 
Competence was ranked as the second most important facet by $55.0 \%$ of the female high school teachers, whereas only $35.5 \%$ of the male high school teachers ranked competence as the most important facet in the trust building process. This difference in how female and male high school teacher’s ranked competence may warrant further investigation. Further, male high school teachers ranked benevolence as the third most important facet, while female high school teachers ranked benevolence as the least important facet in the trust building process. This difference in how female and male high school teacher's ranked benevolence may also warrant further investigation.

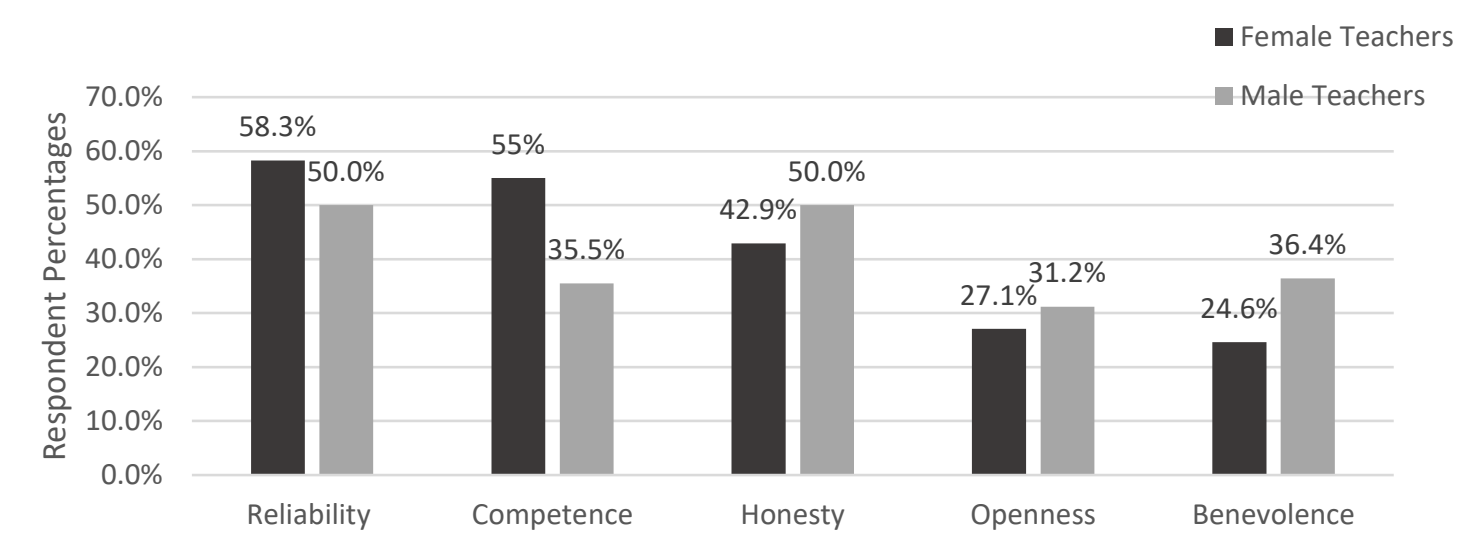

Figure 5. A comparison of the ranked importance of the five facets of relational trust between female and male high school teachers.

\section{RQ 4. How are years of teaching experience related to the conceptualization of relational trust?}

Table 6 depicts how high school teachers of varying years of experience conceptualized the five facets of relational trust. All four groups ranked reliability as one of the top three facets in the trust building process (see Table 6). In addition, three groups (1-5, 6-10, 11-15 years of experience) ranked reliability as the most important 
facet. Almost fifty-seven percent (56.9\%) of the high school teachers with 16 plus years of experience ranked honesty as the most important facet, competence as the second most important facet, and reliability as the third most important facet. High school teachers with 1-5 years of experience and high school teachers with 16 plus years of experience ranked reliability, honesty, and competence as the top three facets, albeit in different orders. High school teachers with 6-10 and 11-15 years of experience ranked reliability as the most important facet in the trust building process. Overall, as noted reliability and competence was consistently ranked by each group of high school teachers as one of the most important facets to the trust building process.

Table 6

A Comparison of Teaching Experience and the Three Most Important Facets of Relational Trust

\begin{tabular}{ccccc}
\hline Participants & Group & Ranked 1 & Ranked 2 & Ranked 3 \\
\hline \multirow{2}{*}{$n=16$} & 1-5 Years of & Reliability & Competence & Honesty \\
& Experience & $53.3 \%$ & $46.7 \%$ & $46.7 \%$ \\
$n=14$ & 6-10 Years of & Reliability & Competence & Benevolence \\
& Experience & $85.7 \%$ & $42.9 \%$ & $28.6 \%$ \\
$n=18$ & 11-15 Years & Reliability & Openness & $\begin{array}{c}\text { Competence } \\
\text { of Experience }\end{array}$ \\
& $58.8 \%$ & $44.4 \%$ & $38.9 \%$ \\
$n=48$ & 16+ Years of & Honesty & Competence & Reliability \\
& Experience & $56.9 \%$ & $53.3 \%$ & $46.8 \%$ \\
& & & & \\
\hline
\end{tabular}

Note. $\mathrm{n}=$ number of participants in each subgroup. 


\section{Summary}

Table 7 provides a summary of how high school teachers ranked the three most important facets of relational trust. Based on survey data $90.9 \%(n=10)$ of the high school teacher groups ranked reliability as the most important facet in the trust building process and $100 \%$ of the teacher groups ranked reliability as one of the three most important facets in the trust building process. Competence was ranked by $72.7 \%$ of the high school teacher groups as the second most important facet in the trust building process. In addition, 10 out of the 11 (90.9\%) high school teacher groups ranked competence as one of the three most important facets in the trust building process. Honesty was ranked by $54.5 \%$ of the high school teacher groups as the third most important facet in the trust building process. Furthermore, nine out of 11 (81.8\%) high school teacher groups ranked honesty as one of the three most important facets in the trust building process. In comparison, 10 out of the 11 (90.9\%) high school teacher groups and nine out of the 11 (81.8\%) high school teacher groups ranked openness and benevolence as the two least important facets in building relational trust. These similarities suggest that gender, ethnicity, and years of experience are not significantly related to the conceptualization of relational trust and that high school teachers largely feel the same way, regardless of gender, ethnicity and years of experience. Most notably, gender may have influenced how male and female high school teachers ranked the importance of competence and benevolence in the trust building process (see Table 7). 
Table 7

The Three Most Important Facets of Relational Trust

\begin{tabular}{|c|c|c|c|c|}
\hline Participants & Group & Ranked 1 & Ranked 2 & Ranked 3 \\
\hline$n=96$ & All Teachers & $\begin{array}{c}\text { Reliability } \\
55.9 \%\end{array}$ & $\begin{array}{c}\text { Competence } \\
47.8 \%\end{array}$ & $\begin{array}{c}\text { Honesty } \\
45.0 \%\end{array}$ \\
\hline$n=63$ & $\begin{array}{l}\text { Female } \\
\text { Teachers }\end{array}$ & $\begin{array}{c}\text { Reliability } \\
58.3 \%\end{array}$ & $\begin{array}{c}\text { Competence } \\
55.0 \%\end{array}$ & $\begin{array}{c}\text { Honesty } \\
42.9 \%\end{array}$ \\
\hline$n=33$ & $\begin{array}{l}\text { Male } \\
\text { Teachers }\end{array}$ & $\begin{array}{c}\text { Reliability } \\
50.0 \%\end{array}$ & $\begin{array}{c}\text { Honesty } \\
50.0 \%\end{array}$ & $\begin{array}{c}\text { Benevolence } \\
36.4 \%\end{array}$ \\
\hline$n=45$ & $\begin{array}{l}\text { White } \\
\text { Teachers }\end{array}$ & $\begin{array}{c}\text { Reliability } \\
52.2 \%\end{array}$ & $\begin{array}{c}\text { Competence } \\
46.6 \%\end{array}$ & $\begin{array}{c}\text { Honesty } \\
41.9 \%\end{array}$ \\
\hline$n=27$ & $\begin{array}{l}\text { Teachers of } \\
\text { Color }\end{array}$ & $\begin{array}{c}\text { Reliability } \\
61.5 \%\end{array}$ & $\begin{array}{c}\text { Honesty } \\
48.0 \%\end{array}$ & $\begin{array}{c}\text { Competence } \\
44.0 \%\end{array}$ \\
\hline$n=28$ & $\begin{array}{l}\text { White } \\
\text { Female } \\
\text { Teachers }\end{array}$ & $\begin{array}{c}\text { Reliability } \\
59.2 \%\end{array}$ & $\begin{array}{c}\text { Competence } \\
53.6 \%\end{array}$ & $\begin{array}{c}\text { Honesty } \\
42.3 \%\end{array}$ \\
\hline$n=22$ & $\begin{array}{l}\text { Female } \\
\text { Teachers of } \\
\text { Color }\end{array}$ & $\begin{array}{c}\text { Reliability } \\
61.9 \%\end{array}$ & $\begin{array}{c}\text { Competence } \\
55.0 \%\end{array}$ & $\begin{array}{c}\text { Honesty } \\
36.9 \%\end{array}$ \\
\hline$n=16$ & $\begin{array}{l}\text { 1-5 Years of } \\
\text { Experience }\end{array}$ & $\begin{array}{c}\text { Reliability } \\
53.3 \%\end{array}$ & $\begin{array}{c}\text { Competence } \\
46.7 \%\end{array}$ & $\begin{array}{c}\text { Honesty } \\
46.7 \%\end{array}$ \\
\hline$n=14$ & $\begin{array}{l}\text { 6-10 Years } \\
\text { of } \\
\text { Experience }\end{array}$ & $\begin{array}{c}\text { Reliability } \\
85.7 \%\end{array}$ & $\begin{array}{c}\text { Competence } \\
42.9 \%\end{array}$ & $\begin{array}{c}\text { Benevolence } \\
28.6 \%\end{array}$ \\
\hline$n=18$ & $\begin{array}{l}\text { 11-15 Years } \\
\text { of } \\
\text { Experience }\end{array}$ & $\begin{array}{c}\text { Reliability } \\
58.8 \%\end{array}$ & $\begin{array}{c}\text { Openness } \\
44.4 \%\end{array}$ & $\begin{array}{c}\text { Competence } \\
38.9 \%\end{array}$ \\
\hline$n=48$ & $\begin{array}{l}16+\text { Years of } \\
\text { Experience }\end{array}$ & $\begin{array}{c}\text { Honesty } \\
56.9 \%\end{array}$ & $\begin{array}{c}\text { Competence } \\
53.3 \%\end{array}$ & $\begin{array}{c}\text { Reliability } \\
46.8 \%\end{array}$ \\
\hline
\end{tabular}

Note. $n=$ number of participants in subgroup. 


\section{Phase II: Analysis of Interview Data with Teachers}

This section provides an analysis of one-on-one interview responses from six high school teachers and further describes how high school teachers conceptualize relational trust.

Teacher interview responses. The one-on-one interviews with three male and three female high school teachers allowed for further exploration and understanding of how high school teachers conceptualize relational trust, building on the survey responses and open-ended responses above. Interviewees were asked nine questions (see Appendix C) and the topics and their responses are listed below.

As noted, the interviews were transcribed by a third party and then coded by the researcher, first by hand and then using Excel database. The data were coded by question with each of the six high school teachers responses analyzed and examined to determine themes and patterns that emerged using the Inductive Content Analysis process (Elo \& Kyngäs, 2008). Specific quotes were extracted and utilized to support the themes and patterns that emerged, while also substantiating the survey results. This section included responses from the six teacher interviewees. The teacher interviewees represented varying years of experience, ethnicities, and gender (see Table 8). Each teacher interviewee voluntarily participated in this phase of the study and was provided an opportunity to ask questions of the researcher. 
Table 8

Demographic Characteristics of Interview Respondents

\begin{tabular}{cccccc}
\hline Interviewee & School & Male & Female & Ethnicity & Years of Experience \\
\hline 1 & 9 & $\mathrm{X}$ & & White & $16+$ \\
2 & 2 & $\mathrm{X}$ & & $\begin{array}{c}\text { Teacher of } \\
\text { Color }\end{array}$ & $11-15$ \\
3 & 3 & $\mathrm{X}$ & & White & $16+$ \\
4 & 4 & & $\mathrm{X}$ & White & $6-10$ \\
5 & 3 & & $\mathrm{X}$ & $\begin{array}{c}\text { Teacher of } \\
\text { Color }\end{array}$ & $16+$ \\
6 & 4 & & $\mathrm{X}$ & White & $1-5$ \\
\hline
\end{tabular}

Note. $\mathrm{I}$ = Interviewee. Coding (I2-7 = Interviewee number 2 and school number 7).

Meaning of trust in a school community. Four out of the six teacher interviewees responded that the meaning of trust in a school community was everyone striving for the same goal and in essence relying on one another to achieve success. Further, one male teacher interviewee responded that in order for trust to be present reliability must be blind (I2-2). He stated the following about what trust means in a school community:

An acknowledgement that we are working towards the same goal. Everybody's headed in the same direction, and relying on each other in order to help or assist one another to reach those goals. And, that reliance (reliability) is blind” (I2-2).

For example, reliance was not based on the role, gender, ethnicity, or years of experience, nor on the status or role in the school community, simply everyone pulling in 
the same direction. In addition, one female teacher interviewee responded that trust has a lot to do with relinquishing control (I6-4). She further stated that for trust to be present:

...I am going to trust that I can release some control. Trusting that my administration will do the right thing, that the students will do the right thing, other teachers will do the right thing, and giving up that feeling that I have to control every single aspect what is going on. The aspect of trusting my students and staff and community has a lot about relinquishing control. (I6-4)

Three of the interviewees responded that when a principal provided autonomy to teachers to perform their roles this was a sign of trust. One female teacher interviewee stated that trust was apparent when judgment was suspended (I5-3). Of note, one female teacher interviewee stated that trust equaled follow through (I4-4), which was a consistent theme from all respondents.

How is trust conceptualized by high school teachers? When asked, three of the teacher interviewees responded that having the autonomy and freedom to do their jobs was how they conceptualized trust. In addition, three of the teacher interviewees stated that they conceptualized trust as feeling safe and having the security to be honest with others or to make mistakes without reprisal. For example, one female teacher interviewee stated the following about how she conceptualized trust: “you’ve got the freedom to do and the safety to be able to take chances and fail and be supported and grow from your experiences” (I4-4). When probed further she stated the following about trust:

Security might be a better way to describe to it...trust is like a nice blanket, I suppose like a nice security blanket where, you know, where you feel supported...it's warm. Trust is, you know, warm and fluffy. (I4-4). 
One male teacher interviewee responded, "trust was like a nice security blanket” (I22). Another male teacher interviewee responded negatively stating he "will always look at administrators as part of their jobs is political, so I would never fully trust an administrator” (I3-3). When probed about his response the interviewee stated his feeling was based on past experiences. One female interviewee stated that she conceptualized trust as follow through (I3-3), which is a theme, which will be further addressed in Chapter 5. Further, another female teacher interviewee stated she conceptualized trust in the following manner:

...it sort of comes from the person who's in the most power needs to demonstrate it first. When we see an administrator own up to a mistake, say they did something wrong that's just maybe a bad choice, but here's what we're going to do to fix it, that creates the safety then for staff to feel like they can own up to a mistake when do something wrong or I'm not confident in this choice that I made. Without it coming from top-down first, I think it's very hard to show that vulnerability to that person who's above you unless they’ve demonstrated to you first. (I6-4)

Examples of when a principal built trust. Five out of the six teacher interviewees described how a principal utilized their competence to build trust with them. Following through with action, asking for input, providing autonomy, and acting in a caring manner were also examples of trust building provided by interviewees. One male interviewee described how principals built trust with him as follows:

...there's been multiple examples of a principal, building trust with me in terms of asking for input, respecting my autonomy, having confidence that I can work independent, being trusted enough to know that, the outcomes of - and the process are not linear. (I1-9)

Further, one female teacher interviewee stated a principal built trust with her when they acted in the following manner: 
... asked for my professional opinion...hey, you know this is what we want to do. What do think about it? I think it goes back to being treated like a professional; feeling like your experience, teaching practice, and that you are a knowledgeable professional. (I4-4).

In addition, one female teacher interviewee stated trust was built with a principal when "they had the faith in me to grow and develop as a professional” (I6-4). Another female teacher interviewee recalled a time when a principal built trust with her by working through a situation to find a resolution even though the teacher was not in favor of the resolution (I3-3). Specifically, she recalled the principal built trust with her when the following occurred:

A kid didn't get suspended...I still knew the process that she went through to have closure, to work towards an answer to that problem, even though it wasn't the answer maybe I would've wanted. This was 15 years ago...but I still trusted her with whatever decisions were made. (I3-3)

Examples of when a principal diminished trust. Three out of six teacher interviewees described a time when a principal was dishonest as diminishing trust with them. Further, teacher interviewees described the following situations as a time when a principal diminished trust with them: (a) changing plans without input, (b) a principal not being transparent, (c) a principal who is inaccessible, (d) lack of support from a principal, and (e) lack of follow through by a principal. Multiple teacher interviewees shared that they had felt betrayed by their principal during their career and this caused them not to trust principals in the future. One female interviewee recalled a time when a principal diminished trust with her as follows:

They told me that they wanted me to come back. The only position that was available was a co-teaching position...in some ways I felt that they sort of manipulated me into taking that position by telling me that there no positions available...they also wanted me to revoke my tenure track 
position. I was told we don't have any jobs in the district, but we do have this temp position. All you have to do is revoke your tenure tracking and you could teach full time. I did go talk to the union. Amazingly enough, within a week there was full time position for me at the same site. (I6-4)

Further, teacher interviewees stated the feeling of betrayal took a long time to overcome. Past experiences lingered with the teacher interviewees and they were quick to recount a time when a principal diminished trust with them even if it was many years ago. One male teacher interviewee recalled how a principal diminished trust with him as follows:

... I could never meet with her (Principal) the entire year. We did not have one meeting just one to one. She was inaccessible. She seemed really friendly in large groups, but if I tried to have a one to one, she would just blow you off and literally walk away...so, for me from that point on, which was a good 12 years ago, I've had a hard time entirely trusting an administrator. (I3-3)

A female teacher interviewee recalled the following incident in which she felt betrayed by a principal:

I was helping to run a program and the state gives us funds and those funds have to be used for certain things... we tried to spend it on a specific program and she said, no you can't do that. I want to do these things over here. I had to send an email to the district and she got into trouble and then got mad at me because no, she could not spend the funds on what she wanted, but told us she was going to anyways. (I4-4)

An important point to note shared by one female teacher interviewee was that she had experienced at least twenty administrative changes in the past five years and it was difficult to build trust due to such high turnover (I5-3). One male teacher interviewee described multiple times that principal's diminished trust with him when they “politicked” and where not direct and to the point (I2-2). In other words, this teacher 
interviewee indicated that principals need to be transparent and consistent in how they communicate and consistent when they follow through with action.

Challenges and barriers in building relational trust. Three teacher interviewees responded that one of the greatest challenges and barriers in building relational trust with principals was principal turnover, while five teacher interviewees stated their past experiences with principals was the greatest challenge and barrier in building relational trust with a principal. Other challenges and barriers that were shared included the following: (a) difference in belief systems between the roles, (b) a lack of perceived competence exhibited by principals, (c) the practicality of time, (d) balancing interests inside and outside the school, (e) the inherent differences that exist between the roles, and (f) when a principal does not act with care or tact when working with a teacher.

One teacher interviewee elaborated on their past experiences working with principals as the greatest challenge and barrier in building relational trust with a new principal (I33). Notably, one female teacher interviewee stated her new principal had to mend a scarred staff that suffered from PTSD and "really had to work hard to reassure everybody that he was not going to do things in the same way...just dealing with past experiences” (I4-4).

One male teacher interviewee shared that one of the greatest challenges and barriers in building relational trust was that someone has to be willing to step forward and let their guard down. Essentially, one party must be willing to become vulnerable and take a risk to trust the other party and say, “I'm willing to trust you, and then that's sort of the opportunity to capitalize on it, in order to build on the relationship” (I2-2). This 
statement correlated to the conceptual framework presented in this study in which vulnerability provides an opportunity for one party to take a risk, thus allowing the trust building process to occur. Without the willingness to become vulnerable, the trust building process cannot begin to develop.

Lastly, one male teacher interviewee stated that the greatest challenge and barrier to building trust with principals was the extreme turnover in his school (I1-9). He further stated that there was a period of time when a principal was rotated every two years; hence, the ability to build trust was inhibited by the short time frame (I1-9).

Practical rules of thumb that practitioners use to measure relational trust. Half of the teacher interviewees responded that they measured relational trust by a gut feeling or subconsciously. When probed further one male teacher interviewee responded by stating,

...my brain puts together all of the previous interactions I've had and goes, you're safe, or you're not entirely safe, or, you're not safe at all. Trust was an emotional experience and administrators are not born, they are made. (I2-2)

A female teacher interviewee expressed,

She measured relational trust by how much she dreads waking up and going to work each day. When the relationship between the principal and teaching staff was bad, everybody was unhappy and the students sensed this feeling as well. In a sense, when relational trust was high, teachers loved to teach, but when it was bad, you simply did not want to be in that toxic place. (I4-4)

Two male teacher interviewees stated they measured relational trust by the follow through that occurred by a principal. One male teacher interviewee stated, "actions speak louder than words," (I3-3), while another stated, "this goes both ways between a principal and teachers” (I1-9). Thus, there was reciprocity for both parties regarding follow 
through and action. Teacher (I1-9) further accentuated this aspect by stating, "being able to follow through on projects and principals trusting they will, whereas teachers need to be less myopic and trust the big picture to the principal.”

One female teacher interviewee stated she measured relational trust by how many teachers want to leave the school (I6-4). If there were a lot of teachers looking for other positions, than relational trust between the principal and teachers was not strong. She further stated she measured relational trust in the following manner:

In a really brutal way, retention, teacher retention, turnover year to year I think is a good measure of the trust between administration and staff. We have very poor trust. Our principal is new this year. For the past few years very poor trust between admin and teachers. I think it creates a decline in the desire to put in work that it takes to stay. It also demonstrates a lack of trust from the admin to the teachers. Like the teachers who are new and struggling, the more turnover, it shows they don't trust you to develop and grow and get better. They'd rather just cut you out. We had I think 17 new teachers this year and a staff of about 45, 48. (I6-4)

Suggestions for principals who are trying to build relational trust. Four out of the six teacher interviewees stated that following through with action and seeking authentic input from the staff were ways to build relational trust. Three out of the six teacher interviewees stated that when a principal was truly transparent with their staff it built relational trust. Specifically, one female teacher interviewee suggested that principals should "not talk in circles and need to be transparent" (I3-3). Further, explaining to the staff why we are doing something, while seeking input was critical to the trust building process. Teacher (I4-4) provided the following suggestions: "I think transparency is big...being able to explain to your teachers, this is why I am doing this. This is why I am making this decision and then follow through. Following through on what you say.” 
One male teacher interviewee stated that it was critical for a new principal to access

the culture of the school and understand how the school community functions prior to taking action (I1-9). He specifically suggested the following ideas for new principals:

I think the administration needs to come in and first figure out, what is the culture. What is the standard operating procedure at this site? And then, based on their individual philosophies, come up with a plan that involves the site...coming together and creating your vision or mission as a unit. (I1-9)

Two out of the six teacher interviewees stated that a principal who was willing to listen and was open to the ideas of the staff built relational trust. Furthermore, one female teacher interviewee described how her new principal was trying to build trust with the staff:

He (Principal) sat in his office from 7:00 a.m. to 4:00 p.m. as an open forum for literally anyone to come in and air grievances. He sat there with a union rep who took notes... by the time I got there he had 15-20 pages of notes. Then by the next day, he was sending out emails addressing the concerns. He published the notes with timelines. Not only was he open to hearing concerns from every single staff member or student, then he followed it up with an official way of submitting questions, concerns, and comments on his own leadership. (I6-4)

In addition, honesty, consistency, and providing autonomy to teachers to do their jobs were ways principals can build relational trust. One male interviewee provided the following suggestion for principals who are trying to build relational trust:

Be as honest as you can. And shoot straight. Tell them - take all - as much into consideration as possible. Not just the facts of the matter, but the feelings that surround those facts” (I2-2).

Of note, one female teacher interviewee provided another example of how a principal can build trust with teachers: “Admitting when you are wrong and saying you are sorry. Just 
being able to say, I messed that one up and I am sorry it happened and I am going to do it differently next time” (I4-4).

How past experiences influence relational trust. One male teacher interviewee stated the following about how past experiences influence relational trust:

Trust is a barometer of past experiences. I assessed how a principal handled certain situations in the past and if patterns started to emerge. For example, who was willing to suspend judgment and figure out how to solve a problem or "throw you under the bus," especially in tough situations. (I1-9)

All six teacher interviewees stated that past experiences influenced relational trust. For example, one male teacher interviewee stated, "his past negative experiences made him gun shy” (I2-2), while one female teacher interviewee stated,

past negative experiences were hurdles for new principals to get over. I think it is unfair when a sour experience colors the rest of your trust with future administrators. I think it is unfair because maybe our distrust of a prior principal or two might fall on the new principal, and I think it is just that much of an effort for him/her to move forward to build trust again. (I3-3)

Another female teacher interviewee stated, "past negative experiences led to the mistrust of the new principal and when rumblings of mistrust started they permeated the school”

(I4-4). One male teacher interviewee stated,

negative past experiences created a bunkered down mentality for the staff. I just wanted to be quiet and stay in my classroom and be under the radar. Which is a strategy. It is a well-known strategy amongst teachers in challenging administrative conditions. (I2-2)

Of note, one female interviewee stated, "new principals needed to invest the time to learn from the past experiences of the staff” (I4-4). She further added,

I think really talking to your staff, in particular your teacher leaders and figuring out what their past experience has been so that you can get sense 
of what you need to do to either mend that relationship between staff and administration or continue to do what the staff has responded positively to. I think it is really important. Taking in the moments to just soak in the campus and what has happened. (I4-4)

Hence, learning from the past can help to influence relational trust in the present. One male teacher interviewee provided guidance on how teachers can support the trust building process:

A contentious element could exist on any school site and it was incumbent upon teachers to extend an olive branch in an effort to build relational trust. In a sense, teachers have to be willing to be vulnerable to new principals to build relational trust. (I2-2)

Relational trust, gender, and ethnicity. One male teacher interviewee stated,

Once trust was established, gender and ethnicity had no bearing on relational trust. In the beginning, there was an "ice breaker" period until trust was established or it was not established. Once a principal demonstrated they were trustworthy then all "things" disappear. (I3-3)

One female teacher interviewee stated that negative past experiences with a poor principal could influence the relational trust between the staff and a new principal (I4-4). She further stated, "when a female principal demonstrated incompetence it can have a longer lasting impact on how teachers may view the next female principal” (I4-4). However, when asked to explain further she stated, “once trust was established everything was overlooked” (I4-4).

One male teacher interviewee explained, gender and ethnicity had no bearing on someone's competency. It has no bearing on how honest they are. They are either going to be honest and genuine, or they are not. They are either going to be competent or incompetent. (I3-3)

Another male interviewee explained, 
I do believe that (gender and ethnicity) they play a role and I have seen it played out in a number of ways. I worked for a lady, she was my interviewer, actually and when I got to work, a lot of people described her in a very unpleasant way. Being new of course, I'm curious, trying to figure what is going on. What I figured out was, because she was a woman, but she communicated in stereotypically male way. Meaning if I asked her question, she would say yes or no, this is why, and that was the end of the conversation. I admired that about her. (I2-2)

One female interviewee stated,

that (gender and ethnicity) does not impact me whatsoever because I know our principal can do his/her job. I know when I go in and I have conversations, it's not male needs or female needs. I feel comfortable to go in to him and talk about race...looking at our demographics in our classrooms and can we open up our pool of candidates. (I3-3)

All interviewees stated their past experiences with principals to some degree set the tone for the new principal and whether or not the staff was willing to become vulnerable and take a risk to build relational trust.

\section{Summary}

As described, past experiences posed one of the greatest challenges in building relational trust between high school teachers and principals. Not only do past experiences influence one's perception of a new principal they have lasting effects and linger for long periods of time. This creates an unwillingness or apprehension by high school teachers to become vulnerable and take the risk to begin the trust building process. Interviewees shared that principal turnover was another major impediment to the trust building process. Further, when measuring relational trust interviewees stated their subconscious feelings about feeling safe and having the security to be open and honest without fear of reprisal from principals was important. 
Professional autonomy was an important aspect that high school teachers coveted in the trust building process. The ability to perform their roles autonomously with the support of the principal was an integral aspect in building relational trust for high school teachers. Furthermore, when asked to conceptualize relational trust interviewees stated having the professional autonomy to perform their roles was a key aspect. Being reliable and following through with action-permeated interviewee responses as ways in which a principal could gain the trust of high school teachers. Principals who displayed competence, honesty, and reliability in their roles regardless of gender, ethnicity, and years of experience was also critical to the trust building process. Moreover, high school teachers stated that the willingness to become vulnerable and take a risk should first come from the principal in the trust building process, thus relinquishing control and power should come from the role that has control and power. 


\section{Chapter 5 - Conclusions}

\section{Introduction and Summary of the Study}

The purpose of this mixed methods study was to identify how high school teachers and principals conceptualize relational trust and to ascertain what relationships, if any, exist among the five facets of relational trust. Furthermore, the study was interested in understanding whether gender, ethnicity, and years of teacher experience were associated with the five facets of relational trust. This final chapter discusses the most significant findings of the study and they are presented based on the quantitative results from Phase I (Survey Data) which were supported by the qualitative results from Phase II (One-onOne Interview Data). The demographic data of the participants added significance to this study in that all participants identified their years of experience and gender. In addition, almost three fourths of the participants identified their ethnicity and exactly half of the high school teachers who participated in the study had 16 plus years of experience in the classroom. These characteristics provided a foundation to build on previous research regarding trust in schools in an effort to answer the four research questions posed in the study.

Chapter 5 highlights the most significant findings presented for each research question with connections to the similarities and differences with past research on the topic of trust in schools presented in the study. Additionally, recommendations and applications of the research on how principals can build relational trust with high school teachers in a hierarchical role relationship are presented. Lastly, recommendations for future research on this topic and implications are discussed. 


\section{Summary of Findings and Conclusions}

The first research question asked how high school teachers and principals conceptualized relational trust. The answer to this question was based on responses to a Likert-type question that asked respondents to rank the relative importance of the five facets of trust. Honesty had the highest mean for high school teachers $(M=4.69)$, while honesty and reliability had the highest means for principals ( $M$ for honesty $=5.0$; $M$ for reliability $=5.0$ ). Further, both participant groups indicated that all five facets of trust were integral to the trust building process. This major finding supported the multidimensional definition of trust presented in this study (Mishra, 1996; TschannenMoran \& Hoy; 1998, 2000). Notably, this finding also supported the research conducted by Bryk and Schneider (2002) that indicated a serious deficiency in any of the following facets (e.g., respect, competence, personal regard for others, integrity) “can be sufficient to undermine a discernment of trust for the overall relationship” (p.23). In addition, these findings supported the seven decades of research conducted on trust presented in the study, which identified the five salient facets of trust.

When asked open-ended questions regarding a time when they experienced each of the five facets, high school teachers shared three consistent themes: (a) follow through with action, (b) being supported, and (c) being valued as a person and as a professional. Interview responses indicated that high school teachers conceptualized relational trust as following through with action and support from their principal. This finding also supported the survey data presented in Chapter 4 and was consistent with the research presented by Brewster and Railsback (2003). In Chapter 2, Brewster and Railsback 
(2003) identified key obstacles and roadblocks to building and maintaining relational trust between teachers and principals, of which one the greatest impediments to the trust building process was the lack of follow through on or support for school improvement efforts by principals.

Having professional autonomy to perform their roles was the second major theme that emerged from the findings regarding how high school teachers conceptualized relational trust. Hence, high school teachers who were provided professional autonomy to perform their roles saw this autonomy as a sign of trust from their principals. This finding supported the literature presented by Darling-Hammond (1988) and Rowan (1990) in which they stated, the relationship between a principal and teacher was one where some principals recognize teachers as equal partners acknowledging their professionalism and utilizing their knowledge and skills. In essence, one important conclusion of this research was that high school teachers trust principals who follow through with action and provide them with the support they need to perform their role. Another important conclusion of this research was that teachers who have professional autonomy feel both supported and valued as a professional, leading them to feel trusted by their principal. Furthermore, these findings supported the data presented in Chapter 4 that identified reliability, competence, and honesty as salient facets in the trust building process. High school teachers conceptualized these three facets as important to the trust building process and when a principal follows through with action that was consistent with the discernment of the teacher these actions by the principal were perceived to be reliable and trustworthy. In addition, when a principal was honest and states that they will support a 
teacher with resources and does so then teachers perceived a principal as being honest, competent, and reliable, thus they are trustworthy. These findings were also supported by previous research.

The second research question asked which facets of relational trust do high school teachers and principals rate as most important? Based on a Likert-type forced ranking scale 10 out of the 11 high school teacher groups ranked reliability as the most important facet in the trust building process. Further, $100 \%$ of the teacher groups ranked reliability as one of the three most important facets in the trust building process. Competence and honesty were ranked as the second and third most important facets in the trust building process. Furthermore, competence was ranked by 10 out of the 11 teacher groups as the second most important facet, while six out of the 11 teacher groups ranked honesty as the third most important in the trust building process. Notably, nine out of the 11 teacher groups ranked benevolence and 10 out of the 11 teacher groups ranked openness as the two least important facets in building relational trust. These similarities among respondent groups suggest that gender, ethnicity, and years of experience were not significantly related to the conceptualization of relational trust and that high school teachers largely felt the same way, regardless of gender, ethnicity, or years of experience. In addition, these findings shared a different set of beliefs between high school teachers and principals and the value they place on specific facets in the trust building process. Of note, these major findings were slightly different than the research presented in Chapter 2. For example, benevolence has been described as the most essential ingredient and commonly recognized facet in the trust building process (Tschannen-Moran, 2004). 
According to principals in the study, benevolence was ranked as the most important facet in the trust building process, whereas high school teachers in the study ranked it as the least important facet in the trust building process. This finding on the importance of benevolence at the secondary level warrants further investigation.

In comparing the findings of the study with the previous research, there were some similarities and differences noted. Most notably, Handford and Leithwood (2013) conducted a mixed method study of three "high trust" and three "low trust" schools. The findings from this study concluded that both groups of teachers identified competence, consistency, and openness, during the follow up interviews and observations as the three most salient facets. The findings presented in this study also suggested that similarity exists in ratings. Competence was identified as one of the three most salient facets by 10 out of the 11 teachers groups as the second most important facet in the trust building process. Furthermore, consistency was also connected with reliability and the two terms are closely related, hence another similarity was identified with the previous research presented by Handford and Leithwood (2013). However, a difference was noted in how the participants of the study ranked the relatively lower importance of openness as compared to the findings presented by Handford and Leithwood (2013) in which it was found to be one of the three most salient facets in the trust building process. The difference noted regarding the importance of openness may be largely contextual in nature and different variables (e.g., elementary, high school, urban, suburban, regional, state) may lead to a different discernment on the importance of openness. 
The third question posed by the researcher, considered how ethnicity and gender were associated with the facets of relational trust. Previous research conducted on trust in schools as presented in this dissertation did not consider whether gender and ethnicity were associated with trust. While, both female and male high school teachers ranked reliability and honesty as two of the three most important facets in the trust building process an important finding from this study indicated female high school teachers ranked competence significantly higher than male high school teachers. In addition, male high school teachers ranked competence lower than reliability, honesty, and benevolence. This finding suggests a need for further consideration of the differences between how male and female high school teachers conceptualized competence and possible connections to outside of school factors, such as societal roles and the privilege that is afforded to male educational leaders. More generally, the findings on gender similarities and differences should be viewed as an area for future research.

Another significant finding was that White female high school teachers and female high school Teachers of Color had congruence in their views of the most important facets in building relational trust. Essentially, both groups of high school teachers ranked the importance of the five facets in an identical manner. The interview findings supported the written survey findings and some teacher interviewees stated that once trust was established, gender and ethnicity are inconsequential; furthermore, some teacher interviewees stated that gender or ethnicity have no bearing on whether or not teachers and administrators are competent, reliable, and honest. 
The fourth research question posed considered whether years of teaching experience were associated with or related to the conceptualization of relational trust. Findings indicated that all four groups (from novices with 1-5 years of experience all the way to veterans with $16+$ years of experience) ranked reliability as one of the top three facets in the trust building process. In addition, three of the four groups (1-5, 6-10, 11-15 years of experience) ranked reliability as the most important facet. High school teachers with 16 plus years of experience ranked honesty as the most important facet in the trust building process. One explanation for this finding may be that past experiences with principals who have broken trust or created distrust have a career-long lingering effect, which continues to influence the perception of the veteran high school teachers. Thus, a principal who exhibited honesty was the most important facet in the trust building process and the influence of a principal that breaks trust lingers over a career, making teachers more vulnerable to distrust. Overall, however, these major findings suggest that years of experience, gender, and ethnicity were not significantly related to how high school teachers conceptualize the importance of the five facets of relational trust.

\section{Implications for Understanding School Leadership and Administrative Practice}

The results of this study for educational leaders emphasized the value to understanding how high school teachers and principals conceptualize relational trust and which facets were the most important to both groups in the trust building process. Of significance, were the findings shared by 10 out of 11 teachers groups, which identified reliability as the most important facet in the trust building process. And, competence and honesty as the second and third most important facets in the trust building process. Of 
note, high school teachers conceptualized each of these three facets as representing the most important actions a principal can take to build relational trust in a hierarchical relationship. In comparison, principals ranked benevolence as the most important facet in the trust building process. This dissimilarity provides valuable information for principals who are trying to build relational trust with high school teachers in that they may view being benevolent and caring about teachers as more important than being reliable, honest, and competent. Furthermore, high school teachers and principals work in a symbiotic relationship and this process requires actions to be congruent based on the view of each party. Thus, one party may demonstrate actions to build relational trust with the other party that are incongruent based on the discernment of the other party. These differences may lead to one party's unwillingness to take risks and become vulnerable; hence, the systemic process of building relational trust does not occur. Furthermore, principals who are seeking to build relational trust with high school teachers must first be reliable, and then competent and honest.

\section{The Importance of Past Experiences in Building and Maintaining Trust}

Bryk and Schneider (2002) conjecture that judgements of trust are grounded in each party's historical perspective (e.g., past experiences), cultural beliefs rooted around the origin of his or her family and community, and prior workplace interactions. Based on the findings presented in this study past experiences influenced the willingness of the high school teachers to trust a principal. For example, data gathered from one-on-one interviews indicated that trust was a barometer of past experiences. All six teacher interviewees stated to some degree that past experiences influenced their willingness to 
build relational trust with their principal. Hence, there was a similarity on the importance of past experiences and how they influence the trust building process that was found in both the literature presented in this study and the findings of this study. Furthermore, this congruence supported the conceptual framework presented in this study, which identified past experiences as a lens in which one party looks through in the trust building process. The implication of this finding on practice is that new principals should take the time to understand the culture and past experiences of the teaching staff prior to the change process. In addition, the preparation and training of principals should prioritize the importance of understanding the culture of schooling and its relation to building trust. Further, the professional development of current principals should emphasize how actions that create distrust or broken trust may linger for long periods of time and result in actions or behaviors that are counterproductive to the trust building process. In addition, there are barriers to building a trusting relationship in schools, many of which are manifested out of distrust on the part of teachers towards principals. One of the most serious issues that schools face is broken trust. As noted by Tschannen-Moran and Hoy (1998) when trust is broken between a principal and a teacher the potential consequences are hypervigilance, punishment, and getting even. These primarily destructive forces undermine the very nature of the conditions that are necessary for an effective school community. Broken trust leads to revenge and betrayal, which can have irreversible consequences if principals and teachers are not cognizant of the dramatic costs of broken trust (Tschannen-Moran \& Hoy, 1998). 


\section{Vulnerability and Risk}

The mutual dependencies that exist between high school teachers and principals within a school environment create feelings of reciprocal vulnerability and risk (Bryk \& Schneider, 2002). "Where there is no vulnerability there is no need for trust" (Tschannen-Moran \& Hoy, 1998, p. 337). According to Bryk and Schneider (2002), reducing the feeling of vulnerability is critical in asymmetric power relations, such as those between principals and teachers. A recognition of vulnerability by the superordinate party and a conscious effort to relieve the uncertainty and unease of the subordinate party can create meaningful social exchanges and bonds for both parties, leading to trust. The responses from teacher interviewees supported the literature presented in that high school teachers shared a sense of inherent fear of new principals as to how their actions would be interpreted. This sense of fear created a "bunkered down" mentality in which teacher interviewees assessed the intentions of the principal from the following perspective; 'I am safe,' to 'I am not entirely safe,' and finally to 'I am not safe at all.' This discernment by high school teachers was largely due to their past negative experiences, but also furthered by high principal turnover. Moreover, teacher interviewees stated that consistent actions from the principal that were perceived to be in the best interest of students and staff created a sense of security, which then created a willingness to become vulnerable and take a risk. However, principals that acted inconsistently or reprimanded teachers for acting in a certain manner created the exact opposite phenomenon. Furthermore, principals must be willing to take the first step and become vulnerable to high school teachers and in return, this recognition creates 
reciprocal causation in which high school teachers sensed a feeling of security. Security then provided them with the opportunity to become vulnerable and take a risk. These actions and feelings are in direct alignment with the conceptual framework presented in this study and are supported by the literature presented. The implication of this finding is that new principals and current principals should understand that building relational trust is a systemic process in which the subordinate party is constantly discerning the actions of the superordinate party. These discernments of actions either create a willingness to become vulnerable and take a risk or create the unwillingness to become vulnerable and not take a risk. Therefore, when a teacher becomes willing to be vulnerable to a principal, he or she can support this risk taking by acting in a manner that is predictable and the expected behavior materializes (e.g., reliability, honesty, competence).

\section{Recommendations for Future Research}

In conclusion, studies have highlighted the difference between struggling schools who made significant gains, and those who did not. This difference was based on the quality of the relationships within a school. Further, this assessment was supported by the U.S. Department of Education's (CSR) Program that emphasized, if school improvement efforts are to be successful, strong relationships based on trust must be built by school leaders (Hale, 2000). Thus, for a principal, positive risk taking may include engaging in shared leadership with teachers and creating open dialogues with teachers to gain feedback and input. However, to take a positive risk the findings of this study point to the fact that high school teachers must have a principal who acts with reliability, honesty, and competence. The awareness and understanding of the inherent vulnerability and risk that 
exists for high school teachers is paramount for principals who are trying to build positive school climates based on trust. Their actions to reduce the sense of uncertainty or unease of high school teachers can provide the opportunity for positive risk taking and the trust building process to begin. Therefore, greater understanding of the systemic process of how vulnerability and risk are connected in the hierarchical relationship between a principal and high school teacher warrants further investigation.

As stated, one of the most serious issues that schools face is broken trust. Further, when trust is broken between a principal and a teacher the potential consequences are, as noted by Tschannen-Moran and Hoy (1998), hypervigilance, punishment, and getting even. Broken trust based on negative past experiences leads to feelings of disengagement, revenge, and betrayal, which can have irreversible consequences within a secondary school community. This outcome can be a serious impediment to the development of trust at the organizational level and more importantly relational trust at the interpersonal level. Positive school climates are conducive for students when interdependent adults such as, principals and high school teachers can build strong relationships based on trust. Unfortunately, the research on repairing broken trust in high schools is limited. Therefore, future studies on the process of repairing broken trust at the secondary level is necessary in order to achieve the lofty goal of providing all students with a meaningful educational experience that prepares them for an unknown future.

In addition, future studies are warranted in the area of understanding the influence of gender on the trust building process in high schools. Therefore, future research should 
continue to explore how male and female high school teachers come to define the actions of principals, which they discern in the trust building process. The findings of this study indicated that a significant difference existed in how male and female high school teachers ranked the importance of competence and benevolence in the trust building process. It is recommended that the five facets of relational trust be further explored through this lens to continue to develop coherence on the role gender plays in the trust building process at the secondary level.

Lastly, the findings of this dissertation may guide future research into the area of trust in schools and provide a framework for school principals to utilize as they seek to build relational trust with high school teachers. As one teacher interviewee stated, “Although, I think people would argue there are more important problems, the more important problems would be easier to address if this (trust) would be addressed first” (I2-2). 


\section{References}

Adams, C. M., \& Forsyth, P. B. (2009). The nature and function of trust in schools. Journal of School Leadership, 19(2), 126-152.

Affeldt, J. T. (2015). California policy supports for resources accountability. Education Policy Analysis Archives, 23(23). Retrieved from http://dx.doi.org/10.14507/epaa.v23.2023

Baier, A. (1986). Trust and antitrust. Ethics, 96(2), 231-260.

Barber, B. (1983). The logic and limits of trust. New Brunswick, NJ: Rutgers University Press.

Battilana, J., \& Casciaro, T. (2013). The network secrets of great change agents. Harvard Business Review, 91(7-8), 62-8.

Berliner, D. C., \& Glass, G. V. (2014). 50 myths \& lies that threaten America's public schools: The real crisis in education. New York, NY: Teachers College Press.

Bigley, G. A., \& Pearce, J. L. (1998). Straining for shared meaning in organization science: Problems of trust and distrust. Academy of Management Review, 23(3), 405421.

Blake, M., \& MacNeil, A. J. (1998). Trust: The quality required for successful management. Creating High Functioning Schools: Practice and Research, 29-37.

Bradach, J. L., \& Eccles, R. G. (1989). Price, authority, and trust: From ideal types to plural forms. Annual Review of Sociology, 15(1), 97-118.

Brewster, C., \& Railsback, J. (2003). Building Trusting Relationships for School Improvement: Implications for Principals and Teachers. Portland, OR: Northwest Regional Educational Laboratory. Retrieved from https://files.eric.ed.gov/fulltext/ED481987.pdf

Bryk, A., \& Schneider, B. (2002). Trust in schools: A core resource for improvement. Russell Sage Foundation.

Bryk, A. S., \& Schneider, B. (2003). Trust in schools: A core resource for school reform. Educational Leadership, 60(6), 40-45.

Butler Jr, J. K., \& Cantrell, R. S. (1984). A behavioral decision theory approach to modeling dyadic trust in superiors and subordinates. Psychological Reports, 55(1), 19-28. 
California Department of Education, Data Reporting Office. (2014). English learner students by language by grade: State of California 2013-2014. Retrieved from https://dq.cde.ca.gov/dataquest/SpringData/StudentsByLanguage.aspx?Level=State\& TheYear=201314\&SubGroup=All\&ShortYear=1314\&GenderGroup=B\&CDSCode= 00000000000000\&RecordType $=\mathrm{EL}$

California Department of Education. (2017). DataQuest. Enrollment Data. Retrieved from https://dq.cde.ca.gov/dataquest/dqcensus/EnrEthGrd.aspx?cds=4369427\&agglevel=di strict \&year=2016-17

California Department of Education. (2017). Positive School Climate - School Environment. Retrieved from https:/www.cde.ca.gov/ls/ss/se/schoolclimate.asp

Coleman, J. S., (1990). Foundations of social theory. Cambridge, MA: The Belknap Press of Harvard University Press.

Cosner, S. H. E. L. B. Y. (2010). Drawing on a knowledge-based trust perspective to examine and conceptualize within-school trust development by principals. Journal of School Leadership, 20(2), 117-144.

Cranston, J. (2011). Relational trust: The glue that binds a professional learning community. Alberta Journal of Educational Research, 57(1), 59-72.

Creswell, J.W. (2015). A concise introduction to mixed methods research. Thousand Oaks, CA: Sage.

Cummings, L. L., \& Bromiley, P. (1996). The organizational trust inventory (OTI). Trust in Organizations: Frontiers of Theory and Research, 302(330), 39-52.

Darling-Hammond, L. (1988). Policy and professionalism. In A. Lieberman (Ed.), Building a professional culture in schools (pp. 55-77). New York: Teachers College Press.

Dirks, K. T., \& Ferrin, D. L. (2002). Trust in leadership: meta-analytic findings and implications for research and practice. Journal of Applied Psychology, 87(4), 611.

Duetsch, M. (1958). Trust and suspicion. Journal of Conflict Resolution, 2(4), 265-279.

Deutsch, M. (1962). Cooperation and trust: Some theoretical notes. In M. R. Jones (Ed.), Nebraska Symposium on Motivation, 1962 (pp. 275-320). Oxford, England: Univer. Nebraska Press. 
Duckor, B. (2017). Got grit? Maybe.... Phi Delta Kappan, 98(7), 61-66.

Ellinger, A. D., Watkins, K. E., \& Marsick, V. J. (2005). Case study research methods. Research in Organizations: Foundations and Methods of Inquiry, 327-350.

Ellison, C. W., \& Firestone, I. J. (1974). Development of interpersonal trust as a function of self-esteem, target status, and target style. Journal of Personality and Social Psychology, 29(5), 655.

Elo, S., \& Kyngäs, H. (2008). The qualitative content analysis process. Journal of Advanced Nursing, 62(1), 107-115.

Firestone, W. A., \& Louis, K. S. (1999). Schools as cultures. Handbook of Research on Educational Administration, 2, 297-322.

Frost, T., Stimpson, D. V., \& Maughan, M. R. (1978). Some correlates of trust. The Journal of Psychology, 99(1), 103-108.

Fukuyama, F. (1995). Trust: The social virtues and the creation of prosperity. New York: Simon \& Schuster.

Gabarro, J. J. (1978). The development of trust, influence and expectations. In A. G. Athos \& J. J. Gabarro (Eds.), Interpersonal behavior: Communication and understanding in relationships, (pp. 290-303). Englewood Cliffs, NJ: Prentice Hall.

Gambetta, D. (1988). Can we trust? In D. Gambetta (Ed.), Trust: Making and breaking cooperative relations (pp. 213-238). Cambridge, MA: Basil Blackwell.

Goodwin, N. R. (1996). Economic meanings of trust and responsibility. Ann Arbor, MI: The University of Michigan Press.

Hale, S. V. H. (2000). Comprehensive School Reform: Research-Based Strategies to Achieve High Standards. A Guidebook on School-Wide Improvement. San Francisco, CA. Northern California Comprehensive Assistance Center. Retrieved from https://files.eric.ed.gov/fulltext/ED448505.pdf

Handford, V., \& Leithwood, K. (2013). Why teachers trust school leaders. Journal of Educational Administration, 51(2), 194-212.

Harry, B., Sturges, K. M., \& Klingner, J. K. (2005). Mapping the process: An exemplar of process and challenge in grounded theory analysis. Educational Researcher, 34(2), 3-13. 
Hosmer, L. T. (1995). Trust: The connecting link between organizational theory and philosophical ethics. Academy of Management Review, 20(2), 379-403.

Hoy, W. K., \& Kupersmith, W. J. (1985). The meaning and measure of faculty trust. Educational and Psychological Research, 5(1), 1-10.

Hoy, W. K., \& Tschannen-Moran, M. (1999). Five faces of trust: An empirical confirmation in urban elementary schools. Journal of School leadership, 9, 184-208.

Kramer, R. M. (1999). Trust and distrust in organizations: Emerging perspectives, enduring questions. Annual Review of Psychology, 50(1), 569-598.

Kramer, R. M., \& Tyler, T. R. (Eds.). (1996). Trust in organizations: Frontiers of theory and research. Thousand Oaks, CA: Sage.

Kensler, L. A., Caskie, G. I., Barber, M. E., \& White, G. P. (2010). The ecology of democratic learning communities: Faculty trust and continuous learning in public middle schools. Journal of School Leadership, 19(6), 697-735.

Ladson-Billings, G. (2006). From the achievement gap to the education debt: Understanding achievement in US schools. Educational Researcher, 35(7), 3-12.

Lapidot, Y., Kark, R., \& Shamir, B. (2007). The impact of situational vulnerability on the development and erosion of followers' trust in their leader. The Leadership Quarterly, 18(1), 16-34.

Leithwood, K., Jantzi, D., \& Steinbach, R. (1999). Changing leadership for changing times. International Journal of Educational Management, 13(6), 301-302. Retrieved from https://doi.org/10.1108/ijem.1999.13.6.301.4

Leithwood, K. A., \& Riehl, C. (2003). What we know about successful school leadership. Nottingham: National College for School Leadership.

López, G. R., \& Burciaga, R. (2014). The troublesome legacy of Brown v. Board of Education. Educational Administration Quarterly, 50(5), 796-811.

Mayer, R. C., Davis, J. H., \& Schoorman, F. D. (1995). An integrative model of organizational trust. Academy of Management Review, 20(3), 709-734.

Merriam, S. B., \& Tisdell, E. J. (2016). Qualitative research: A guide to design and implementation. Thousand Oaks, CA: Jossey-Bass.

Meyerson, D., Weick, K. E., \& Kramer, R. M. (1996). Swift trust and temporary groups. Trust in Organizations: Frontiers of Theory and Research, 166, 195. 
Miles, R. E., \& Snow, C. C. (1992). Causes of failure in network organizations. California Management Review, 34(4), 53-72.

Milner IV, H. R. (2007). Race, culture, and researcher positionality: Working through dangers seen, unseen, and unforeseen. Educational Researcher, 36(7), 388-400.

Mishra, A. K. (1996). Organizational responses to crisis. Trust in Organizations: Frontiers of Theory and Research, 261.

Powell, W. W. (1990). Neither market nor hierarchy: Network forms of organization. In B. M. Staw \& L. L. Cummings (Eds.), Research in Organizational Behavior, 12, 295336.

Putnam, R. D. (2001). Bowling alone: The collapse and revival of American community. New York: Simon and Schuster.

Ray, B. (1997). How many home schoolers are there? Retrieved from HSDLA advocates for homeschooling since 1983 website: http://nche.hslda.org/docs/study/ray1997/03.asp.

Robinson, S. (1996). Trust and Breach of the Psychological Contract. Administrative Science Quarterly, 41(4), 574-599. doi:10.2307/2393868

Rotter, J. B. (1967). A new scale for the measurement of interpersonal trust. Journal of Personality, 35(4), 651-665.

Rousseau, D. M., Sitkin, S. B., Burt, R. S., \& Camerer, C. (1998). Not so different after all: A cross-discipline view of trust. Academy of Management Review, 23(3), 393404.

Rowan, B. (1990). Chapter 7: Commitment and Control: Alternative Strategies for the Organizational Design of Schools. Review of Research in Education, 16(1), 353-389.

Sutherland, I. E., \& Yoshida, R. K. (2015). Communication competence and trust in leaders. Journal of School Leadership, 25(6), 1039-1063.

Tschannen-Moran, M. (2003). Transformational leadership and trust. Studies in Leading and Organizing Schools, 2, 157.

Tschannen-Moran, M. (2004). Trust matters: Leadership for successful schools. San Francisco, CA: Jossey-Bass. 
Tschannen-Moran, M., \& Hoy, W. (1998). Trust in schools: A conceptual and empirical analysis. Journal of Educational Administration, 36(4), 334-352.

Tschannen-Moran, M., \& Hoy, W. K. (2000). A multidisciplinary analysis of the nature, meaning, and measurement of trust. Review of Educational Research, 70(4), 547-593.

Tschannen-Moran, M., \& Gareis, C. R. (2015). Principals, trust, and cultivating vibrant schools. Societies, 5(2), 256-276.

Voight, A., Austin, G., \& Hanson, T. (2013). A Climate for Academic Success: How School Climate Distinguishes Schools That Are Beating the Achievement Odds (Full Report). California Comprehensive Center at WestEd. Retrieved from https://www.wested.org/resources/a-climate-for-academic-success-how-schoolclimate-distinguishes-schools-that-are-beating-the-achievement-odds-full-report/

Whalstrom, K. L., \& Louis, K. S. (2008). How teachers experience principal leadership: The roles of professional community, trust, efficacy, and shared responsibility. Educational Administration Quarterly, 44(4), 458-495.

Wang, C., \& Bird, J. J. (2011). Multi-level modeling of principal authenticity and teachers' trust and engagement. Academy of Educational Leadership Journal, 15(4), 125-147.

Williamson, O. E. (1993). Calculativeness, trust, and economic organization. The Journal of Law and Economics, 36(1), Part 2, 453-486. Retrieved from https://doi.org/10.1086/467284

Zand, D. (1972). Trust and Managerial Problem Solving. Administrative Science Quarterly, 17(2), 229-239. doi:10.2307/2393957 
Appendix A. Teacher Survey Instrument with Consent Form 


\section{San Jose State University, Research Survey Teacher-1}

Request for your Participation in Research

Trust an Essential Ingredient in Schools: A Systemic Approach to Understanding the Importance of Relational Trust in High Schools

Shawn Tennenbaum, Graduate Student and Dr. Arnold Danzig, San Jose State University Director of Ed.D Program and

Advisor

PURPOSE

The purpose of this study is to understand how principals and teachers conceptualize the five key facets (e.g.

benevolence, reliability, competence, honesty, and openness) of building relational trust in a hierarchical role relationship.

Specifically, this study will identify which of the five key facets teachers rate as more important and which key facets

principals rate as more important. The significance of this study is to identify whether principals and teachers in a

comprehensive public high setting conceptualize the key facets of building relational trust in a similar fashion.

Further, the research aims to determine if the ethnicity and gender of the teacher or the principal plays a significant role in

the conceptualization of relational trust.

PROCEDURES

In this voluntary survey, you will be asked to rate which of the key facets are more important in building relational trust between principals and teachers. We anticipate the survey will take no longer 15 minutes to complete. At the end of the survey, you will be asked if you are willing to participate in a follow-up interview to discuss your experiences in building relational trust

POTENTIAL RISKS

Some people may feel nervous about taking part in research. However, no identifying information will be collected or used in the final report. Responses will be confidential. When necessary, ID numbers and pseudonyms will be used when

analyzing and disseminating our results in the final report.

POTENTIAL BENEFITS

While we do not anticipate any direct benefits to individual participants, surveys and follow-up interviews will help us to better understand how principals and teachers conceptualize relational trust, which of the key facets principals and teachers rate as more important, and to determine if gender and ethnicity plays a significant role. Further, since trust is viewed as a critical ingredient for school productivity your participation will provide context to better understand this topic.

CONFIDENTIALITY

Survey responses will remain confidential. Pseudonyms and identification numbers will be used throughout the study

COMPENSATION

No compensation will be given for participating in this study.

PARTICIPANT RIGHTS

Your participation in this study is completely voluntary. You can refuse to participate in the entire study or any part of the study without any negative effect on your relations with San Jose State University. You also have the right to skip any question you do not wish to answer. This is a written description of what will happen during the study if you decide to participate, and there is no penalty for stopping your participation in the study.

\section{QUESTIONS OR PROBLEMS}

You are encouraged to ask questions at any time during this study. For further information about the study, please contact Shawn Tennenbaum at 831-345-0163 or shawntennenbaum@gmail.com

Complaints about the research may be presented to Dr. Arnold Danzig, Director, Ed.D Program at San Jose State, 408-9243722. For questions about participants' rights or if you feel you have been harmed in any way by your participation in this study, please contact Dr. Pamela Stacks, Associate Vice President of the Office of Research, San Jose State University, at 408-924-2479.

\section{SIGNATURES}

Your participation consent below indicates that you voluntarily agree to be a part of the study, that the details of the study have been explained to you, that you have been given time to read this document, and that your questions have been answered. You will receive a copy of this consent form for your records.

\section{Participation Consent}

I agree to participate in this survey.

I do not agree to participate in this study 
Identifying the key facets of building relational trust between principals and teachers in a hierarchical relationship.

Please rate the importance of each of the five facets of building relational trust.

Demonstrating benevolence (caring about another persons' well being) is necessary in building relational trust.

$\begin{array}{lllllll}1 & 2 & 3 & 4 & 5 & \\ \text { Not important } & 0 & \bigcirc & \bigcirc & \bigcirc & \bigcirc & \text { Very important }\end{array}$

Please share a time when you experienced this.

Long answer text

Demonstrating reliability is necessary in building relational trust. *

\begin{tabular}{|c|c|c|c|c|c|c|}
\hline & 1 & 2 & 3 & 4 & 5 & \\
\hline Not importa & 0 & 0 & 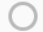 & 0 & 0 & Very important \\
\hline
\end{tabular}

Please share a time when you experienced this.

Long answer text

Being competent in your position is necessary in building relational trust? *

$\begin{array}{lllllll} & 1 & 2 & 3 & 4 & 5 & \\ \text { Not important } & \bigcirc & \bigcirc & \bigcirc & \bigcirc & \bigcirc & \text { Very important }\end{array}$

Please share a time when you experienced this. 
Being honest is necessary in building relational trust. *

\begin{tabular}{|c|c|c|c|c|c|c|}
\hline & 1 & 2 & 3 & 4 & 5 & \\
\hline Not important & 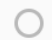 & b & 0 & 0 & 0 & Very important \\
\hline
\end{tabular}

Please share a time when you experienced this.

Long answer text

Being open and willing to listen is necessary in building relational trust. *

$\begin{array}{lllllll} & 1 & 2 & 3 & 4 & 5 & \\ \text { Not important } & \bigcirc & \bigcirc & \bigcirc & \bigcirc & \bigcirc & \text { Very important }\end{array}$

Please share a time when you experienced this.

\section{Ranking the five facets of building relational trust.}

Please rank the following key facets of building relational trust in order of importance. Select only one number per category without duplication. A rank of 5 represents the most important and a rank of 1 represents the least important.

Five facets of relational trust *

Benevolence

Reliability

Competence

Honesty

Openness

2

0
0
0
0

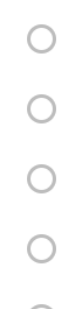


Please list any additional key facets or characteristics that are important to you in building relational trust.

Long answer text

After section 3 Continue to next section

\section{Participation in Follow-Up Interview}

Thank you for participating in the survey.

Would you be willing to be contacted to participate in a follow-up 1:1 interview? If so, please provide your email address below or contact me at shawntennenbaum@gmail.com or 831-345-0163. Note: your response to this question will be dissociated from your responses to the previous questions.

A one to one interview

Thanks, but I am not interested in participating in a follow up study.

\section{General Information}

Please share a bit of information about yourself

Please indicate your gender.

Male

Female

Please indicate your ethnicity. 
Please state the number of years you have worked in education. *

1 to 5 years

6 to 10 years

11 to 15 years

16 plus years

\section{Thank you!}

Description (optional) 
Appendix B. Principal Survey Instrument with Consent Form 


\section{San Jose State University, Research Survey Principal-1}

Request for your Participation in Research

Trust an Essential Ingredient in Schools: A Systemic Approach to Understanding the Importance of Relational Trust in High Schools

Shawn Tennenbaum, Graduate Student and Dr. Arnold Danzig, San Jose State University Director of Ed.D Program and

Advisor

\section{PURPOSE}

The purpose of this study is to understand how principals and teachers conceptualize the five key facets (e.g., benevolence, reliability, competence, honesty, and openness) of building relational trust in a hierarchical role relationship. Specifically, this study will identify which of the five key facets teachers rate as more important and which key facets principals rate as more important. The significance of this study is to identify whether principals and teachers in a comprehensive public high setting conceptualize the key facets of building relational trust in a similar fashion. Further, the research aims to determine if the ethnicity and gender of the teacher or the principal plays a significant role in the conceptualization of relational trust.

\section{PROCEDURES}

In this voluntary survey, you will be asked to rate which of the key facets are more important in building relational trust between principals and teachers. We anticipate the survey will take no longer 15 minutes to complete. At the end of the survey, you will be asked if you are willing to participate in a follow-up interview to discuss your experiences in building relational trust.

POTENTIAL RISKS

Some people may feel nervous about taking part in research. However, no identifying information will be collected or used in the final report. Responses will be confidential. When necessary, ID numbers and pseudonyms will be used when

analyzing and disseminating our results in the final report.

\section{POTENTIAL BENEFITS}

While we do not anticipate any direct benefits to individual participants, surveys and follow-up interviews will help us to better understand how principals and teachers conceptualize relational trust, which of the key facets principals and teachers rate as more important, and to determine if gender and ethnicity plays a significant role. Further, since trust is viewed as a critical ingredient for school productivity your participation will provide context to better understand this topic.

CONFIDENTIALITY

Survey responses will remain confidential. Pseudonyms and identification numbers will be used throughout the study.

COMPENSATION

No compensation will be given for participating in this study.

PARTICIPANT RIGHTS

Your participation in this study is completely voluntary. You can refuse to participate in the entire study or any part of the study without any negative effect on your relations with San Jose State University. You also have the right to skip any question you do not wish to answer. This is a written description of what will happen during the study if you decide to participate, and there is no penalty for stopping your participation in the study.

QUESTIONS OR PROBLEMS

You are encouraged to ask questions at any time during this study. For further information about the study, please contact Shawn Tennenbaum at 831-345-0163 or shawntennenbaum@gmail.com

Complaints about the research may be presented to Dr. Arnold Danzig, Director, Ed.D Program at San Jose State, 408-9243722. For questions about participants' rights or if you feel you have been harmed in any way by your participation in this study, please contact Dr. Pamela Stacks, Associate Vice President of the Office of Research, San Jose State University, at 408-924-2479.

\section{SIGNATURES}

Your participation consent below indicates that you voluntarily agree to be a part of the study, that the details of the study have been explained to you, that you have been given time to read this document, and that your questions have been answered. You will receive a copy of this consent form for your records. 
Participation Consent

I agree to participate in this survey.

I do not agree to participate in this study.

After section 1 Continue to next section

Section 2 of 6

$\therefore \quad \vdots$

Identifying the key facets of building relational trust between principals and teachers in a hierarchical relationship.

Please rate the importance of each of the five facets of building relational trust.

Demonstrating benevolence (caring about another persons' well being) is necessary in building relational trust.

$\begin{array}{lllllll} & 1 & 2 & 3 & 4 & 5 & \\ \text { Not important } & \bigcirc & \bigcirc & \bigcirc & \bigcirc & \bigcirc & \text { Very important }\end{array}$

Please share a time when you experienced this. 
Demonstrating reliability is necessary in building relational trust. *

\begin{tabular}{|c|c|c|c|c|c|c|}
\hline & 1 & 2 & 3 & 4 & 5 & \\
\hline & 0 & 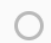 & 0 & 0 & 0 & Very important \\
\hline
\end{tabular}

Please share a time when you experienced this.

Long answer text

Being competent in your position is necessary in building relational trust? *

$\begin{array}{lllllll} & 1 & 2 & 3 & 4 & 5 & \\ \text { Not important } & \bigcirc & \bigcirc & \bigcirc & \bigcirc & \bigcirc & \text { Very important }\end{array}$

Please share a time when you experienced this.

Long answer text

Being honest is necessary in building relational trust. *

$\begin{array}{lllllll} & 1 & 2 & 3 & 4 & 5 & \\ \text { Not important } & \bigcirc & \bigcirc & \bigcirc & \bigcirc & \bigcirc & \text { Very important }\end{array}$

Please share a time when you experienced this.

Long answer text

Being open and willing to listen is necessary in building relational trust. *

\begin{tabular}{|c|c|c|c|c|c|}
\hline & 1 & 2 & 3 & 4 & 5 \\
\hline t important & 0 & 0 & 0 & 0 & 0 \\
\hline
\end{tabular}

Please share a time when you experienced this.

Long answer text 


\section{Ranking the five facets of building relational trust.}

Please rank the following key facets of building relational trust in order of importance. Select only one number per category without duplication. A rank of 5 represents the most important and a rank of 1 represents the least important.

Five facets of relational trust *

\begin{tabular}{|c|c|c|c|c|c|}
\hline & Benevolence & Reliability & Competence & Honesty & Openness \\
\hline 5 & & & & & \\
\hline$t$ & & & & & \\
\hline$\beta$ & & & & & \\
\hline 2 & & & & & \\
\hline 1 & & & & & \\
\hline
\end{tabular}

Please list any additional key facets or characteristics that are important to you in building relational trust.

Long answer tex

\section{Participation in Follow-Up Interview}

Thank you for participating in the survey.

Would you be willing to be contacted to participate in a follow-up 1:1 interview? If so, please provide your email address below or contact me at shawntennenbaum@gmail.com or 831-345-0163. Note: your response to this question will be dissociated from your responses to the previous questions.

A one to one interview

Thanks, but I am not interested in participating in a follow up study. 


\section{General Information}

Please share a bit of information about yourself

Please indicate your gender.

Male

Female

Please indicate your ethnicity.

Short answer text

Please state the number of years you have worked in education. *

1 to 5 years

6 to 10 years

11 to 15 years

16 plus years

After section 5 Continue to next section

Section 6 of 6

\section{Thank you!}


Appendix C. One-on-One Interview Protocol 


\section{Interview Protocol}

Date:

Participant ID:

Site ID:

\begin{tabular}{|l|l|l|}
\hline Questions & Interviewee Response & Interviewer Notes \\
\hline $\begin{array}{l}\text { 1. What does 'trust' } \\
\text { mean to you in a } \\
\text { school community? }\end{array}$ & & \\
\hline 2. What does 'trust' \\
look like to you \\
(conceptualize)?
\end{tabular}









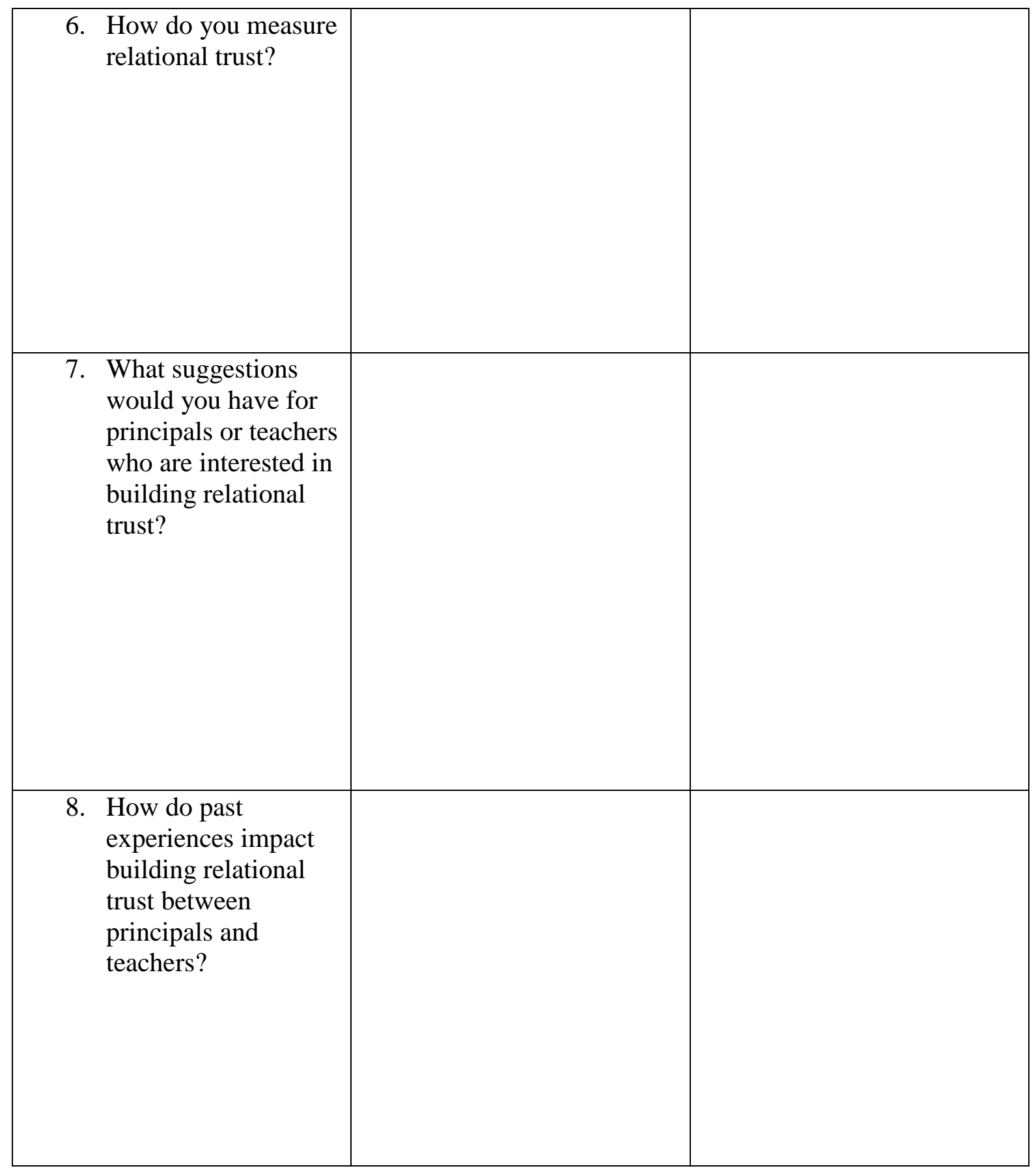




\begin{tabular}{|l|l|l|}
\hline 9. $\begin{array}{l}\text { Does gender and or } \\
\text { ethnicity have an } \\
\text { impact on building } \\
\text { relational trust } \\
\text { between principals } \\
\text { and teachers? }\end{array}$ & & \\
& & \\
& & \\
\end{tabular}


Appendix D. Interview Consent Form 


\section{SJSU}

Ed.D. Leadership Program
Connie L. Lurie college of

Education
San José State University

One Washington Square

San José, CA 95192-0064
TEL: 408-924-4098

edd-leadership@sjsu.edu

\section{Request for your Participation in Research}

\section{Trust an Essential Ingredient in Schools: A Systemic Approach to Understanding the Importance of Relational Trust in High Schools}

Shawn Tennenbaum, Graduate Student and Dr. Arnold Danzig, Faculty Advisor

\section{PURPOSE}

The purpose of this study is to understand how principals and teachers conceptualize the five key facets (e.g., benevolence, reliability, competence, honesty, and openness) of building relational trust in hierarchical role relationships. Specifically, this study will identify which of the five key facets teachers rate as more important and which key facets principals rate as more important. The significance of this study is to identify whether principals and teachers in a comprehensive public high school setting conceptualize the key facets of building relational trust in a similar fashion. Further, the research aims to determine if the ethnicity and gender of the teacher or principal plays a significant role in the conceptualization of relational trust.

\section{PROCEDURES}

In this voluntary interview, you will be asked to report on your perspective about trust in a school community and to provide experiences in building relational trust. The 1:1 interview should take no more than thirty minutes to complete. You may "opt-out" of the interview at any time. Each interview will be conducted in a 1:1 format and will be held at a neutral location selected by the participant. The interview will be audiotaped for later translation.

POTENTIAL RISKS

Some people may feel nervous about taking part in research. However, no identifying information will be collected or used in the final report. Responses will be confidential. When necessary, ID numbers and pseudonyms will be used when analyzing and disseminating our results in the final report.

POTENTIAL BENEFITS

While we do not anticipate any direct benefits to individual participants, follow-up interviews will help us to better understand how principals and teachers conceptualize relational trust, which of the key facets principals and teachers rate as more important, and to determine if gender and ethnicity plays a significant role. Further, since trust is viewed as a critical ingredient for school productivity your participation will provide context to better understand this topic.

\section{CONFIDENTIALITY}

Interview responses will remain confidential and those volunteering for the 1:1 interviews may opt-out at any time. ID numbers and pseudonyms will be used throughout the study. 


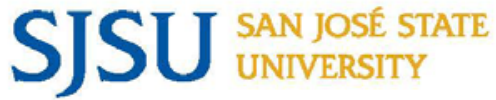

Ed.D. Leadership Program
Connie L. Lurie college of

Education
San José State University

San José, CA $95192-0064$
TEL: 408-924-4098

edd-leadership@sjsu.edu

\section{COMPENSATION}

No compensation will be given for participating in this study.

\section{PARTICIPANT RIGHTS}

Your participation in this study is completely voluntary. You can refuse to participate in the entire study or any part of the study without any negative effect on your relations with San Jose State University. You also have the right to skip any question you do not wish to answer. This is a written explanation of what will happen during the study if you decide to participate. You will not waive any rights if you choose to participate, and there is no penalty for stopping your participation in the study.

\section{QUESTIONS OR PROBLEMS}

You ae encouraged to ask questions at any time during this study.

- For further information about the study, please contact Shawn Tennenbaum at 831345-0163 or shawntennenbaum(a) gmail.com

- Complaints about the research may be presented to Dr. Arnold Danzig, Director, Ed.D Leadership Program at San Jose State University at 408-924-3722.

- For questions about participants' rights or if you feel you have been harmed in any way by your participation in this study, please contact Dr. Pamela Stacks, Associate Vice President of the Office of Research, San Jose State University at 408-924-2479.

\section{SIGNATURES}

Your signature indicates that you voluntarily agree to be a part of the study, that the details of the study have been explained to you, that you have been given time to read this document, and that your questions have been answered. You will receive a copy of the consent form for your records.

\section{Participant Signature}

Participant's Name (print) Participant's Signature Date

Researcher Statement

I certify that the participant has been given adequate time to learn about the study and ask questions. It is my opinion that the participant understands his/her rights, risks, benefits, and procedures of the research and has voluntarily agreed to participate. 
Appendix E. Repeated Measures ANOVA 




Figure 6. A Repeated Measures ANOVA with (forced) ranking as the dependent variable shows that respondents are significantly more likely to rank 'reliability' $(\mathrm{M}=3.5$ $\mathrm{SD}=1.2)$ and 'honesty' ( $\mathrm{M}=3.4, \mathrm{SD}=1.3)$ higher than 'competence' ( $\mathrm{M}=3.1, \mathrm{SD}=1.5)$, 'benevolence' (M=2.5, $\mathrm{SD}=1.6)$ and 'openness' $(\mathrm{M}=2.6, \mathrm{SD}=1.4)$. 